University of San Diego

Digital USD

1997

\title{
Empowering Teachers, Empowering Leadership: A Multisite Case Study of School Restructuring and Accountability for Student Achievement
}

Sally Jean Bennett EdD

University of San Diego

Follow this and additional works at: https://digital.sandiego.edu/dissertations

Part of the Leadership Studies Commons

\section{Digital USD Citation}

Bennett, Sally Jean EdD, "Empowering Teachers, Empowering Leadership: A Multisite Case Study of School Restructuring and Accountability for Student Achievement" (1997). Dissertations. 623.

https://digital.sandiego.edu/dissertations/623

This Dissertation: Open Access is brought to you for free and open access by the Theses and Dissertations at Digital USD. It has been accepted for inclusion in Dissertations by an authorized administrator of Digital USD. For more information, please contact digital@sandiego.edu. 


\title{
EMPOWERING TEACHERS, EMPOWERING LEADERSHIP
}

\section{A MULTISITE CASE STUDY OF SCHOOL RESTRUCTURING AND ACCOUNTABILITY FOR STUDENT ACHIEVEMENT}

\author{
by \\ Sally Jean Bennett \\ A dissertation submitted in partial fulfillment \\ of the requirements for the degree of \\ Doctor of Education
}

University of San Diego

1997

\author{
Dissertation Committee \\ Mary Abascal-Hildebrand, Ed. D., Director \\ Mary W. Scherr, Ph. D. \\ Freda P. Callahan, Ed. D.
}




\begin{abstract}
EMPOWERING TEACHERS, EMPOWERING LEADERSHIP A MULTISITE CASE STUDY OF SCHOOL RESTRUCTURING AND ACCOUNTABILITY FOR STUDENT ACHIEVEMENT
\end{abstract}

Accountability is the watchword of the 1990s, particularly in education. In exchange for greater flexibility and autonomy, schools have been asked to assume greater accountability for student outcomes. Implicit in this shift of authority and responsibility is the belief that changing the locus of control will result in changes in student achievement. Decentralizing accountability thus has multiple implications for the teaching and learning process, governance and decisionmaking, and school site leadership.

In 1993, San Diego City Schools adopted a student achievement accountability policy and initiated a demonstration program to develop an accountability system model for the district. This ethnographically-oriented case study investigated three of these pilot schools through interviews with teachers and site administrators, site observations, and document review. The purpose was to explore issues, challenges, and successes involved in school reform around student achievement accountability; identify what kinds of governance and leadership were most embraced by the teachers and administrators; look into school accountability cultures; and discuss implications for educational policymakers and practitioners.

The study found that implementation of the accountability policy occurred uniquely in each context in interaction with school culture and collective experience. At all three schools, however, focusing on standards 
and developing related assessments engaged teachers in substantive conversations about student performance, and teaching and learning, which began to influence instructional practices. These schools embraced participatory governance structures that empowered teachers to engage in and influence decisionmaking, and school site leadership began to evolve into a communal endeavor shared among teachers and administrators.

The intersection of student achievement accountability, school restructuring, and school site leadership has significant implications for educators. The study presents the following recommendations to educational policymakers and practitioners: (a) encourage and sustain site autonomy and accountability by building capacity for meaningful, participatory school site decisionmaking; (b) invest heavily in ongoing, systematic professional and organizational development; (c) promote entrepreneurial mindsets grounded in sound educational practice, and consider reform efforts as research and development opportunities; and (d) reconceptualize and develop leadership as an empowering, relational process. 
C 1997 by Sally Jean Bennett

Reproduced with permission of the copyright owner. Further reproduction prohibited without permission. 


\section{DEDICATION}

This dissertation is dedicated to the San Diego teachers, administrators, and school communities involved in the Leadership in Accountability Demonstration (LAD) School project. They have illustrated that school reform can emerge and even thrive within a large urban public school district through vision, collaboration, commitment, and just plain hard work.

This work is also dedicated to educators everywhere who summon the vision, courage, and spirit to undertake collaborative journeys in pursuit of educational reform. Through empowering school communities and empowering leadership, they are changing schools and schooling in the best interest of children.

May the wind be always at your back. 


\section{ACKNOWLEDGMENTS}

To the teachers and administrators at three special schools: Thank you for inviting me into your professional homes and lives; and for sharing your journeys, your ideas, your tribulations, your joys, your successes. Your words make these stories come alive and your spirit energized me to not only complete this project, but to continue to champion the cause of school reform in the best interest of children.

To my committee: Mary Jo, thank you for supporting my efforts to take on this venture and tell these schools' stories; you've heard about LAD for a long time now! Thanks, too, for always having just the right words to help me out with this work, and with so many others. Mary, thanks for encouraging me, as my advisor, throughout my time at USD. Thank you, also, for introducing me to case studies through the qualitative research course. Freda, thank you for letting me share the LAD journey, which inspired me to undertake this research. As a colleague and friend, you kept me true to the project and to the voices of these teachers and administrators.

To the professors in the USD Leadership Program: Thank you for the invigorating discussions, the interesting reading, the tough assignments that kept opening doors onto new avenues. You have challenged me to stretch myself, and especially to think about and practice leadership differently.

To my fellow doctoral students: Thanks for the intellectual stimulation, the mutual support, the spirit of we're in this together. I've learned so much more through sharing this experience with all of you. 
To a great group of professional colleagues: Thanks to Frank, Freda, Mary, and Ruben for giving me the flexibility in my work schedule to pursue this research. And thanks as well to my co-workers who have helped out with presentations and deadlines, put up with my complaints, and just listened to all the ideas I brought in from my reading and my research.

To my technical support: Thank you, Sandi, for those hours of listening to sometimes garbled tapes, and for your flying fingers. I always knew I could count on getting the transcripts when I needed them!

To my friends, who I'm sure never want to hear words like class, exam, or dissertation again: Thanks for bearing with me for four years, even when I know you often had no clue what I was ranting and raving about! I'm looking forward to once again enjoying, without guilt, a leisurely cup of coffee, an evening at the theater, a vacation cruise.

Finally, to my parents: Thanks for instilling in me, from an early age, an implicit understanding that education was not just a way into the world but a value in itself. Thank you also for giving me a joy of reading; I have found that books are always there for pleasure, for adventure, for learning. Mom, thank you for those supporting notes, which always seemed to arrive just when I thought I'd never make it through another week. And Dad, thanks for inspiring me through your example as a lifelong learner yourself who thought nothing of starting computer classes at age 80 !

To all of you: Thanks for encouraging and supporting me to start this journey, to keep going, and now, at last, to finish this part of my odyssey! 


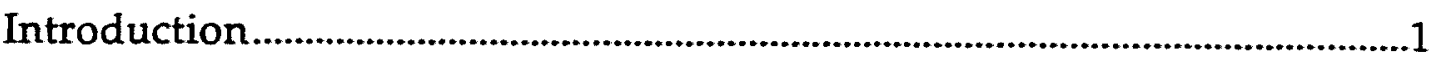

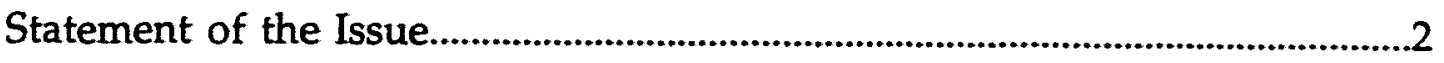

Background and Significance of the Issue ..........................................................4

Public and School Site Demands......................................................................5

Accountability and Restructuring in San Diego City Schools......................6

The Leadership in Accountability Demonstration (LAD) Project...............8

Purpose of the Study ....................................................................................12

Limitations of the Study.............................................................................13

Specific Terminology …...............................................................................15

CHAPTER TWO: REVIEW OF THE LITERATURE..............................................19

PERSPECTIVES ON EDUCATIONAL ACCOUNTABILITY

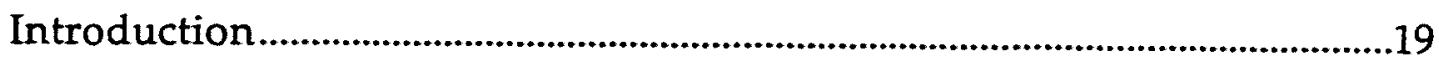

Historical Perspective of Educational Accountability ......................................20

Accountability, School Reform, and Restructuring.......................................22

The Nature of Educational Accountability in the 1990s.................................27

Definitions and Descriptions of Educational Accountability....................28

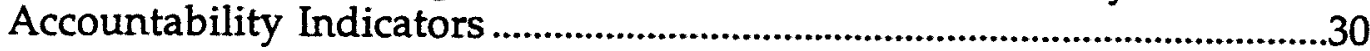

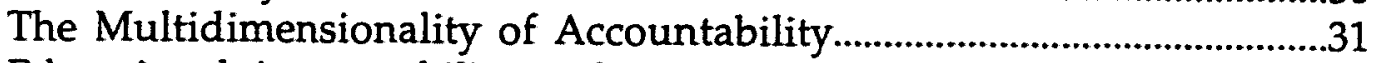

Educational Accountability in the 1990s....................................................33

Accountability Policies and Practices..................................................................34

National Level Accountability Systems.....................................................34

State Level Accountability Systems ..............................................................35

District Level Accountability Systems..........................................................38

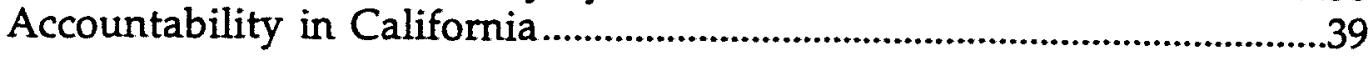

Effects of the Implementation of Accountability Systems...............................41

Leadership, School Reform, and Accountability ............................................43

The Nature of Leadership......................................................................44

Leadership and School Reform ...................................................................46

Leadership for change .................................................................................46

The changing nature of educational leadership .......................................48

Leadership and the changing educational community........................50

Leadership and Educational Accountability …………..................................51

Leadership and the school principal..........................................................52

Accountability, autonomy, and the educational leader .........................53 
Interconnecting Accountability, Reform, and Leadership..........................54

Issues and Concerns .....................................................................................54

Summary

CHAPTER THREE: METHODOLOGY........................................................................58

A MULTISITE CASE STUDY

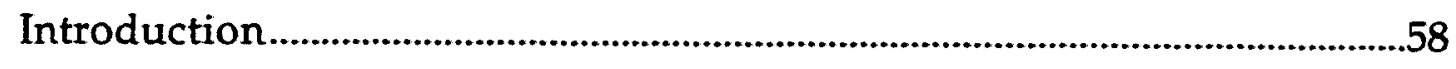

Methodological Framework...........................................................................59

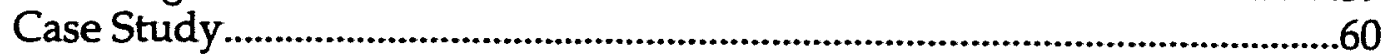

Ethnographic Orientation..........................................................................62

Rigor in Qualitative Research........................................................................62

Overview of the Research Design .....................................................................65

Selection of Sites and Participants...............................................................66

Selection of sites.....................................................................................67

Entry to the population ..............................................................................67

Selection of participants .............................................................................68

Protection of Participants ................................................................................69

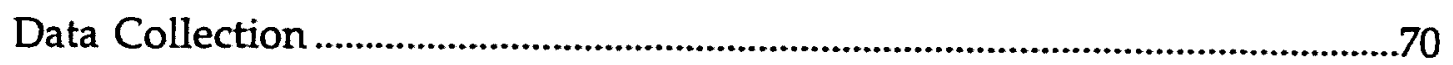

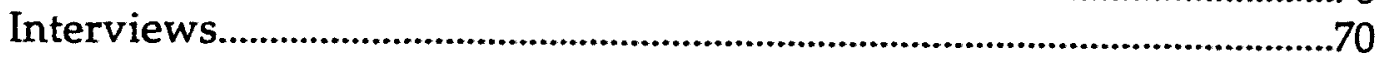

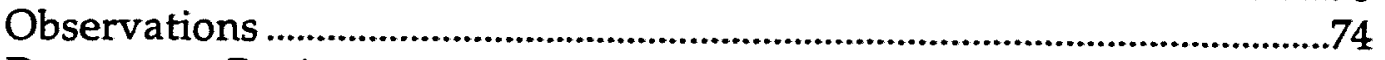

Document Review..........................................................................................

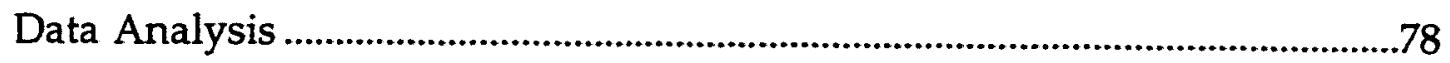

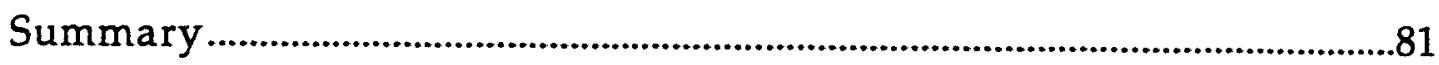

Background of the Researcher .....................................................................82

CHAPTER FOUR: CASE ANALYSES ................................................................84 THREE STORIES OF SCHOOL RESTRUCTURING AND ACCOUNTABILITY FOR STUDENT ACHIEVEMENT

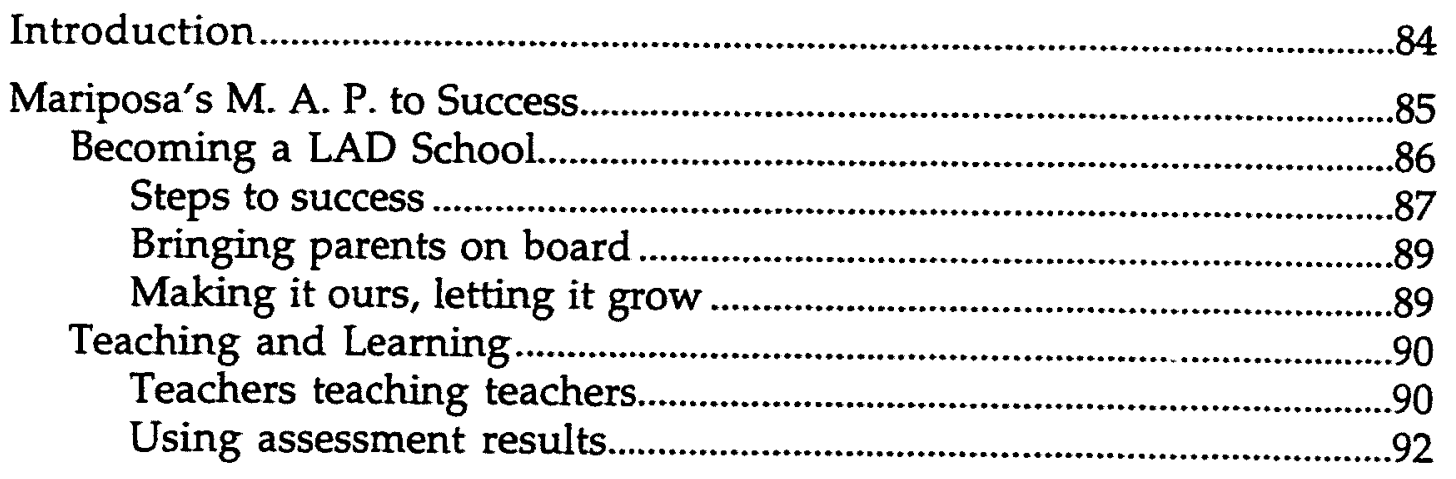


Decisionmaking and Governance.............................................................93

Governance structure ........................................................................93

Input, involvement, decisionmaking...................................................96

In the best interest of . . . ? ..................................................................97

Teachers and decisionmaking..............................................................98

The Challenges of the LAD Project..............................................................98

Commitment and confidence.............................................................99

Time, time, time ...............................................................................100

Does anyone know what we're supposed to do here? .........................100

Will the district come in and tell us ... ? .............................................101

The Successes of Being a LAD School ...........................................................102

All together now.................................................................................102

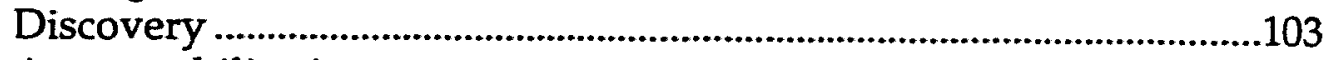

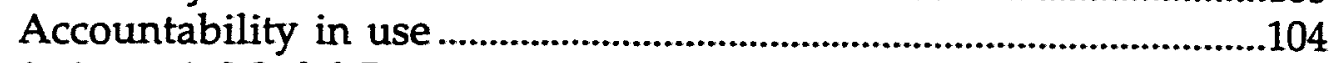

Variation: A Model Program ..................................................................105

Mariposa's M.A.P.: An Accountability Culture in Action.......................107

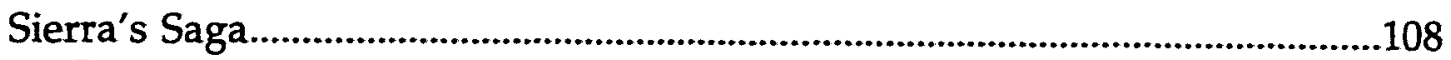

Becoming a LAD School.............................................................................110

Prologue..........................................................................................110

Chapter 1: Beginning the LAD project................................................111

Chapter 2: Implementing, refining, growing .......................................113

Chapter 3: Institutionalization and evolution.....................................114

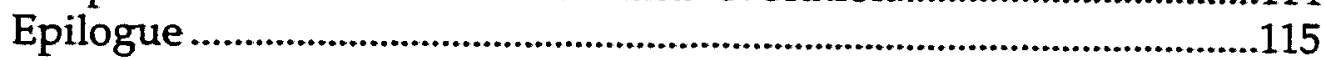

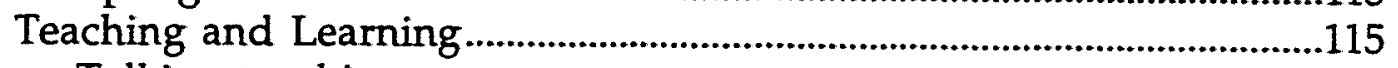

Talking teaching.................................................................................115

Connecting assessment to instruction ................................................116

Reflecting on teaching ..........................................................................119

Decisionmaking and Governance.............................................................120

Governance structure ........................................................................120

Governance process............................................................................122

When it works $=$ teacher power ..........................................................123

When it doesn't work = teacher frustration ........................................124

For shared decisionmaking to work. . . ...............................................125

The Challenges of the LAD Project.........................................................126

Bringing everyone on board................................................................126

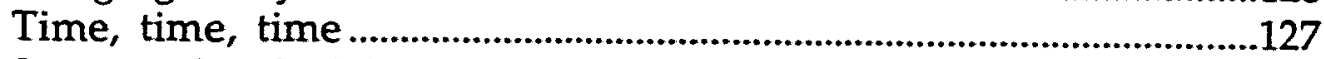

Starting ahead of the crowd....................................................................128

The Successes of Being a LAD School .....................................................129

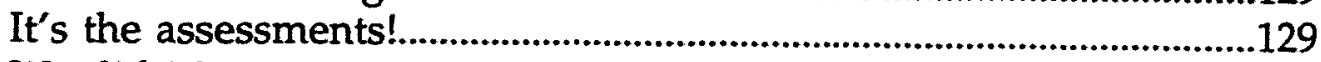

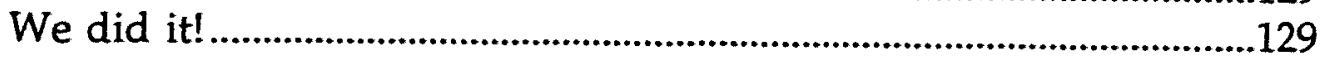

Moving in the right direction............................................................130

Variation: Bringing It All Together...........................................................131

Sierra: A Continuing Saga .......................................................................134 
Paloma: Reform Meets Reality ..............................................................136

Becoming a LAD School: Reform Times Three........................................137

Reform x 1: The Comer School Development Program....................138

Reform $\times$ 2: The National Alliance for Restructuring Education...140

Reform $\times$ 3: The LAD Program...............................................................141

Teaching and Learning..............................................................................144

From isolation to collaboration........................................................144

Benefits to teaching and learning........................................................146

From teacher development to student development ........................147

Authentic assessment, authentic learning.............................................148

Decisionmaking and Governance.............................................................150

Governance structure .......................................................................150

The ups and downs of shared decisionmaking....................................153

The Challenges of School Reform .........................................................154

A new kind of newcomer ................................................................155

Too many programs, too much confusion .............................................156

Teachers come, teachers go...................................................................157

Where's the support?.........................................................................158

The Successes of Paloma's Involvement in School Reform...................161

Time to learn, time to share .................................................................161

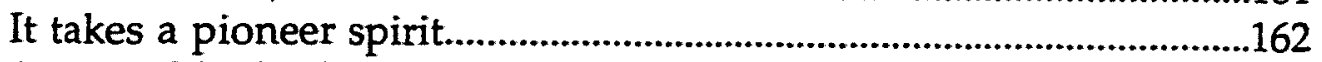

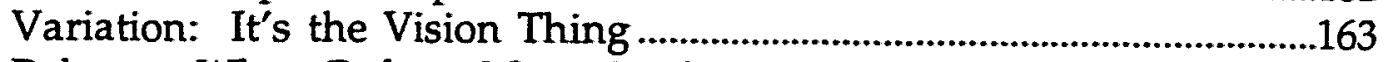

Paloma: When Reform Meets Reality ........................................................164

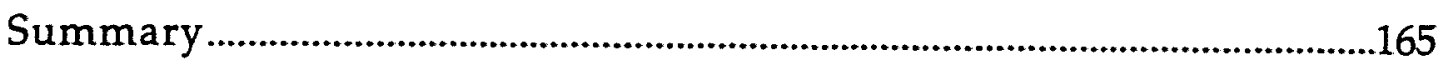

CHAPTER FIVE: CROSS-CASE ANALYSIS..................................................167

RESTRUCTURING, ACCOUNTABILITY, AND LEADERSHIP

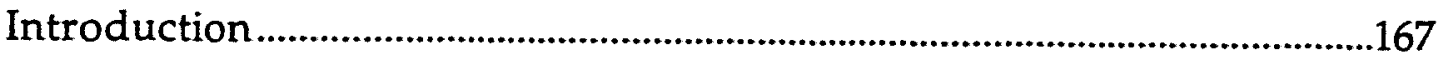

Becoming Accountable for Student Achievement .......................................168

The Adventure Begins ..........................................................................169

What Should Students Know and Be Able to Do? .................................169

Assessment at the Heart of Accountability ................................................172

Teaching and Learning ..................................................................................174

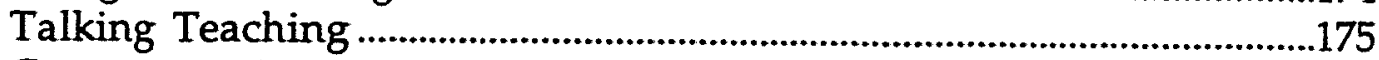

Connecting Assessment to Instruction....................................................177

The Core Processes of Schooling ................................................................180

Teacher Empowerment and Shared Decisionmaking..................................180

The Values of Shared Decisionmaking …………...................................181

The Pitfalls of Shared Decisionmaking........................................................184

Empowerment................................................................................................186

viii 
Challenges and Successes: Worst of Times, Best of Times...........................186

No One Said School Reform Is Easy .........................................................187

Never enough time..............................................................................188

Where are we going? .......................................................................189

Where's the support?.......................................................................190

Reform meets reality.........................................................................190

Nothing Breeds Success Like Success .......................................................191

Accountability and School Site Leadership......................................................193

School Leadership in the Modern Context .............................................194

School Leadership in a Postmodern Context............................................195

Participatory democracy.....................................................................195

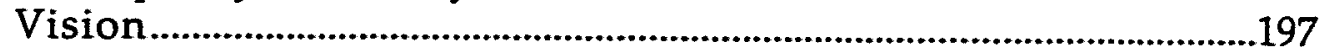

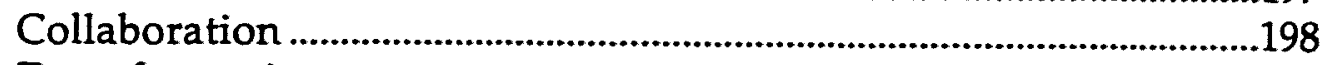

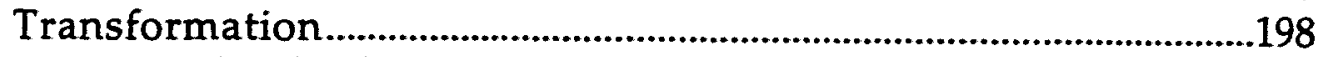

Empowering Leadership .....................................................................199

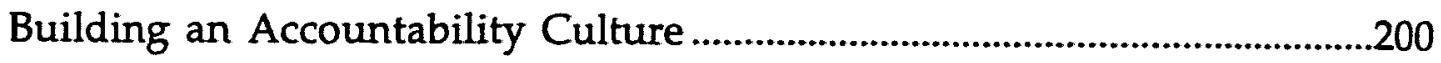

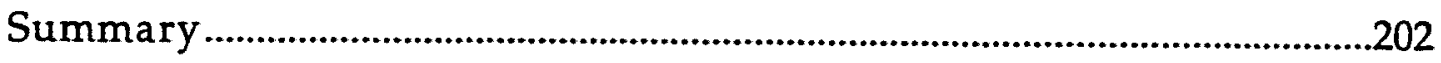

CHAPTER SIX: SUMMARY, IMPLICATIONS, RECOMMENDATIONS ......204 WHAT CAN WE LEARN FROM WHAT WE HAVE LEARNED?

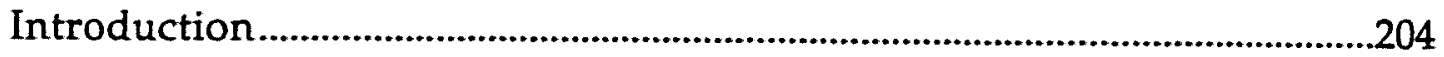

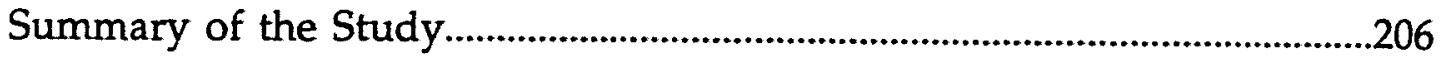

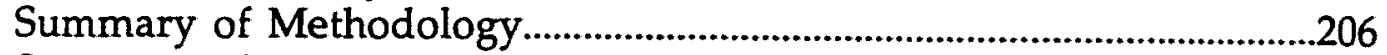

Summary of Key Findings........................................................................208

Common paths, divergent branches ...................................................209

The core processes of schooling ..........................................................210

Teacher empowerment and shared decisionmaking ........................211

The challenges and successes of engagement in school reform......212

Leadership in accountability cultures.....................................................213

Change and Educational Accountability..................................................214

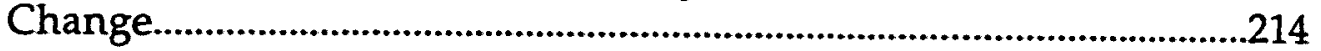

The nature of educational accountability ........................................216

Implications ...................................................................................................217

Restructuring, Accountability and the Core Processes of Schooling....218

Site-Based Management and Shared Decisionmaking............................220

Accountability, Restructuring, and Leadership.........................................223

Translating Policy Into Practice in a Reform Culture..............................224 


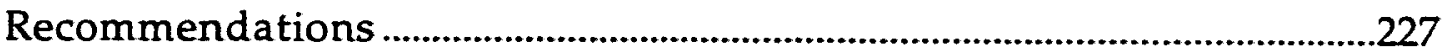

Words of Wisdom From Participants.....................................................227

Have a vision and keep it alive..........................................................228

Start slow and keep focused.....................................................................228

School site power, school site models.................................................229

Learning from those out in front.........................................................230

Recommendations From the Researcher.....................................................230

Recommendation 1: Encourage and sustain site autonomy

and accountability by building capacity for meaningful,

participatory decisionmaking.

Recommendation 2: Invest heavily in ongoing, systematic professional and organizational development

Recommendation 3: Promote entrepreneurial mindsets that are grounded in sound educational practice, and consider reform efforts as a research and development process..

Recommendation 4: Reconceptualize and develop school site leadership as an empowering and relational process...................235

Suggestions For Further Study ...............................................................226

The San Diego accountability demonstration project..........................237

The interconnection of school restructuring, site-based accountability and school site leadership ...............................................238

Concluding Remarks: Odysseys .................................................................239

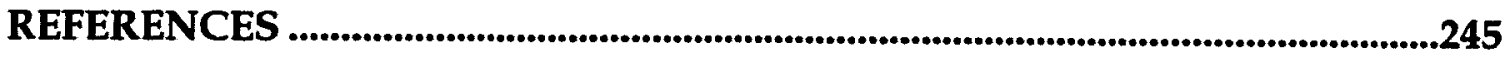

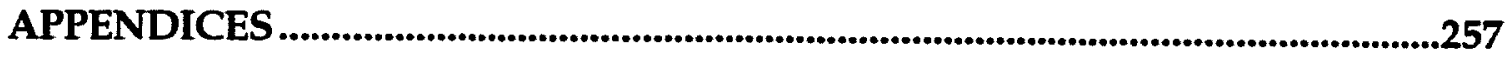




\section{LIST OF FIGURES}

Figure 1: Steps in the Mariposa Accountability Process .......................................87

Figure 2: Mariposa's Governance Structure..........................................................94

Figure 3: Mariposa's Proclamation for Student Success .....................................107

Figure 4: Sierra's Governance Structure..............................................................121

Figure 5: Sierra's Annual Action Plan Implementation Flow Chart............134

Figure 6: Comer School Development Model...................................................139

Figure 7: Paloma's Paradigm Shift ................................................................145

Figure 8: Paloma's Governance Structure.........................................................151 


\section{LIST OF APPENDICES}

Appendix A: Leadership in Accountability Demonstration School Application Procedure .257

Appendix B: Approval to Conduct Research in San Diego City Schools .......261

Appendix C: Sample Interview Invitations and Follow-Up Letters .................263

Appendix D: Informed Consent Form ....................................................................268

Appendix E: Interview Guides..............................................................................270

Appendix F: School Profiles ...............................................................................273 


\section{CHAPTER ONE \\ STATEMENT OF THE ISSUE}

\section{ACCOUNTABILITY FOR STUDENT ACHIEVEMENT}

\section{Introduction}

Accountability is the watchword of the 1990s. Newspaper editorials, television talk shows, campaign speeches, lunchroom conversations, business meetings, council discussions, all resound with demands for results and calls to hold individuals and institutions accountable for their actions. As the twentieth century draws to a close, accountability is one of the prevailing social, economic, political, and educational issues.

Nearly ten years ago, a state accountability study group convened by the U. S. Department of Education observed that "concern about accountability in education mirrors a growing interest in holding all types of public and private institutions accountable for their performance" (U. S. Department of Education, 1988, p. 1). In recent years, public outcry has kept education and student achievement in the limelight. "Never before in history has there been such a demand for American educators to 'stand and deliver' regarding their performance," write Streshly and Newcomer (1994, p. 62). Weber comments that "accountability is the flag, motherhood, and apple pie of education" (in Amundson \& Richardson, 1991, p. vii). It appears, therefore, 
that accountability must be central to any discussion of restructuring, student achievement, teacher empowerment, and school leadership.

\section{Statement of the Issue}

This centrality of accountability brings with it a host of challenges for the educational system. As Brown (1990, p. 3) notes, "although accountability is a much used term, and demands for public accountability are frequent and loud, it is an under-developed concept." Among the tasks faced by educators, therefore, are reaching consensus about the nature of accountability within the context of schools and school districts; finding the appropriate locus of control, and balance of autonomy and accountability; defining the roles and responsibilities of teachers, administrators, parents, and community; building capacity to engage in achievement-focused decisionmaking and governance; and developing and empowering school site leadership.

Since the late 1980s, accountability has been intricately interwoven with the school restructuring movement. A common feature of many earlier reform efforts was an emphasis on changing the content and process of education. Energized by reports such as $A$ Nation At Risk (U. S. Department of Education, 1983), A Place Called School (Goodlad, 1984), and A Nation Prepared: Teachers for the 21st Century (Carnegie Forum, 1986), school reform added a focus on changing educational structures as well. In particular, restructuring typically envisions shifting decisionmaking responsibility from the district to the school level, and involving those closest to the action-principals, teachers, and parents-in discussions about how 
teaching and learning will be carried out, how a school will be organized, how resources will be allocated, and how a site will be governed (Cohen, 1989; Conley, 1996; Hill, Bonan, \& Warner, 1992; Lane \& Epps, 1992; Murphy, 1992; Payzant, 1991).

Implicit in this shift of responsibility is the belief that changing the locus of control will result in changes in student achievement. In exchange for increased site flexibility and autonomy, therefore, schools are being asked to assume greater accountability for student outcomes. As Hill et al. (1992, p. 22) write, "site-based management challenges centralization with the belief that schools will become more effective only if teachers and principals gain a sense of personal responsibility for their students' performance. Relocating initiative to the school level is a precondition to this sense of responsibility." What does accountability look like when it devolves to the site level? "Accountability is achieved only if a school's policies and practices work both to provide good education and to correct problems as they occur," observe Darling-Hammond and Ascher (1991, p. 28). "Each school must design its own accountability structures." Decentralizing authority and accountability to the local school site level thus has multiple implications-for the teaching and learning process, for school governance and decisionmaking, for school culture, and for school site leadership. This study investigates those issues within the context of three elementary schools participating in an accountability pilot project in the San Diego City Schools. 


\section{Background and Significance of the Issue}

Accountability is not a new idea in education. Its American roots lie in the nineteenth century and it has resurfaced throughout the history of educational reform. As the study group impaneled by the U. S. Department of Education (1988) reports:

Deeply held democratic traditions lie at the heart of public schooling in the United States. Although they are often difficult to put into practice, the notion of a common public interest in schooling and the widespread belief that educators should be accountable to the larger body politic have endured, even as the nature of schooling and students has changed. (p. 1)

"Accountability has always been a basic concept in public education," add Darling-Hammond and Ascher (1991, p. 1), "although ideas about how to accomplish it have changed."

Triggered by changing economic, social, political, and demographic conditions, the past 25 years have seen various approaches to educational accountability. Mechanisms for holding schools accountable for what they do reflect a shift in emphasis from inputs, like the adequacy and equity of school resources; to process, including decisionmaking, planning, and school operations; to outcomes-student achievement (Brown, 1990). The 1970s brought technical approaches to the accountability issue, such as testing, performance contracting, and effective schools studies. The 1980s interwove accountability with school restructuring and focused on participatory 
decisionmaking. The 1990s have introduced a responsive, client-centered, outcome-based perspective.

\section{Public and School Site Demands}

Just as accountability has become focused on student outcomes, so has public attention. Amundson and Richardson (1991, p. 1) indicate that "schools are faced with increasing demands to provide the public with concrete examples of student achievement." Brown (1990, p. 1) similarly comments that "as policymakers and the public have become more concerned with the quality of American public education, there has been an increased emphasis on the outcomes of education and holding educators accountable for those outcomes."

Throughout the 1990s, the attention of the public, policymakers, the business world, the media, and educators themselves has been riveted on well-publicized educational outcome indicators such as test scores, achievement gaps, dropout rates, and remedial efforts at colleges and in the workplace (Cohen, 1989; McDonnell, 1990; Streshly \& Newcomer, 1994). "From the perspective of observers both inside and outside the educational ranks," writes Schwartz (1991, p. 231), "American schooling continues to be in critical condition."

At the same time public attention has focused on schools and student achievement, school sites have begun demanding increased flexibility and decisionmaking autonomy. One emphasis of educational reform efforts since the late 1980s has been site-based management-moving decisionmaking 
authority, and the accompanying responsibility, closer to the delivery of services. McDonnell $(1989$, p. 2) indicates that school-based management is founded on the "premise that schools have different cultures and needs ... state and local officials should let each school decide how to organize itself and solve its own problems."

A significant problem for educators, therefore, is to balance public demands for improved educational outcomes with site demands for increased flexibility and decisionmaking authority. "These pressures," notes Stinnette (1993, p. 2), "create a climate of crisis that demands substantive changes in the ways schools structure the learning environment, deliver educational services, govern themselves, and are held accountable." Schools and school systems continue to spend considerable time, energy, and resources struggling with this issue.

\section{Accountability and Restructuring in San Diego City Schools}

The San Diego Unified School District has exemplified this interplay among school autonomy, public pressure, and accountability. In the late 1980s, San Diego City Schools began pursuing school reform through a process of restructuring, focusing primarily on promoting participatory governance at the site level. The board of education adopted a formal policy statement on restructuring in 1988, which "recognized that schools should have greater site autonomy and control over budgets, shared decisionmaking among staff members, parents, and students, and appropriate accountability standards for student outcomes" (Payzant, 1991, p. 19). 
Simultaneously, however, concerns about student achievement were increasing. In particular, parents and community members expressed continued concern about the achievement gap exhibited by various student ethnic groups. In response, in December 1990 the school board approved the formation of a Student Achievement Accountability Committee (SAAC). This group of parent, community, staff, and school board representatives was charged with arriving at consensus about the nature and purpose of accountability for student achievement and developing structures to assure such accountability.

In March 1993, after more than two years of development, the school board adopted the Report and Recommendations of the Student Achievement Accountability Committee (1993), which included the following district accountability policy statement:

It is the policy of San Diego City Schools to be accountable for the educational achievement of all its students. The school district demonstrates its commitment to this policy through a mutual accountability system. Each school is required to emphasize student achievement as measured by equitable district standards for all students. Each school also is required to integrate accountability into its existing planning processes. The district administration and central office staff are required to provide school sites with the resources needed to enable students to meet district and school site standards of achievement. (p. 9) 
In addition to the policy statement, the report included guiding principles for a student achievement accountability system and a description of four major constituent elements of that system: high standards, related assessments, recognition and intervention measures, and public reporting practices. The SAAC also recognized that understanding and implementing a system of accountability for student achievement is a complex process, particularly in a large and diverse urban school district. Thus the report also recommended that the district commit resources to support a demonstration school project that would provide leadership in developing an accountability system model for the district.

\section{The Leadership in Accountability Demonstration (LAD) Project}

In March 1993, nine elementary schools and one middle school volunteered to become Leadership in Accountability Demonstration (LAD) schools. These schools were charged with articulating and implementing site-based accountability systems based on the guidelines in the SAAC report (see Appendix A). Their responsibilities included:

- receiving training in the four facets of accountability (standards, assessments, recognition/intervention, and reporting);

- infusing accountability elements into existing planning processes;

- identifying multiple criteria for assessing student progress;

- establishing baseline measures and improvement targets;

- designing simple reporting tools; 
- describing appropriate recognition and intervention measures; and

- serving as mentors for other district schools.

Each school identified a team of teachers, administrator(s), and parents to attend five days of initial training between March 31 and May 12, 1993. These sessions introduced participants to the accountability process and helped them begin planning for implementation at their school sites. School teams reviewed research, discussed roles and responsibilities of stakeholders, assessed site needs, diagnosed organizational capacity and readiness, developed models to collect and analyze data, and determined implications for change and a process to effect change.

During the 1993-94 and 1994-95 school years, site teams came together for monthly focus group sessions to continue their discussions, share their challenges and successes, and network with colleagues. Each school was assigned a central office staff member as an advocate, to broker services and support for the site. These advocates also met in a monthly forum with the site administrators to discuss the activities, progress, and issues involved as the schools worked toward designing and implementing their site systems.

In the fall of 1994, recognizing the value of the work in which these schools were engaged, the district allocated funds for a second phase which added thirteen more schools to the demonstration project. The original ten schools assisted in the initial training and became partners for the new sites. Teams from all the schools participated in monthly focus group sessions during the 1994-95 school year. Formal project funding ended in June 1995, 
with the expectation that student achievement accountability would be expanded districtwide based on the work of these demonstration schools.

Three studies, conducted between February 1994 and June 1995, examined the efforts of the original ten demonstration schools at various points in the process. Interim progress reports delivered to the board of education in June 1994 and January 1995 found that school staffs were engaged in extensive work relative to standards and assessment, but were just beginning to address the areas of recognition/intervention and public reporting (Bennett, 1995a; Forest, 1994).

A final study, conducted in the spring of 1995 after two full years of the program, reported that "the primary result of the schools' two years of work with the LAD project was the establishment of site 'accountability cultures' wherein stakeholders recognize, accept, and perform their responsibilities and associated accountability for student achievement" (Bennett, 1995b, p. 25). Four elements were identified as central to the process: communication and collaboration, site empowerment and ownership, working as a site on standards and assessments, and focusing on student needs and student achievement. The report also found that "site leadership, from administration and among staff, was identified by many of the study participants as central to the success of the school efforts" (p. 25).

In October 1995, following presentation of this final evaluation study, the school board requested details and a specific timeline for the expansion of accountability into a districtwide system. In response, a preliminary 
implementation plan was taken forward and approved by the board in November 1995 (Carriedo, Callahan, Bennett, \& Morgan, 1995). In January 1996, a task force was impaneled to articulate the process for operationalizing the accountability system. In particular, this group was charged with identifying indicators for assessing school performance, and determining specific processes for district-level recognition and progressive interventions.

The task force was sidelined by a district teachers' strike in February 1996, in which the processes for shared decisionmaking and accountability were key areas of contention. Following the strike settlement, the task force was reconfigured to include equal representation among three stakeholder groups: teachers, administrators, and parents/community. This committee worked collaboratively for several months, and reached consensus on the basic structure for a district accountability system which the school board approved in November 1996. The report delineated the legal and policy basis for accountability in the district, and the district strategic direction which drives the accountability system. It also outlined the accountability cycle, school performance indicators, recognition measures for successful schools, and procedures for reviewing and intervening with schools that need support (Accountability Implementation Task Force, 1996).

The task force continued its work, and presented a companion report to the board in March 1997 to further define several areas of the accountability process (Accountability Implementation Task Force, 1997). This report also articulated the need for a district support system for schools and staff 
members. Central to that system must be a focus on building capacity at school sites for high quality, student achievement-focused planning and decisionmaking among administrators, teachers, staff, parents, and community who share mutual accountability for improving student achievement. It is in this area, particularly, that the district can learn from the Leadership in Accountability Demonstration (LAD) schools. However, the studies conducted to date, while providing extensive information on the process in which the pilot schools engaged, provided only limited information in key areas such as learning environment and instructional practices, decisionmaking and governance structures, and school site leadership issues.

\section{Purpose of the Study}

The work of San Diego's LAD schools offers a great deal to inform educational policy and practice. This study, therefore, undertook an investigation of three of the original pilot schools, to report on their efforts to demonstrate accountability for the achievement of their students. The threefold purpose of the study was to investigate the issues, challenges, and successes involved in engaging teachers in school reform efforts; identify what kinds of site governance and leadership have been most embraced by schools accepting site accountability in exchange for increased flexibility and autonomy; and discuss implications for policymakers and practitioners relative to the intersection of student achievement accountability, school restructuring, and school site leadership. 
The three participating schools took different approaches to the Leadership in Accountability Demonstration School project. They also represent different student populations, organizational structures, and governance processes. One common element, however, was the recognition by district and site staff that these schools were out in front of the rest of the pilot schools in their commitment to, and engagement in, the process of becoming accountable for improving student achievement.

To investigate their work, this study revolved around interviews with teachers and administrators, two of the major stakeholder groups in sitebased accountability. These interviews were contextualized by observations of site decisionmaking forums along with a review of relevant site documents and district records. Through descriptive and interpretative analyses of data from each school, and through the examination of themes that emerged within and across sites, the study describes the accountability implementation process and its related challenges and successes. It also addresses changes in teaching and learning, delineates decisionmaking and governance processes, explores school accountability cultures, and discusses school site leadership. The report then presents implications and recommendations for educational policymakers and practitioners relative to school restructuring, student achievement accountability, and school site leadership.

\section{Limitations of the Study}

The study focuses on three elementary schools that were pilot sites in the San Diego City Schools' Leadership in Accountability Demonstration 
(LAD) School project. As such, the findings are tied to issues and conditions specific to those sites and experiences peculiar to those who participated in school efforts during the period under study. Thus, the results are unique to the interaction of the participants and the contexts included in the study, although elements of the process and some of the outcomes may be transferable to other settings.

Data collection for this study occurred across two school years and was affected somewhat by changes in site administrators and teaching staff. Some teachers influential in the schools' work during the demonstration project transferred to other locations and were unavailable for interviews. Teachers' schedules (including meetings, off-site conferences, and job sharing arrangements) also influenced the selection of interview participants. In addition, work-related scheduling conflicts inhibited my ability, as the researcher, to conduct some planned site observations.

Semi-structured, open-ended interviews were the primary method of data collection. Interviews, subjective by nature, may be influenced by the questions themselves, the interview context, and mental filters applied by the researcher during data collection and analysis. Careful listening, accurate transcription, sharing preliminary findings with participants and colleagues, and conducting multiple analyses were all employed to enhance the validity and reliability of this methodology.

Finally, this study recognizes and values that qualitative research entails an interaction between researcher and context. In this case, my 
involvement with the LAD project allowed me access to the field and the participants, and also established a particular sensitivity to the topic and the information being gathered. It was essential, however, that I remain rigorously faithful to the data throughout the collection and analysis process.

\section{Specific Terminology}

Accountability: There are multiple definitions and conceptualizations of accountability within the context of education. The following definition was developed by the San Diego City Schools' Student Achievement Accountability Committee (1993) from the work of Darling-Hammond and Ascher (1991):

A system of commitments, policies and practices to 1) ensure that students are exposed to good instructional practices in a supportive learning environment; 2) ensure that students are not exposed to harmful teaching practices; 3 ) provide internal self-correctives to identify, diagnose and change courses of action that are harmful or ineffective; and 4) provide information to students, parents, educators, the school board and the public on the strengths and weaknesses of student performance at the school, district and statewide levels. (p. 2)

Assessment: Various processes, such as tests, performances, and portfolios, that provide students with opportunities to demonstrate acquired skills and knowledge.

Constructivism: A worldview which believes that "we construct our own social realities ... there are no universal truths or principles" (Bergquist, 
1993, p. 18). In education, constructivism is grounded in the assumption that students construct their own knowledge through active engagement with learning experiences (Darling-Hammond, 1993).

Empowerment: Giving power or authority to individuals or groups. In connection with site-based management and shared decisionmaking, empowerment refers to providing school site stakeholders, particularly teachers, with formal decisionmaking authority and other avenues of influence (Murphy, 1992). Bredeson (1994) identifies four dimensions, describing empowerment as a collaborative and participatory process; a sense of personal and professional identity; an opportunity for autonomous professional behavior; and an environmental characteristic encompassing trust, sharing, openness, flexibility, and affirmation.

Inputs: Resources such as funding, materials, and personnel; the term is usually used in connection with adequacy and equity. Accountability mechanisms focusing on inputs have included revenue controls, categorical funding, curriculum guidelines, and teacher certification (Brown, 1990).

Intervention: The process of interceding to modify school practices that have not resulted in improved student achievement.

\section{Leadership in Accountability Demonstration (LAD) Schools: A San}

Diego City Schools' pilot project in which twenty-three schools developed and implemented site-based student achievement accountability systems based on guidelines in the district's accountability policy report (Student Achievement Accountability Committee, 1993). Ten schools became Phase I sites in the 
spring of 1993, and an additional thirteen schools joined as Phase II sites in October 1994. Project funding formally ended in June 1995.

Modern: The predominant worldview in the twentieth century, emerging with the industrial era of the late 1800s. Modernism is characterized by a structural/functionalist paradigm, an emphasis on scientific and technical solutions to problems, and a culture of individualism and competition (Bergquist, 1993; Foster, 1986; Rost, 1993).

Outcomes: What students should know and be able to do as a result of schooling. To Finn (1992, p. 82), they are the "skills and knowledge that we'd like every young American ... to reach by the threshold of adulthood."

Postmodern: A new worldview that is emerging in the late twentieth century. The postmodern view is characterized by values and ideas such as complexity, collaboration, diversity, and sensitive critique of social systems like education (Bergquist, 1993; Rost, 1993).

Recognition: The process of publicly acknowledging and/or rewarding performance that contributes to improved student achievement.

Reculturing: The process of developing new values, beliefs and norms; in education this includes new conceptions about instruction and new forms of professionalism for teachers (Fullan, 1994, p. 9).

Restructuring: A "wide-ranging series of endeavors to improve education by introducing fundamentally different methods of school governance and significantly different ways of organizing schooling, particularly the work performed by teachers and the teaching-learning process 
unfolding in classrooms" (Murphy, 1992, p. 3). Fullan (1994, p. 9) adds that "restructuring concerns the roles, structure and other mechanisms for enabling new cultures to thrive."

Shared decisionmaking: "An empowering joint planning and problem-solving process that seeks to improve the quality of education and working life" (San Diego City Schools, 1990, p. 3).

Site-based management: Structural decentralization and devolution of authority from the state and district to the school site level. The basic principle entails expanded local control and influence, with schools having greater responsibility for their own affairs (Murphy, 1992, pp. 10-11). David (1989, p. 46) indicates that school-based management includes two elements: increasing school autonomy and sharing decisionmaking authority.

Stakeholder: In its educational sense, stakeholder refers to an individual with an interest in and responsibility for improving the achievement of students (Student Achievement Accountability Committee, 1993). Teachers, administrators, parents, students, and community members are all stakeholders in the educational process.

Standards: Statements of what students should know and be able to demonstrate in various subjects and domains, at certain junctures in their educational careers. 


\section{CHAPTER TWO \\ REVIEW OF THE LITERATURE \\ PERSPECTIVES ON EDUCATIONAL ACCOUNTABILITY}

Introduction

A researcher must become intimately familiar with the topic under study to provide both a history and a context to the project. To build a knowledge base for this investigation, a search was conducted on the topic of educational accountability. This exploration uncovered a collection of books from the 1970s followed by a proliferation of materials from the late 1980s and the 1990s. These readings revealed that education, reform, and accountability have been intertwined since the nineteenth century. However, discussions in the recent literature provide the perspective that educational accountability has reemerged in the 1990s with new definitions and conceptualizations, and has taken center stage once again in the educational drama.

This chapter explores six themes synthesized from the literature: (a) an historical perspective of accountability in education; (b) the link among accountability, school reform, and school restructuring; (c) the nature of educational accountability in the 1990s; (d) accountability policies and practices at national, state, and local levels; (e) effects of the implementation of educational accountability systems; and (f) leadership, school reform, and 
accountability. The chapter concludes with the delineation of issues and concerns which evoke a need for further study.

\section{Historical Perspective of Educational Accountability}

Accountability is not a new idea in education. Kirst (1990, p. 29) concludes that "educational accountability is a very old concept that continues to grow and diversify." According to Wynne (1972, p. 30), the concept of educational accountability might be traced back "two millennia ago, (when) Plutarch advised 'Fathers, themselves, ought every few days to test their children, and not rest their hopes on the disposition of a hired teacher; for even those persons will devote more attention to the children if they know they must from time to time render an account."

The American roots of the educational accountability movement can be found in the nineteenth century, when "educational reformers and school administrators strove to create a federal commitment to improving elementary and secondary education" (Wynne, p. 31). The 1840 United States census contained questions about the national level of literacy, and the original U. S. Department of Education was established in 1867 around congressional arguments favoring greater accountability (Hansen, 1990).

In the early twentieth century, school reform and accountability were characterized by educational applications of Taylor's scientific management principles. The 1930 s and 1940 s were dominated by the testing movement, which focused on pupil performance rather than school performance; as 
Wynne (1972, p. 35) comments, "it was acceptable to measure how well students learned but not how well schools taught."

The 1954 Brown v. Board of Education decision and the post-Sputnik era revived concerns for educational reform and accountability. Coupled with economic and demographic changes across the country, this led to activities such as Project TALENT in 1959, the first large-scale output evaluation, and the accountability audit requirements in the 1965 Title I legislation. These efforts primarily tried to relate input variables such as expenditures, socioeconomic background, and teacher qualifications to outputs as measured by what were perceived to be uniform, objective tests (Hansen, 1990; Wynne, 1972).

The 1970s ushered in another round of attention to accountability, sparked in part by President Nixon's 1970 message to Congress on education reform; it stated that school administrators and teachers are responsible for their performance, and it is in their interest as well as in the interest of students that they thus be held accountable. Standardized testing became a primary accountability tool, with the first National Assessment of Educational Progress (NAEP) conducted in 1970. In addition, spearheaded by Lessinger (1971a, 1971b), attention refocused on scientific management and efficiency. School reform and accountability became characterized by cost accounting and performance contracting, the effective schools movement, and educational applications of systems approaches (Hansen, 1990; Martin, Overholt, \& Urban, 1976; Porter, 1971). 
The next wave of educational reform and accompanying attention to accountability began with the 1983 publication of $A$ Nation at Risk (U. S. Department of Education) and continued with subsequent reports such as $A$ Place Called School (Goodlad, 1984), and A Nation Prepared: Teachers for the 21st Century (Carnegie Forum, 1986). Kirst (1990, p. 4) observes that, beginning in 1983, "school reforms brought with them still another wave of accountability legislation, focusing this time on such concepts as school report cards, merit schools, outcome-based accreditations, and interstate achievement comparisons." Wagner (1989) writes that the reemergence of accountability in the 1980s came from a concern with rising costs in public services, the use of modern business as a model for school management, and the apparent failure of schools with large numbers of youth.

\section{Accountability, School Reform, and Restructuring}

By the late 1980s, accountability became even more intricately interwoven with school reform as the focus turned to restructuring educational systems with increased emphasis on site-based management, teacher empowerment, and parent and community involvement (DarlingHammond \& Snyder, 1992; Hansen, 1990; Lieberman, 1992; McDonnell, 1989). Darling-Hammond et al. (1993, p. v) describe the impetus for this connection: "The school restructuring movement has called attention to the need to find new ways to organize schools so that they are genuinely accountable for their students and to their communities." 
Restructuring, according to the Council of Chief State School Officers (1989, p. 9), is "the fundamental redesign of the organization and methods of schooling." David (1991, p. 11) suggests that "it is a long-term commitment to fundamental, systemic change." Moorman and Egermeier (1992) provide the following summary statement:

Thus we can say that restructuring is a complex, purposeful process of social evolution that transforms the educational system and institutions by reordering the organizational rules, roles, and relationships and engaging participants in work that develops and expresses increasingly interesting, worthwhile academic and social values so that desired changes result in what schools do and in the kinds of outcomes they produce. (p. 19)

Restructuring, in the educational lexicon, generally involves the following concepts: changing district and school organizational structures and operating practices; changing school governance structures; changing curriculum and instruction, and giving sites flexibility and control over the teaching and learning process. It also includes instituting professional roles for educators and empowering teachers to participate in making schoolwide decisions; and increasing parent and community involvement in site-level educational and decisionmaking processes (Bredeson, 1994; Cohen, 1989; Glickman, 1993b; Herman \& Herman, 1993; Lane \& Epps, 1992; Lemahieu \& Foss, 1994; Lieberman \& Miller, 1990; Murphy, 1992). These concepts, 
frequently placed under the headings of site-based management and shared decisionmaking, appear to have significant implications for accountability.

If, as Hill et al. (1992, p. 21) report, "the purpose of site-based management is to improve performance by making those closest to the delivery of services-teachers and principals-more independent and more responsible for the results of their schools' operations," then accountability must shift along with the shift in responsibility and authority. David (1991, p. 15) suggests that one of the thorny issues raised with restructuring is determining how to allocate responsibility in a way that matches authority.

"The price of freedom is a new set of obligations," note Hill and Bonan (1991, p. 45), where school staff members must "take responsibility for their performance as individuals and for the performance of the school as a whole, and to consult with and anticipate the reactions of diverse constituencies." Thus the nature of accountability changes in site-managed schools to a multidirectional concept where schools are accountable upward, to the district and state; laterally, to one another and to other schools; and downward, to parents, students, and community members. "In decentralized organizations," Hill and Bonan continue, "most people exist in a complex web of dependency, responsibility, and accountability relationships" (p. 46).

Cohen $(1989$, p. 44) reports that, in restructuring schools, "school decisionmaking and governance patterns must change as well. Creating greater discretion at the school site level also should involve broader participation in decisionmaking." Hill and Bonan (1991, p. 34) add that "a 
significant feature of site-based management is the commitment to changing the locus of authority for key educational decisions, including curriculum, institutional strategies, and school organization and management." According to Darling-Hammond and Ascher (1991, p. 9), "most school-based management proposals call for shared decisionmaking among faculty, staff, parents, and students. They assume that better decisions will be made when those who are closest to the situation, and who must live with the decisions, are involved."

The intent of shared decisionmaking, then, is to empower multiple stakeholders in the educational community-administrators, teachers, parents, community members, students-to engage in the decisionmaking process. As noted, those who accept the devolution of authority for school management must also accept the devolution of accountability for student achievement. Similarly, those within the school community who accept the authority and responsibility for decisionmaking must also accept accountability for the results of those decisions.

Several concerns appear in the literature in connection with site-based management and shared decisionmaking. Research by Malen, Ogawa, and Kranz (1990) indicates that site decisionmaking groups rarely address central, salient policy issues; are often handcuffed by deeply ingrained norms and expectations; lack resources and innovation; and have limited actual autonomy. Malen and Ogawa (1992) question whether site-based management, as currently configured, has actually modified formal 
decisionmaking arrangements in school systems; altered traditional influence relationships among principals, teachers, and parents; or resulted in the implementation of major changes in the instructional component of schools.

Other writers and researchers focus on the types of decisions available to be made at the school site level, and the degree of attention that is being paid to the results of site-based decisionmaking. Finn and Rebarber (1992, p. 182) observe that it cannot be "automatically assumed that shifting the locus of decisions from one level to another will lead to markedly different decisions being made." They also report that "in most instances, buildinglevel decisionmakers gain only limited control over such important variables as curriculum, budget, and personnel." According to Moloney (1989, p. 23), "restructuring is about power-empowerment, if you prefer-but it is power defined as achieving results, not merely making decisions. A decision-and who makes it-is of no consequence if that decision does not lead to results."

What amount of restructuring is actually occurring? Are the core processes of education-teaching and learning-really changing? Is control over significant decisions actually devolving to school sites, staffs, and parents? These questions have not yet been fully answered. O'Neil (1990, p. 8) comments that "perhaps the trickiest part of restructuring schools ... will be to completely reshape a system that has been measured thus far by compliance with bureaucratic mandates into one focused on the bottom line-evidences of authentic student achievement." This is the challenge of 
accountability inherent in the restructuring process, and one which has significant implications for educators and policymakers.

\section{The Nature of Educational Accountability in the 1990s}

The school reform movement and the focus on restructuring have significantly influenced discussions about the nature of educational accountability for the 1990s. Previously a primarily technical concept, based in cost accounting and efficiency, accountability is evolving toward an approach based on a democratic tradition of participatory governance, complementary ideas of responsibility and responsiveness, and a constructivist conception of teaching and learning. The focus is the school site level with the expectation that, in exchange for increased autonomy and flexibility, there will be an associated acceptance of accountability. Accountability is oriented toward outcomes and performance, rather than inputs and compliance. And accountability involves a multidirectional relationship among school staff, district administration, legislators, parents, the business community, and students (Brown, 1990; Darling-Hammond \& Snyder, 1992; Lieberman, 1992; Schmoker, 1996; Theobald \& Mills, 1995; Wiggins, 1994).

Darling-Hammond and Ascher (1991, p. 13) observe that "recently, in response to pressure to improve American education ... states, districts, and local schools have moved rapidly to put accountability systems into place. Although there is widespread pressure on schools to find better ways to attend to their 'bottom line'-student learning-ideas about how to both stimulate and measure school improvement are still in their infancy." Key 
questions surrounding the exploration of educational accountability in the 1990s seem to be: Who is responsible? For what? and To whom?

\section{Definitions and Descriptions of Educational Accountability}

Webster's dictionary defines accountable as "(1) obliged to account for one's acts; responsible; (2) capable of being accounted for; explainable" (Neufeldt and Guralnik, 1994, p. 9). Wagner (1989, p. 8) approaches the terms historically, reporting that "accountability and the adjective accountable ultimately derive from the verb account, which in its earliest usage meant literally 'to reckon, count, count up or calculate.' ... The definition 'to render an account of, to explain and to answer for' came into use between the early and late 1600s."

Zurhellen (1987, pp. 1-2) offers a "working, operational definition of accountability ... (as) the acceptance of responsibility for consequences by those entrusted with the public service of education." He explains that, “defined variously as responsibility, explicability, and answerability, accountability has traditionally been used with reference to service in the public interest, where the stewardship of public funds requires some form of accounting." To Amundson and Richardson (1991, p. 11), "accountability is the process of taking stock-trying to determine what has been accomplished and what remains to be done." Brown (1990, p. 3) indicates that, "in its simplest and most frequently used form, accountability means holding someone responsible for his/her actions." 
The literature includes a variety of statements about and descriptions of accountability in the educational arena, further refining our understanding of its nature in the 1990s. Theobald and Mills (1995, p. 466) indicate that "communities are well served by connecting accountability to those things that constitute an education and that go toward making an educated person." According to Wiggins (1994, p. 15), "at its core, accountability involves faculties that are always client-centered and results-focused." DarlingHammond and Ascher (1991, p. 14) report that "accountable schools establish policies and practices in all areas likely to produce responsible and responsive education for their students." They add, "the point is that accountability is achieved only if a school's policies and practices work both to provide good education and to correct problems as they occur" (p. 28).

Brown (1990, p. 3) introduces the concept of an accountability loop with five elements: key actors, goals, resources, pre-determined standards, and rewards/sanctions; she notes that "an effective accountability system should address each of these components." DeMoulin and Kendall (1993) call for the formation of accountability networks that include not only administrators and teachers, but also students, community members, politicians, and university personnel. They suggest that "this participatory network must work collectively for the teaching/learning process to be successful" (p. 691).

Finally, Finn (1992, p. 83) proposes that "accountability in education can be visualized as a three-legged stool." The first leg involves delineating the goals and having clear standards to know when they are achieved; the second 
involves having reliable information to determine whether the standards are being met; and the third leg involves consequences-good things when goals are being met, and interventions when they are not.

\section{Accountability Indicators}

To make an accountability system workable, some type of performance indicators are needed. Brown (1990, p. 2) defines indicators as "sets of statistics that reveal something about the condition of an education system-a school, district, state, or nation." She also comments that "the most useful system indicators, from a policy or accountability perspective, are linked to system performance."

Darling-Hammond and Ascher (1991, p. 13) observe that "one aspect of the accountability quest is the search for types of information about school and student performance that can be used on a regular basis to inform policymakers, the public, and educators about educational trends and needs." They report that accountability indicators should offer at least one of the following types of information about student learning or school performance: problem-oriented information, policy-relevant information, information on educational outcomes, information on students' backgrounds and placements, and/or information about school context factors.

It is essential that the indicators be carefully selected and provide useful information that is meaningful and appropriate to the educational context to which they are being applied. As Darling-Hammond and Ascher (1991, p. 14) write, "indicators that are poor measures, or are badly used, can actually 
undermine accountability." Performance indicators can easily be misused or misinterpreted, which may have consequences ranging from narrowing the curriculum to the misapplication of rewards or sanctions.

Indicators are the foundation of an accountability system and Amundson and Richardson (1991, p. 6) suggest that "by their choice of indicators, policymakers determine who will be accountable, for what, and to whom." The report of the Office of Educational Research and Improvement (OERI) Study Group (U. S. Department of Education, 1988) proposes six basic criteria for accountability indicators: they should measure the central features of schooling, measure what is actually being taught or considered important for students to know, provide information that is policy-relevant, focus on the school site, and allow for fair comparisons.

\section{The Multidimensionality of Accountability}

Educational accountability is a multidimensional concept, according to much of the current literature. Cullen and Altschuld (1994) introduce four types of accountability identified by teachers: personal accountability, collegial accountability, contractual accountability, and accountability to clients. Brown (1990, p. 4) describes four accountability strategies, differentiated by the degree and locus of control: bureaucratic strategies, which assume an authoritative relationship between superiors and subordinates; legal strategies, where the relationship depends on a process of rewards or punishments to induce compliance; professional strategies, which involve clear outcomes with an opportunity for individual judgment; and political strategies, through which 
representatives are responsible to constituents. To these, Darling-Hammond and Ascher (1991) add a fifth-market accountability—which focuses on parental choice and involvement.

In discussing these various accountability strategies, DarlingHammond (1988) indicates that:

In education, it is easy to see that legal and bureaucratic forms of accountability have expanded their reach over the past twenty years, while electoral accountability has waxed and waned.... Market accountability is more often discussed as a possibly useful vehicle, but still rarely used. ... Professional accountability is gaining in prominence as an idea for strengthening teaching quality, but it is yet poorly defined and partially at odds with other forms of accountability currently in use. (p. 11)

She promotes an increased focus on professional accountability, to ensure that teachers are adequately prepared to teach responsibly, that best practices are sought out and used, and that practitioners pledge their primary commitment to the welfare of their clients-the students.

No single accountability strategy stands alone and, in fact, they should be used interactively to create an appropriate, responsive accountability system. Kirst (1990, p. 10) observes that "all accountability mechanisms have their strengths and weaknesses, and each is more or less appropriate for certain types of educational interventions and contexts .... (They) should be combined in creative and effective ways." Brown (1990) concurs: 
In large complex organizations like public education, multiple accountability strategies are needed to hold the whole system accountable.... For a system to be held fully accountable, these mechanisms must also be integrated with each other so that all aspects of the institution are under control and operating under a consistent set of expectations. (p. 4)

\section{Educational Accountability in the 1990s}

How, then, do these definitions, descriptions, indicators, and strategies help respond to those key questions about educational accountability in the 1990s: Who is responsible, for what, and to whom?

Who is responsible? Zurhellen (1987, pp. 4-5) suggests that "all of the parties to the total system-teachers, principals, superintendents, boards of education, legislators, and even parents-have their roles in viable accountability systems. Persons at each level are responsible for making decisions and for the results of those decisions." Thus, accountability is a shared responsibility among all members of the educational community.

For what are we responsible? Peterson (1992, p. 110) proposes that "the ultimate purpose is to improve teaching and learning among all students." Accountability systems must use multiple strategies and indicators to ensure that students achieve. As a bottom line, educators cannot stop at being accountable for just the instructional process, but must assume accountability for learning outcomes-connected to high standards-as well. 
And to whom are we accountable? Wiggins (1994, p. 15) proposes that the customers are "where accountability begins and ends.... (Schools are) only successful to the extent that their clients are satisfied and their goods and services are of obvious high quality." Our clients are the same stakeholdersstudents, parents, educators, the community and business world-who share the accountability. Thus, accountability is a multidirectional relationship, as Zurhellen (1987, p. 12) describes, "between and among all participants at all levels of the educational process."

\section{Accountability Policies and Practices}

Across the country, accountability policies and accompanying implementation systems are in place or in development at national, state, district, and school site levels. Some are still grounded in the 1980s technical approach, while others have begun emerging around new conceptualizations.

Nationally, the approach to accountability was influenced by the Goals 2000 legislation and the reauthorization of Title I. Across the states, according to the OERI State Accountability Study Group (U. S. Department of Education, 1988, p. 1), there is "considerable diversity in their accountability systems." At the local level, some districts have implemented new accountability processes over the past few years.

\section{National Level Accountability Systems}

At the national level, accountability has traditionally been tied to nationwide testing, such as the National Assessment of Educational Progress, and to the collection of state statistics such as college board scores, graduation 
rates, per-pupil expenditures, and demographic information (Amundson \& Richardson, 1991). The first indication that this approach might be changing appeared with the 1994 passage of the Goals 2000: Educate America Act and the reauthorization of the Elementary and Secondary Education Act. Both focus on high standards for all students; and on associated systemic reform in areas such as curriculum and instruction, assessment, governance, and parent involvement to support student achievement of those standards.

These concepts are at the heart of the 1994 Title I legislation, which requires states and local districts to set challenging standards for all students, implement high-quality assessments to measure student progress toward those standards, and demonstrate accountability for the performance of all students (U. S. Department of Education, 1996a, 1996b). "Title I gives teachers and principals (in collaboration with parents) more freedom to make decisions about how to best use program funds to help students achieve more ... and promotes increased school-level accountability based on whether students are making adequate progress" (U. S. Department of Education, 1996b, p. 40). Accountability is thus tied not to inputs and process as in the past, but to student achievement outcomes.

\section{State Level Accountability Systems}

The OERI study group (U. S. Department of Education, 1988, p. vii) observes that "the majority of states pursue accountability in public education by collecting and reporting data about schools.... But the kinds of data collected, and how those data are reported and used in holding schools 
accountable, differ from state to state." The Southeastern Regional Vision for Education (SERVE), a federally-funded education laboratory which explored accountability in six southeastern states, indicates that "the accountability 'cart' has been far ahead of the goals, standards, and assessment 'horses' needed to drive it" (1994, p. 1).

In particular, the SERVE report notes that most states are still struggling with the question: What do we want learners to know and be able to do on graduation from school? However, because of a demand to move forward, states continue to use tests that may not measure what they actually want students to know and be able to do, while holding schools accountable for student performance based on those inappropriate measures. Thus, when high stakes are attached, many classrooms focus on teaching to the traditional tests rather than reorienting teaching and learning toward challenging content and performance standards.

A few states, such as Kentucky and Texas, have designed and implemented accountability systems based on newer conceptualizations. In these systems, the policy is to develop standards for what students should know and be able to do, implement curriculum and instruction designed to help students achieve the standards, administer assessments that evaluate student progress toward the standards, and subsequently tie accountabilityincluding rewards and interventions-to student achievement results.

Kentucky, whose educational system was declared unconstitutional in 1989, initiated a comprehensive change effort through the 1990 Kentucky 
Education Reform Act. Oriented around site-based management, a statewide performance-based assessment program, and rewards and sanctions to hold schools accountable for their students' performance, the system represents a shift in focus from inputs to outcomes. An accountability decision is made every two years. At the beginning of each biennium, individual school accountability indices and thresholds are determined, and improvement targets are set based on cognitive (academic) and non-cognitive components. At the end of each two year cycle, schools are assigned to one of five accountability categories: Eligible for Rewards, Successful, Improving, In Decline, or In Crisis. Schools at the highest level receive bonus money; schools in the lower three levels develop improvement plans, receive support from state-identified distinguished educators, and may ultimately be placed under state control (Guskey, 1994; Harrington-Lueker, 1990; Kentucky Department of Education, 1995; Kifer, 1994; Steffy, 1993).

The Texas Education Agency Accountability System is described as "a method for evaluating school districts and campuses with regard to their performance on certain base indicators" (Houston Independent School District, 1996, p. 1). These indicators include student performance on the Texas Assessment of Academic Results, a criterion-referenced assessment system correlated to the state curriculum, as well as attendance and dropout rates. Performance on these indicators is calculated for all students as well as particular special student populations; based on annual ratings, schools may be identified as exemplary, recognized, academically acceptable, or 
academically unacceptable. Schools in the highest categories receive financial rewards; low performing schools are inspected annually by the state to determine progress and needed interventions (Houston Independent School District, 1996; Trinity University, 1993; Webster \& Edwards, 1993).

In Texas, each district personalizes the accountability system within state guidelines, particularly in terms of site-based school improvement processes and support for low performing schools. Webster and Edwards (1993) describe the Dallas Independent School District accountability system, initiated in 1991, which they indicate "focuses attention on the important outcomes of schooling" (p. 25). This three-tier system begins at the school level with school improvement plans developed through site-based decisionmaking processes. A second tier is directed at the district level and specifies district accountability objectives and central office support for schools. The third tier involves school effectiveness indices, based on various outcome and background variables; these data provide information on how effective schools are with the students they serve, and determine which schools are eligible for rewards.

\section{District Level Accountability Systems}

Several districts across the country have independently implemented, or are working toward, district-level accountability systems based on high standards, performance indicators, and school-level decisionmaking. Charlotte-Mecklenburg, North Carolina, began its Benchmark Goals Program in 1992. School performance is reported according to progress toward meeting 
specific academic and non-academic goals. Baseline scores on measures for each goal area are used to set annual improvement targets for all students as well as for specific ethnic groups. Schools earn points for targets that are fully or partially met. Those exceeding specified point values receive financial bonuses, while schools that do not meet goals for more than one year receive assistance from district and university experts (Charlotte-Mecklenburg Schools, 1995).

In 1994, the School District of Philadelphia embarked on an ambitious school reform project entitled Children Achieving, which is supported in part by a grant from the Annenberg Foundation. The project's action design charts a five year course that proposes, among other things, to set high expectations for all students, design accurate performance indicators, let schools make more decisions, provide intensive professional development to all staff, provide students with the necessary community supports and services, and engage the public in school reform. Accountability is a central element in this process; it will include performance-based assessments tied to high standards, and an incentive system for staff that links student achievement to rewards and penalties (School District of Philadelphia, 1994a, 1994b).

\section{Accountability in California}

Until recently, accountability in California has exemplified the 1980s technical approach. In 1983, the state began producing quality indicator reports based on information such as course enrollments, attendance and dropout data, and California Assessment Program test results. In 1988, 
Proposition 98 established a requirement for districts to publicly disseminate individual School Accountability Report Cards, which primarily report technical information in several mandatory categories (Fetler, 1990; U. S. Department of Education, 1988). However, Law (1994, p. 39) comments that "these activities are all in place, but accountability questions still remain: Have we actually accepted the responsibility for children's education? Do we hold ourselves accountable for our schools?"

The Education Commission of the States (1995) studied the California school system in view of the significant economic and demographic changes affecting the state. The report concludes that "the state must have a different, more effective, more achievement-oriented, more efficient education system" (p. 1). Among its recommendations are a new achievement-based system of schools; statewide content and performance standards; a new statewide assessment; and a statewide accountability system. The report also adds that the accountability system should include significant community involvement in planning, monitoring, and evaluating school and district improvement efforts; regular reporting to the public on school and district progress toward improving educational quality and student achievement; and rewards for effective performance and sanctions for poor performance.

In 1995, the state took a step in this direction when the Superintendent of Public Instruction "challenged California school districts to move to a standards-based system of education that measures success by gains in student achievement rather than by adherence to procedures" (California Department 
of Education, 1996, p. 1). The challenge includes a call for districts to set high standards for student achievement and to hold themselves accountable for meeting those standards based on this fundamental question: Are students achieving below, at, or above grade-level expectations? The challenge initiative is voluntary, but many districts in the state are now at least beginning to develop or adapt content and performance standards, devise appropriate assessment strategies, and investigate methods to demonstrate accountability for student achievement. San Diego, while not participating at this time in the challenge initiative, has been involved in work on many of the required elements including a school accountability system.

\section{Effects of the Implementation of Accountability Systems}

What is the impact of these national, state, and district accountability efforts on student achievement, on school organization and governance, on teaching and learning? Hansen (1990, p. 12) declares that his "extensive search of the literature on effects of accountability yielded sparse evidence that it had produced measurable or observable improvements in educational outcomes." The OERI State Study Group (U. S. Department of Education, 1988, p. ix) indicates that "the investigation of the ways in which accountability systems are influencing schools shows mixed results." The report notes, for example, that some accountability systems have caused principals and teachers to change their behavior, but those changes were primarily based on helping students to perform well on state tests. 
Some of the states and districts which have implemented systemwide accountability systems have published student outcome data which they attribute to their changes in practices and to their focus on accountability for the improvement of student achievement. The Charlotte-Mecklenburg School District (1995, p. 1) attests that, "by every measure the Benchmark Goals program is a success." They note that the number of schools earning bonuses has grown steadily, and believe the program has led to impressive improvements in student outcomes at the district level and in most schools. From Kentucky, an October 1996 press release reports that "more than 92 percent of Kentucky's public schools ... showed improvement in the latest round of the Kentucky Instructional Results Information System (KIRIS) statewide assessment and accountability system. . . Nearly 450 (37 percent) demonstrated staying power by meeting or exceeding their goals in the previous (1991-92 to 1993-94) and current (1993-94 to 1995-96) accountability cycles" (Kentucky Department of Education, 1996).

However, most evaluative studies found in the recent literature focused on policies and procedures, and on implementation processes. They did not include a systematic assessment of outcomes, a description of the impact on classrooms, or a discussion of school organization and governance. Most of the current state and district accountability systems were initiated within the past five to six years. Therefore, outcome data and assessment of actual changes in classroom and school practices are still limited, as Petrosko (1993) indicates in his report on the Kentucky accountability process. The 
Council of Chief State School Officers (1989, p. 9) observes that, in terms of restructuring efforts, "one reason for the paucity of evaluation reports is the time required for fundamental change to take hold." The same concept would appropriately apply to accountability systems as well.

Studies of San Diego's accountability efforts have also focused mainly on the implementation process. As noted in the final evaluation report of the Leadership in Accountability Demonstration School project, "quantifying the effects of the accountability demonstration school project is still difficult" (Bennett, 1995b, p. 25). The study found that "becoming truly accountable for student achievement is a process" (p. 26), thus an examination of changing practices or outcome indicators needs further study over a longer timeline.

\section{Leadership, School Reform, and Accountability}

While the current literature on educational accountability pays considerable attention to its nature, especially its conceptual and operational aspects, it gives limited mention to leadership. In fact, references to leadership are significantly missing from most of the books, articles, and papers reviewed. In the literature on educational reform, however, the issue of leadership is addressed extensively.

The discussion that follows focuses first on changing views of the nature of leadership in general. It then addresses the connections between leadership and school reform; and the interrelationship among leadership, educational reform, and accountability. 
The Nature of Leadership

"Leadership," writes Foster (1989, p. 46), "does not reside in an individual but in the relationship between individuals." He further says that "leadership is a consensual task, a sharing of ideas and a sharing of responsibilities" (p. 61). This conceptualization of leadership embedded in relationship is one connected not with the primarily modern framework of the industrial era, but with a postmodern perspective that has emerged in the late twentieth century.

American society, during the industrial era of the late nineteenth through the twentieth century, has been characterized by an entrapment in individualism. In this culture, write Bellah, Madsen, Sullivan, Swidler, and Tipton (1985, p. 142), "we believe in the dignity, indeed the sacredness, of the individual." Thus, they point out in a later book, "everyday practices of work, school, and politics trained Americans to think and act in terms of individual competitive success" (Bellah et al., 1991, p. 61). Reflecting this tradition, leadership in the modern era has been viewed from a predominantly functionalist perspective, one rooted in political/historical and administrative/management traditions and characterized by association with personal characteristics or with position (Foster, 1986, 1989; Rost, 1993). As Bergquist (1993, p. 107) explains, "the modern model of leadership is built on a solid base of history and reason."

However, Bergquist (1993), along with many others, believes that the industrial model no longer serves the needs of our society as it faces the 
twenty-first century. He proposes that a new order, a new worldview, is emerging: "The postmodern world is in the midst of being born" (p. 15). This emergent paradigm is changing societal views and practices, and thus has corresponding implications for leadership. Starratt (1993, p. 108) proposes that "the promotion of individual happiness and freedom at the expense of the environment, community, public involvement, and civic responsibility cannot be the driving ideology of leadership." Rost (1993, pp. 100-101) suggests that, "if a transformation to a postindustrial era is to happen in the 1990s, we need leaders who are imbued with a postindustrial model of leadership." He adds: "Indeed, leadership may be crucial to a peaceful and orderly process as people individually and collectively struggle with that paradigm shift" (p. 127). Heifetz (1994, p. 2) says that, "we need a different idea of leadership and a new social contract that promote our adaptive capacities."

Thus in the late twentieth century, a new view of leadership has begun emerging, one grounded in complementary concepts of relationship and process. Burns (1978, p. 452) was one of the first to suggest that "leadership is collective." Astin and Leland (1991, p. 8) extend the idea, calling leadership "a process by which members of a group are empowered to work together synergistically toward a common goal or vision that will create change, transform institutions, and thus improve the quality of life." Foster (1989, p. 49) epitomizes this view with the following: "The idea that leadership occurs within a community suggests that ultimately leadership resides in the community itself." 


\section{Leadership and School Reform}

This emerging conceptualization of leadership coincides with many of the descriptions of educational leadership that appear in school reform literature from the past few years. In this literature, leadership is connected with educational reform in two ways. First, leadership is called on to be the driving force for changes in education. Second, the nature and practice of educational leadership itself must change as a result of the reforms.

Leadership for change. The demand for educational reform is nearly always connected with a cry for leadership. "A revolution in education requires competent, skilled and visionary leadership," propose Griffiths, Stout, and Forsyth (1988, p. xiii). Thomson (1992, p. v) reports that, "realizing with commonsense insight that leadership makes a difference in all institutions, the public now expects leaders to make a difference in schools." Smyth (1989) adds:

If we were to try to find a more alluring, seductive, even magnetic word in the educational language to fire the collective imaginations of educational policy analysts, we would be hard pressed to go beyond the notion of leadership. In its reified form, the term leadership has all the qualities that have instant appeal to those who are looking for a way of remedying what is deemed to be wrong with schools in Western democracies. (p. 1)

What are the key concepts that connect leadership and educational reform? Three repeating themes are vision, collaboration, and 
transformation. To begin, according to much of the literature, leadership must provide the vision for educational reform. The Council of Chief State School Officers (1992, p. 4) writes that, "to bring about change ... you must also believe in a vision for change." "If reform is to succeed," adds Chance (1992, p. 110), "school administrators must become proactive leaders who possess a vision of what their schools should become." Educational leaders are often characterized as the builders, keepers, and actualizers of the vision for future schools and for the future of education.

Another concept appearing extensively in the literature on educational reform is that of collaboration; leadership to create educational change must be shared among participants throughout all levels of the school or system. Caldwell and Spinks (1992, pp. 19-20) express that "a capacity for leadership emerges as the central requirement for schools and systems of schools... . The need for outstanding and widely dispersed leadership at all levels is palpable." Angus (1989, p. 88) furthers the concept, writing "the emergence of collective reform efforts at the school level is more feasible if there is facilitative educational leadership in which many school participants have access to forms of self-determining power within the context of participative democracy." Thus, just as leadership is conceptualized as collective and relational in the postmodern sense, so is the process of school leadership for educational reform.

Transformational leadership is another essential element in the process of creating change in education. "What the reinvention of American 
education calls for," insists Schlechty $(1990$, p. 151), ". . are transformational leaders." Goens and Clover (1991, p. 164) similarly call on transforming leadership to "pull schooling and all of its participants into the twenty-first century, confident and armed with the abilities to be successful." Carlson (1996, p. 137) asserts that "there is a consensus view that the organizations (schools) of the future, in their struggles with a rapidly changing environment, will need leaders and followers invested in a transformational process." And Sergiovanni (1990, p. 24) translates Burns (1978) view of transformational leadership into an educational setting: "In transformative leadership ... leaders and followers are united in pursuit of higher-level goals common to both. Both want to become the best. Both want to shape the school in a new direction."

The changing nature of educational leadership. "As schools restructure to share decisionmaking authority and responsibility," writes Mojkowski (1991, p. 59), "new forms of leadership will be essential." Carlson (1996) proposes three leadership perspectives for postmodern organizations and postmodern schools: leadership as a transformational process, a dialectical process, and a democratic process. He suggests that those engaging in leadership in the schools of the future must be adaptable, and find which processes best fit different contexts and situations.

According to the educational reform literature, leadership that will drive educational change must involve vision, collaboration, and 
transformation. Similarly, the literature proposes, leadership in tomorrow's schools must also be visionary, collaborative, and transformational.

The development, articulation, and sharing of a vision is cited as a critical part of future educational leadership. Caldwell and Spinks (1992) suggest that leaders in self-managing (restructured) schools must first have the capacity to work with others in the school community to formulate a vision for the school, then must be able to communicate that vision in such a way that ensures commitment among members of that educational community. As Chance (1992, p. 52) describes, "a crucial aspect of proactive leadership is the development of a vision that not only calls for excellence but establishes an educational environment and culture where this can be achieved." He also proposes that:

One thing the visionary leader knows for sure is that the journey to actualize the vision cannot be made alone.... The vision provides the ultimate destination, and when a visionary leader collaborates with the stakeholders of the school, the trip can be an exciting and rewarding one. (pp. 111-112)

Thus future leadership in education must also be a collaborative process dispersed throughout the educational community. Foster (1988, p. 76) proposes that, in future schools, "participation and voice are fundamental and ... decisionmaking becomes shared to a much greater degree." Rivzi (1992, p. 163) adds that "leadership should be seen as located neither in individuals nor in institutional positions, but in particular acts... Thus 
viewed, leadership may originate with any person within a community, and not just those who have been officially designated as leaders." Caldwell and Spinks (1992, p. 203) write that "we cannot stress too highly the need for widely dispersed leadership in the school."

Finally, leadership in schools of the future must be transformational. Duignan and Macpherson (1992, p. 184) term this educative leadership, which is a "holistic, pragmatic, values-driven and cultural activity intended to enhance performance in the areas of learning, teaching and leading." Goens and Clover (1991, p. 287) propose that transforming schools will require leaders who use "multi- and interdisciplinary thinking-not isolated to educational perspectives, strategies, or experts." They add that leaders who will transform schools must have an "entrepreneurial mindset: They encourage independent thinking and can accept and adapt to ambiguity and uncertainty. They can conceptualize issues and mobilize alternatives for actions and are long-range thinkers" (p. 262).

Leadership and the changing educational community. The educational setting itself is also changing as we move toward a new century. Throughout the literature, schools of the future are described as communities with unique cultures that must be nurtured and developed by school leaders, and that must nurture and develop school leadership within them.

In this educational community of the future, participants work together and transfer leadership roles among themselves. The school, according to Foster (1989), becomes a community of agents not an 
organization of members. He thus notes that leadership in such a community is involved "with transforming the values of followers so that they too exert leadership.... Each of these (followers), from students to teachers to administrators, can in fact be leaders with respect to their influence over others" (p. 60).

Caldwell and Spinks (1992) view the school as a set of communities: the community of teachers, the community of parents, the community of students, the community outside the school. To bring these communities together in a mutually supporting fashion, they suggest that leadership must be "transformational, nurturing and empowering, underpinned by a vision of excellence and a commitment to self-management, and energised [sic] by knowledge about learning and teaching" (p. 137).

Leadership and Educational Accountability

Despite an extensive treatment of leadership in the educational reform literature, there is only limited discussion in the associated literature on educational accountability. Leadership, when it appears in accountability discussions, is primarily connected to school administration and to the principal. There is also some mention of the complications that may occur when accountability and shared leadership are intermixed at the site level, and when school administrators try to balance accountability with autonomy.

It appears, however, that the conceptions of both leadership and accountability need to be restructured as schools are restructured. Traditional notions need to be rethought, particularly those which indicate that 
accountability solely or primarily rests with the principal or school district administration.

Leadership and the school principal. There is some literature that interconnects educational accountability, the role of the school principal, and leadership. Heck (1992), for example, discusses the extension of the effective schools research into the accountability movement. He writes:

Increasingly, district administrators, including principals, are being held accountable for school's performance. ... Although effective schools research has established that strong principal leadership influences school academic achievement at least indirectly, this relationship is more complex than originally thought. (pp. 21-22) Murphy (1994) addresses what he terms the accountability dilemma in connection with the evolving role of the principal in restructuring schools: Perhaps the most fundamental concern awaiting resolution in the minds of school principals trying to reinvent their leadership roles is the issue of accountability, specifically the dilemma of having the ultimate responsibility lying with the principal while others are empowered to make the decisions. (p. 45)

Louis and Murphy (1994, p. 273) add that "the viability of a diffused communal responsibility that coexists with more traditional hierarchical notions of accountability ... needs further exploration."

In writing about facilitative leadership, an approach which broadens the leadership function of principals by empowering others to participate in 
the achievement of shared or complementary goals, Conley and Goldman (1994) address a similar concern. They observe that "unresolved questions concerning accountability continue to surround facilitative leadership.... As educational accountability demands increase, so will the pressure on the principal to assume responsibility for school performance. This will have interesting implications for facilitative leaders" (pp. 32-33).

Accountability, autonomy, and the educational leader. As reported earlier, common to most discussions of educational accountability in the 1990s is the notion of autonomy. Through the restructuring movement, in exchange for increased site flexibility and autonomy, schools are being asked to assume greater accountability for student outcomes.

Inserting leadership into this equation, Edwards (1991) comments on the delicate position in which school administrators may find themselves. He cites the need to balance accountability for outcomes of education, which are often difficult to measure, with the autonomy which those engaged in teaching and learning activities prefer in their desire to be treated as responsible professionals. Thus accountability and autonomy are "dual strands which create a dilemma for the administrator" (p. 29). He concludes:

Endeavouring [sic] to achieve an appropriate balance between accountability and autonomy remains one of the most challenging and exciting policy and management tasks facing today's and tomorrow's educational leaders in their pursuit of the dual results of the best use of resources and enhanced teaching and learning. (p. 49) 


\section{Interconnecting Accountability, Reform, and Leadership}

Separately, accountability and leadership have become closely linked with educational reform and restructuring. It appears that the discussions of educational leadership, school reform, and accountability now need to be interconnected as well as reconceptualized to align with both new ideas about leadership and new views of the nature of educational accountability.

Organizational literature introduces the concept of leadership as stewardship, which "asks us to be deeply accountable for the outcomes of an institution, without acting to define purpose for others, control others, or take care of others" (Block, 1993, p. 18). This idea broadens the notion of leadership beyond any individual or position, and mixes "accountability with partnership, empowerment, and service" (p. 22). Applied to education, stewardship might help integrate empowering and collective leadership with responsive and responsible accountability for student achievement.

Further investigation into this concept, as well as the exploration of other views and approaches, needs to occur. There is a great deal of room for study, and for the development of new ideas for policy and practice, relative to the interconnection and the reconceptualization of leadership, school reform, and accountability for student achievement.

\section{Issues and Concerns}

The OERI Study Group (U. S. Department of Education, 1988, p. 2) observes that "the design and use of an accountability system is hard and riddled with ambiguities." Their report identifies several dilemmas with 
which policymakers must wrestle: balancing oversight and improvement, determining the appropriate level of accountability, balancing statewide comparability with local ownership, expanding the alternatives to traditional standardized tests, making fair comparisons, and ensuring adequate capacity. Streshly and Newcomer (1994, p. 65) find that there is often resistance to outcome-based accountability. They observe that "some teachers and administrators do not wish to be responsible; it is much easier to follow standard operating procedures and therefore not be held accountable for making a different in student learning." They add that "other teachers and principals fear that accountability for learning outcomes will take place only in those areas where measurement is relatively simple, thus leaving important areas unattended and/or deemphasized."

Theobald and Mills (1995) note that there is growing polarization over the question of accountability. They write:

That struggle shows up in the battles between teachers and administrators, between rival factions of teachers, between teachers and school boards, between superintendents and school boards, between groups of community members and school boards, and so on. While these groups have always been divided to some degree, during the 1990s the question of accountability seems to have brought an intensity to these struggles that is unequaled in the history of education in this country. (p. 462) 
The Southeastern Regional Vision for Education (1994, p. 2) observes that, "while the concept of accountability is ultimately at the heart of school reform, the hasty implementation of state accountability systems stands as one of the chief impediments to real reform." Hansen (1990), however, suggests that accountability can serve a constructive role in the reform process. To make this happen, he writes, "teachers must perceive it as valuable and use it in a constructive fashion. Building and central office administrators must view it as more meaningful than a bureaucratic requirement. Community involvement must be value-driven, data-based and well orchestrated" (p. 19). These issues all have implications for educators as they strive to delineate the nature of educational accountability in the postmodern era; integrate accountability with restructuring and leadership; and find an appropriate balance among oversight, autonomy, and accountability for the improvement of student achievement.

DeMoulin and Kendall (1993, p. 689) comment that "accountability in education cannot be isolated to one particular segment of society; rather, all of society must be held accountable for the past, present and future status of education because its obligations extend not just to a particular group of shareholders or sponsors, but to the public at large." As Brown (1990, p. 2) adds, education "is subject to multiple demands, multiple constituencies, and multiple control systems." Considering the demands and obligations facing educators, there are still tough questions to be answered and concerns to be addressed about educational accountability. 


\section{Summary}

As can be seen, the literature describes a multiplicity of historical and current perspectives about educational accountability. While the movement has roots in the nineteenth century, it has experienced a resurgence in the late twentieth century and become interwoven with school reform and restructuring. Educational accountability in the 1990s is described as outcomeoriented, responsible, responsive, and client-centered. Some states and districts have begun developing and implementing accountability policies and practices around these new conceptualizations.

Brown (1990, p. 2) comments that "accountability in public education remains a slippery concept." It is apparent that further study is needed to analyze the implications of the accountability movement, particularly relative to the school site implementation of accountability policies and the relationship with changing instructional practices, school governance, and student outcomes. In addition, since much of the current work in educational accountability is tied to reform, restructuring, and site-based decisionmaking, it would seem that further attention to leadership is appropriate, if not essential. 


\section{CHAPTER THREE}

\section{METHODOLOGY}

\section{A MULTISITE CASE STUDY}

\section{Introduction}

Policy implementation occurs only in interaction with context.

"Policies, ultimately, must be implemented in particular places, in particular circumstances, and by specific persons," observes Hess (1992, p. 181). "Qualitative research, combining observation of events and interviewing of the major actors in the process of implementation, has an advantage in explaining why things happen the way they do." For this study, qualitative methodology thus seemed an appropriate way to investigate how implementation of the San Diego City Schools' student achievement accountability policy occurred in three particular schools involved in the district's accountability demonstration project.

Merriam (1988, p. xiii) comments that a "qualitative case study is a particularly suitable methodology for dealing with critical problems of practice and extending the knowledge base of various aspects of education." Through naturalistic inquiry and interpretive analysis, hallmarks of qualitative method, this research project seeks to deal with the critical problems of accountability for student achievement, and extend the educational knowledge base relative to the interconnection of restructuring, 
accountability, and leadership. Using a multisite case study with an ethnographic overlay, the project aims to describe three unique approaches to student achievement accountability, identify challenges and successes, explore changes in school practices, investigate governance and decisionmaking, look into school accountability cultures, and discuss school site leadership.

This chapter delineates the methodology for the project, including the methodological framework, its application to the study, the research design, and the particular processes for data collection and analysis. In addition, since "the importance of the researcher in qualitative case study cannot be overemphasized" (Merriam, 1988, p. 19), the chapter concludes with a synopsis of the background of the researcher.

\section{Methodological Framework}

According to Merriam (1988, p. 17), "qualitative research assumes that there are multiple realities-that the world is not an objective thing out there but a function of personal interaction and perception. It is a highly subjective phenomenon in need of interpreting rather than measuring." Thus, notes Singleton (1983, pp. 209-210), qualitative inquiry draws from "constructivist, phenomenological, and even hermeneutic traditions of science." These assumptions undergird this study. The implementation of educational policy plays out in a realm of uniquely-constructed multiple realities; each policy interacts with each context to create situations that must be approached not as objective events to be defined and measured but as subjective experiences to be discovered and reconstructed. 
Schwandt (1993, p. 15) proposes a contrast between scientific reasoning, where "scientists deductively demonstrate necessary truths from premises that themselves are necessarily true," and ethical reasoning, which requires "deliberation-sizing up a situation and weighing information-and making decisions on a case-by-case basis." Placing qualitative research within the realm of ethical reasoning and the narrative paradigm, he states:

What guides our ethical deliberation is the virtue of practical wisdom and a kind of knowledge that Aristotle called phronesis that can be acquired only through experience. This kind of knowledge is always context-bound or situated and guided by qualitative analogies rather than abstract principles. It emphasizes interpretation over logical analysis." (pp. 15-16)

Eisner (1991) introduces several features of qualitative study which help delineate further the character of this research project. Qualitative studies, he proposes, are field focused, emphasize the self as an instrument, have an interpretive character, use expressive language, attend to particulars, and present their findings with coherence and insight. He also comments that qualitative inquiry can provide "the kind of understanding we need in order to create better schools and to evaluate the results of our efforts" (p. 23). Case Study

Yin (1984, p. 23) defines a case study as an empirical inquiry that investigates a contemporary phenomenon within its real-life context, when 
the boundaries between phenomenon and context are not clearly evident, and in which multiple sources of evidence are used. He also suggests that "the case study is the method of choice when the phenomenon under study is not readily distinguishable from its context" (1993, p. 3), a description decidedly apropos to this project. In the LAD program, each school's work on creating and implementing a site-based accountability system could only occur in the context of the school, in a particular place and time, among the members of that school's educational community.

Patton (1987, p. 19) adds that "case studies become particularly useful where one needs to understand some particular problem or situation in great depth, and where one can identify cases rich in information-rich in the sense that a great deal can be learned from a few exemplars of the phenomenon in question." For this project, a multisite case study served to investigate, in-depth, three unique but interrelated settings, each of which is a rich exemplar of the accountability pilot program.

Yin (1984, p. 48) suggests that "the evidence from multiple cases is often considered more compelling, and the overall study is therefore regarded as being more robust." In this study, each school site represents a single bounded system, allowing for both description of the experience and an investigation into how processes are shaped by specific local contextual variables. Together, the three schools provide an opportunity for the exploration of similarities and differences; and the development of cross-site themes, interpretations, and conclusions. 


\section{Ethnographic Orientation}

Ethnography can add a valuable dimension to case study research through its "concern with the cultural context" (Merriam, 1988, p. 23). As Wolcott (1987, p. 42) notes, "the purpose of ethnographic research is to describe and interpret cultural behavior." Extending this into the educational realm, Zaharlick (1992, p. 122) observes that "ethnography, with its inherent sensitivity to people, culture, and context, offers one approach to providing valuable new insights that can contribute to educational improvement and reform.... Ethnography can help educators learn more about the culture of schools and about the total context of schooling so that they can be in a better position to improve educational practice."

The concept of culture permeated discussions of the LAD schools' work. This study thus added an ethnographic overlay to the case study to help in the investigation of the school accountability cultures, with the goal of adding to the total understanding of each case and thus providing additional information to policymakers and practitioners.

\section{Rigor in Qualitative Research}

Qualitative research is a rigorous process, but the traditional concepts most closely associated with quantitative research-reliability, validity, objectivity-must be discussed differently when connected with a qualitative approach. Merriam (1988, p. 170) observes that "qualitative research . . . is not seeking to isolate laws of human behavior. Rather, it seeks to describe and explain the world as those in the world interpret it." Thus, instead of looking 
for generalizability, predictability, accuracy, and consistency, as expected with quantitative studies, Guba and Lincoln (1989) suggest that transferability, dependability, and confirmability may be more appropriate correlates for qualitative studies.

As Eisner (1991, p. 207) notes, "qualitative case studies are full of opportunities for generalization... Every case is a case of something." Results from a qualitative case study may not be replicable in the quantitative sense, since they are tied to context-specific issues, conditions, and experiences. But information from the study and its findings may be transferable to other situations if the researcher provides "extensive and careful description of the time, the place, the context, the culture" (Guba \& Lincoln, 1989, p. 241).

Dependability comes through "documenting the logic of process and method decisions" made by the researcher, so that subsequent reviewers can "explore the process, judge the decisions that were made, and understand what salient factors in the context led ... to the decisions and interpretations made" (Guba \& Lincoln, 1989, p. 242). Confirmability is then concerned with "assuring that data, interpretations, and outcomes of inquiries are rooted in contexts and persons apart from the evaluator and are not simply figments of the evaluator's imagination" (p. 243). In this light, Hess (1992, p. 180) stresses "the reliability of the researcher to include all relevant materials and the integrity of the researcher to not seriously distort the interpretation of the data included." 
Establishing this type of reliability and validity requires the thoughtful selection of participants and contexts for the study, followed by careful recording and transcription of data collected from interviews and observations. Sharing preliminary assumptions and interpretations with participants and colleagues can provide confirmation and substantiation. Multiple levels of analysis are also essential to elicit themes and make confident interpretations.

Qualitative researchers do not makes claims to objectivity, as least as it is defined in quantitative research. They in fact embrace subjectivity in the constructivist sense. "We are always in a constructive position," writes Eisner (1991, p. 60). "We make our experience, not simply have it." $\mathrm{He}$ proposes that constructivist qualitative narratives become believable through their coherence, consensus, and instrumental utility.

Coherence responds to questions such as: “Does the story make sense? How have conclusions been supported? To what extent have multiple data sources been used to give credence to the interpretation that has been made?" (Eisner, 1991, p. 53). Consensus, he adds, "is the condition in which investigators or readers of a work concur that the findings and/or interpretations reported by the investigator are consistent with their own experience or with evidence presented" (p. 56). And, Eisner concludes, "the most important test of any qualitative study is its usefulness" (p. 58). Qualitative research may be useful in comprehending particular phenomena, 
analyzing individual circumstances as exemplars of larger types, or calling attention to aspects of a situation that might otherwise be missed.

\section{Overview of the Research Design}

Eisner (1991, p. 170) comments that "flexibility, adjustment, and iterativity are three hallmarks of qualitative 'method.' Even aims may change in the course of inquiry, depending upon what happens in the situation." The design for this study was, indeed, emergent. While I began the research project with a data collection framework, the initial interviews and observations, as well as changes in the settings under investigation, guided the acquisition of subsequent data as well as the analysis.

Data collection revolved around the researcher as the instrument, with the most extensive information gathered through group and individual interviews with site administrators and teachers at each of the selected schools. Observations of site decisionmaking forums and staff workshops, along with a review of associated documents, then served to inform, contextualize, and augment the interviews.

The teachers and administrators invited me into their schools as a guest, but also as a friend. They were open and honest, allowing me to see their schools, warts and all, and to hear their opinions, interests, and concerns. My knowledge of the educational community was a considerable help in this study; my familiarity with schools and schooling let me focus on the content of the conversations rather than first having to learn a new language and culture. 


\section{Selection of Sites and Participants}

Site selection for this study reflects what Yin (1993, p. 12) describes as exemplary case design, where the "rationale means that all of the cases will reflect strong, positive examples of the phenomenon of interest." Patton (1987, p. 54) calls these critical cases, "those that can make a point quite dramatically or are, for some reason, particularly important in the scheme of things." I chose to include three sites from a desire to provide for variation as well as a broader base for potential transferability. As noted in Chapter One, I also selected schools that were considered out in front with their work in the pilot project-strong exemplars of the project under study.

Participant selection was purposive and criterion-based (Merriam, 1988). Purposive sampling is "based on the assumption that one wants to discover, understand, gain insight; therefore, one needs to select a sample from which one can learn the most" (p. 48). Initially, I used a set of criteria to identify a preliminary sample (described subsequently under selection of participants). As data collection evolved and themes emerged from preliminary analysis, additional participants were selected through further refinement of the criteria and through referrals.

I believe my sample was, as Patton (1987, pp. 58-59) describes, "large enough to be credible ... but small enough to permit adequate depth and detail for each case." Seidman (1991, p. 45) cites two criteria that may help a researcher decide how many participants to include in a study-sufficiency and saturation of information. Following these guidelines, I first strove to 
include a sufficient number to reflect the range of participants that make up the population so that others outside the sample might have a chance to connect to the experiences of those in it. Second, I concluded the process at a point when little new information was being obtained.

Selection of sites. The three elementary schools involved in the study were selected based on their enthusiastic, comprehensive, and innovative work with the accountability project. These three schools took the opportunity provided by the demonstration school program, and carried it above and beyond the project requirements into broad-based schoolwide reform efforts.

The schools represent diverse areas of the district and serve widely varied student populations. They have different programs and special areas of focus, and exemplify distinct governance structures and site leadership styles. They also took unique approaches to the pilot project, as will be seen in Chapter Four. (General demographic information is included in Chapter Four; more detailed school profiles can be found in Appendix F.)

Entry to the population. As part of my work, I became involved with the accountability demonstration project in 1993. I came to know the site administrators as well as the teachers on the school accountability leadership teams. To initiate the research project, I was able to call upon those relationships to arrange a preliminary meeting with each principal to outline the study and data collection process. My involvement with these schools through the accountability project also eased my access to the sites for 
observations and helped pave the way to contact individual teachers for interviews. To further encourage teachers to participate in the group and individual interview sessions, I offered refreshments and door prizes, and arranged for all attendees to be reimbursed for one hour of preparation time.

Selection of participants. As indicated, two stakeholder groups were represented in the study's interviews: site administrators and teachers. Selection of interview participants within these groups was based on their involvement at the sites during the three years of the LAD project, as well as on their knowledge of the schools' work.

To select administrators for interviews, I consulted with the district project coordinator to determine which principals and vice principals were most knowledgeable about the schools' experience with the project. Two schools underwent a change of administration during the study, and I conducted interviews with the former and current site administrators from both of these schools.

The preliminary selection criteria for teachers was their involvement at the site during the three project years, either as a member of the school accountability leadership team or as a classroom teacher. All teachers meeting the criteria were invited to participate in a group interview. Individual teacher interviewees were then identified in several ways. First, at the end of each group interview, I asked participants to indicate their interest in a follow-up interview; from the respondents, I selected teachers who represented different grade levels, teaching experience, and participation in 
site activities. Second, I sent a follow-up letter to those teachers who were invited but did not attend the group interview; all responding to that invitation were contacted and the majority were interviewed if schedules could be aligned. (See Appendix $C$ for sample invitation and follow-up letters.) Finally, I asked the principals and other key staff for the names of teachers who were knowledgeable about particular aspects of the project. Protection of Participants

The nature of the study suggested minimal risk to participants beyond the demands on their time. The focus was on an intellectual discussion of their work with reform and accountability, emphasizing their professional involvement in and analysis of school site activities related to the demonstration project. Prior to each interview, I assured participants of anonymity, the confidentiality of their responses, and their option to withdraw from the study at any time; all interviewees also reviewed and signed informed consent forms (see Appendix D). All participants were identified only by pseudonyms; to further protect their identities, tapes and transcripts were coded and secured away from any district location.

Participation in the study did require both candor and honest reflection. Therefore, while I was given permission by each principal to use the school's name, I chose to instead use pseudonyms to identify the schools as well as the individuals, due to the potentially sensitive nature of some comments and recommendations. 


\section{Data Collection}

Data collection for the study proceeded through an interactive and iterative process of interviews, observations, and document reviews. Interviews led to the identification of opportunities for observation and documents to review, while observational and archival data informed subsequent interviews.

Before initiating data collection, I applied to the school district for permission to conduct this research; approval was received on January 8, 1996 (see Appendix B). All data were subsequently collected between May and November, 1996, beginning with initial administrator and key teacher interviews, followed by one or more site observations. I then proceeded with group and individual teacher interviews, and with further observations. Document review was interwoven throughout the study as relevant district and site records were identified.

Interviews

"The primary way a researcher can investigate an educational ... process," observes Seidman (1991, p. 4), "is through the experience of the individual people." Patton (1987, p. 109) adds that "the purpose of interviewing is to allow us to enter the other person's perspective." Interviews were thus central to this study, as each participant could provide a unique story about the school's work, a unique perspective on changes that have occurred, and a unique analysis of the challenges and the successes. As Brenner, Brown, and Canter $(1985$, p. 3) comment, interviews show a 
"willingness to treat individuals as the heroes of their own drama, as valuable sources of particular information."

Interviews were semi-structured and open-ended, framed by preliminary questions but open to topics arising during the conversation (see Appendix E for general interview guidelines). This format, notes Merriam (1988, p. 74), "allows the researcher to respond to the situation at hand, to the emerging worldview of the respondent, and to new ideas on the topic." My approach reflects a combination of the interview guide approach, which involves a list of questions or issues that are to be explored in the course of an interview; and the informal conversational interview, which relies on the spontaneous generation of questions in the natural flow of an interaction (Patton, 1987). This strategy allowed me to ask predetermined questions about certain aspects of the project, while also letting me pursue emergent themes and thus obtain additional insights.

My first intent was to hear the story of each school's involvement in the LAD project from the individual perspectives of the participants. I then inquired into five additional areas during the interviews: teaching and learning, decisionmaking and governance, leadership, challenges, and successes. As a concluding question, I asked many of the participants to add comments about where they see the school going next, and what professional and personal words of wisdom they might offer to others engaging in the process of school reform. 
I conducted twenty-seven interview sessions for this study involving a total of thirty-eight participants: thirty teachers, seven administrators, and one parent. Of these interview sessions, two involved groups of teachers, four were held with pairs of teachers, and twenty-one were conducted with individuals. Interviews were arranged at locations and times convenient to the participants, with the majority conducted at the respective school sites before or after the school day. Interview sessions averaged thirty-five to forty minutes, but ranged from twenty minutes to over an hour. All interviews were audiotaped, with notes taken to highlight key points and annotate behavioral observations.

The interview process and participants are described below; they varied for each of the schools based on staffing, school structure, and schedules:

- Mariposa: I began in July with interviews with the former principal (who retired at the end of the 1995-96 school year), and the former vice principal (who was assigned in September 1996 as principal at another school). In October, I scheduled two group interviews-one with teachers from the accountability leadership team and another with other teachers who had been at the school three years or more. Two teachers came to each of these sessions, and were interviewed in pairs. Three more teachers responded to a follow-up letter, and two of these were interviewed in late October. Finally, in mid-November I conducted interviews with the new principal and new vice principal. 
- $\underline{\text { Sierra: }}$ Between May and July, I individually interviewed the principal, then two resource teachers who were identified as leaders in the school's progression through the LAD project. In October, I arranged a group interview session for teachers who were members of the original accountability leadership team or the school's assessment and accountability committee; nine teachers participated. At the end of the session, participants were asked to indicate their interest in a follow-up interview by completing a short reply form; three of the respondents were selected for individual interviews. I also scheduled a second group interview in October for other teachers who had been at the site since the beginning of the project; six teachers participated in the group session and two were contacted for subsequent individual interviews.

- Paloma: I began in May with an interview with the former principal, who had transferred the previous fall to a central office position; he was the one who initiated the school's involvement in several reform efforts including the LAD project. In October, I conducted an interview with the current principal, who at that time had been on site approximately a year. Also in October, I scheduled a group interview for teachers who had been at the site two or more years; two teachers came to that session and were interviewed as a pair. I then sent follow-up letters to those who did not attend, and interviewed three of the respondents in October and November. I also sent letters to three accountability team members who had just transferred to other schools for the 1996-97 school year. All three responded; 
two were interviewed together and the other was interviewed by telephone. Finally, both the former and current principal identified one particular parent as a leader and member of the accountability team; I interviewed her in October at her place of business in the community.

\section{Observations}

These interviews were informed and supplemented by observations, at each site, of selected governance/decisionmaking forums and staff activities which related to the focus of the study. As Merriam (1988, p. 88) notes, the observer "gets to see things firsthand and to use his or her own knowledge and experience in interpreting what is observed." The purpose was to observe site decisionmaking in action as well as observe teachers engaged in discussions about student work and student achievement. These observations helped provide a context for the interviews.

During each observation, I focused on content as well as process. My field notes included a description of the activity under observation; selected quotations or paraphrased comments; and interpretive remarks about the process, the behaviors, and other contextual factors. My professional relationship with the schools and the teachers led, I believe, to authentic observations; those engaged in the activities did not appear to modify their behaviors in any way because of my presence. However, my role periodically became that of participant observer when I was asked specific questions or engaged in the conversation. I believe that, rather than detracting in any way 
from the validity of the study, this instead enriched the process and provided me with valuable, contextual information about school reform in action.

As with the interviews, the observations I conducted varied from siteto-site, based on the decisionmaking structures and on the particular methods of engaging staff in discussions about student achievement.

- Mariposa: In May, I spent about four hours observing during a nonstudent staff development day in which teachers were engaged in scoring the end-of-year assessments and recording results in student portfolios. During that morning, following an opening whole staff session which addressed a variety of schoolwide issues, I spent approximately two hours with the fourth grade team and one hour with the first grade team. About two weeks later, I observed the subsequent governance team meeting during which the assessment results were reported and discussed. In October, I observed another governance team meeting where the discussion focused primarily on the fall pre-assessment results and related program implications. I also viewed a videotape of a presentation made by members of the accountability leadership team to staff in another school district.

- Sierra: I began in May with an observation of a governance team meeting which touched on a variety of schoolwide issues and reports. In July and again in October, I spent about three hours at retreats where representative teachers, support staff, and parents reviewed and analyzed student achievement data and other documentation, and used that information to revise the school site plan. I also participated in a meeting of 
the Assessment and Accountability design team in July, where a small group of teachers discussed how to graph and analyze the results from the school site assessments, and brainstormed ways to modify the annual sixth grade student exhibition. In September, I attended the Back-to-School Night where I was able to briefly visit about a dozen classrooms.

- Paloma: My first site visit occurred in May and involved observation of, and presentation at, a staff development workshop where teachers concluded their year-long process of collecting and analyzing student work in preparation for development of the new school site plan. Following that session, I observed a meeting of the School Planning and Management Team (SPMT) which addressed a wide range of schoolwide issues such as datadriven decisionmaking, the school-community coalition, the SPMT charter, lunchtime discipline, and staff development. I also attended the school's spring exhibition, in May, which showcased student work for parents and community, including student performances and displays. In October, I observed a meeting of the design team lead teachers where they presented their areas of focus for the year and identified common concerns.

Document Review

Merriam (1988, pp. 104, 118) comments that documents are "a readymade source of data easily accessible to the imaginative and resourceful investigator. ... (They) can help the researcher uncover meaning, develop understanding, and discover insights relevant to the research problem." For this study, I first obtained documents from district files that provided general 
information about the schools, their student populations, and their programs. I then gathered and reviewed both district and school site documentation that furnished historical information about the LAD project itself and each school's individual progress through the program. Finally, during site visits I collected a variety of site-specific documents to continually contextualize the picture being drawn through the observations and interviews.

For all three schools, I reviewed their 1995-96 School Accountability Report Cards as well as district-produced school profiles which present historical demographic and student achievement data. I also obtained, from the central office, historical files from the LAD project, site self-assessments and validation review reports from the fall 1994 progress study, and interview summaries and staff survey responses from the spring 1995 evaluation study. From each school, I collected LAD project materials, school site plans, and site governance documents.

In addition, for Mariposa, I reviewed a copy of the school accountability binder containing all the assessments and portfolio documentation; and a parent guide addressing the school standards, assessments, scoring rubrics, and suggested activities for parents. From Sierra, I examined the sitedeveloped reading and math assessments; needs assessments and plan evaluations from the past two years; an organizational chart of the school governance structure; and a parent handbook, parent newsletters, and parent survey results. For Paloma, I studied informational brochures and displays on special school programs; draft documents on the site-developed 
Professional Development and Accountability Model (PDAM) for teacher evaluation; and rosters of committee participants and teacher leaders.

\section{Data Analysis}

In qualitative research, there is no definitive point where data collection ends and analysis begins. As Merriam (1988, p. 123) observes, "a qualitative design is emergent: One does not know whom to interview, what to ask, or where to look next without analyzing data as they are collected.... The process of data collection and analysis is recursive and dynamic." In this study, data analysis began with transcription of the first interview and a review of the first observation notes. Initial themes were identified along with issues for clarification or further investigation. At this point I was, as Merriam (p. 131) describes, "virtually holding a conversation with the data, asking questions of it, making comments, and so on." This iterative process continued throughout the data collection period.

Following completion of the data collection process, more intensive analysis began. I immersed myself in the data to find patterns, themes, and variations. Patton (1987, p. 146) observes that "the analysis of qualitative data is a creative process ... demanding intellectual rigor and a great deal of hard, thoughtful work." Firestone and Dawson (1988, p. 210) add that "through immersion and contemplation, findings emerge." By nature, data analysis in a qualitative study is descriptive, interpretive, and often evaluative. It involves what Angus (1986, p. 65) calls a "dialectic between theory and data." Miles and Huberman (1988) make the following statement: 
Qualitative data are attractive. They are a source of well-grounded, rich description and explanation of processes occurring in local contexts. With qualitative data, one can preserve chronological flow, assess local causality, and derive fruitful explanations. Serendipitous findings and new theoretical integrations can appear. (p. 225)

For this study, the goal was to not only describe the accountability implementation experiences, but to then integrate, synthesize, and interpret the information to identify themes and develop conclusions. During data analysis, I wanted to be true to the purpose of the study while also open to surprises. As Coffey and Atkinson (1996, p. 153) observe, "the generation of ideas can never be dependent on the data alone. Data are there to think with and to think about." To achieve this goal, I progressed through the following steps (Miles \& Huberman, 1988; Patton, 1987):

- First, I assembled the raw case data from each site-interview transcripts, field notes, and archival documents.

- Next, I undertook a process of data reduction through selectively abstracting information from the voluminous piles of paper. To begin, I coded interview transcripts with highlighting and margin notes, starting first with themes generated by specific areas of questioning then rereading to identify additional, emergent topics.

- As this process progressed, I triangulated the findings with data from field notes and archival documents, continually looking for patterns, 
connections, and explanations. The idea was to bring conceptual and theoretical coherence to the multitude of data.

- At this point, I constructed a case record for each school organized both chronologically, in terms of the project history, and topically, around the identified themes.

- Once the case records were prepared, I began the process of creating the three case study narratives, using the themes to tell each school's story. In preparing a case study narrative, the researcher must decide how to balance description, analysis, and interpretation. Patton (1987, p. 163) notes that "an interesting and readable report provides sufficient description to allow the reader to understand the analysis and sufficient analysis to allow the reader to understand the interpretations and explanations presented." The narratives presented in Chapter Four include a combination of description, analysis, and interpretation. They are organized first around the common elements-the accountability implementation process, teaching and learning, decisionmaking and governance, challenges, and successes. These are then followed by the presentation of unique themes that distinguish each site's experience and culture.

Following the reduction and analysis of each site's data, the complete data set was reanalyzed to elicit themes that transcend the sites. As Merriam (1988, p. 154) indicates, "a qualitative inductive multicase study seeks to build abstractions across cases." Through this meta-analysis, I was able to identify similarities and contrasts across the settings, and generate the cross-site 
interpretations and conclusions that are presented in Chapter Five. Ultimately, I revisited the data, the analyses and interpretations, and the literature review to develop the implications and recommendations presented in Chapter Six.

\section{Summary}

"Qualitative inquiry," observe Eisner and Peshkin (1990, p. 367), "pervades human life." If so, then qualitative inquiry as a research methodology has particular applicability to the educational arena, where human life learns and grows. Eisner (1991, p. 8) suggests that "educational inquiry will be more complete and informative as we increase the range of ways we describe, interpret, and evaluate the educational world." This project applied qualitative methodology, in the form of a multisite case study with an ethnographic orientation, to the realm of education and the implementation of educational policy within that realm. It seeks to add to our understanding of the educational enterprise by investigating, describing, and interpreting three school reform efforts.

The three schools involved in this study were all involved in a pilot project that connected school restructuring with the implementation of sitebased accountability systems. The schools took unique approaches to the project, with unique results. The stories of the participants, and the themes which emerged from an analysis of their accounts, provide a comprehensive description of the process as it occurred in these contexts, and an exploration of changing practices, decisionmaking structures, school cultures, and school 
site leadership. These findings can hopefully add to the educational knowledge base, and inform practitioners and policymakers relative to school restructuring, student achievement accountability, and school site leadership.

\section{Background of the Researcher}

"The researcher is the primary instrument for data collection and analysis," emphasizes Merriam (1988, p. 19). Recognizing this, it is valuable if not essential to know some characteristics of the background this researcher brought into the research context.

I began my association with the field of education through work and volunteer experiences at schools and child care centers during my college years. Like many students, I was exploring various futures, unsure of my ultimate destination; I dabbled in psychology and sociology, and investigated a career designing parks and playgrounds. Late in my undergraduate study, I finally decided to focus on teaching. My experience with schools served me well at that point, helping me assess my interests and talents.

I entered my first full-time teaching position in 1977 as an enthusiastic, dedicated, bilingual teacher. For the next fifteen years, I worked as a classroom teacher and site resource teacher in three elementary schools in the predominantly Hispanic barrios of southeast San Diego. I also had the opportunity to do some curriculum writing for the school district. Among other things, these experiences confirmed my belief in the philosophy of bilingual education, introduced me to the essential integration of school with the real world, and exposed me to current research and practice in standards 
and assessment. I felt well prepared for a transition, in 1992, to a position in the district's Planning, Assessment, and Accountability Division. First as a resource teacher and now as a program administrator, this work resulted in my interest in, and involvement with, the Leadership in Accountability Demonstration School project.

I am an avid reader, enthusiastic traveler, and strong believer in lifelong education. While my curiosity often translates itself into an inability to say "no," it has also stimulated me to investigate many things, from new countries to new books to new concepts. Among these ideas is leadership. As I wrote in my application for doctoral study, a desire to further develop my leadership philosophy and abilities led me to this particular program at the University of San Diego. Now, my doctoral work in general, and this project in particular, represent the integration of my personal, intellectual, and professional interests and talents. Seidman (1991, p. viii) notes that "writing a book takes place in the context of a life." So, too, does a doctoral dissertation. 


\section{CHAPTER FOUR}

\section{CASE ANALYSES}

\section{THREE STORIES OF SCHOOL RESTRUCTURING AND}

\section{ACCOUNTABILITY FOR STUDENT ACHIEVEMENT}

\section{Introduction}

"As qualitative researchers," observe Coffey and Atkinson (1996, p. 55), we can collect and analyze the stories and narratives of our informants." Qualitative textual data thus has a storied quality. To analyze these rich data, a qualitative researcher deconstructs the participants' accounts into their constituent elements. The many ideas and their nuances can then be reconnected into integrated narratives that tell new stories.

This chapter relates the stories of three schools that engaged in a common enterprise with unique outlooks and outcomes. Mariposa's story tells of the map staff members created to take them on a continuing accountability journey. Sierra's story is an accountability saga that unfolds in episodes, telling of teacher engagement in a process of research and development. Paloma's story describes what happens when reform clashes with tough realities, and how energy and commitment to the best interests of children carried the school through rough times.

Five common themes structure the stories so that the reader may see the similarities and differences across the contexts. These themes include the 
process of becoming a Leadership in Accountability Demonstration (LAD) school, changes in teaching and learning, decisionmaking processes and governance structures, the challenges of participation in the LAD project, and the successes. The stories continue with unique variations that embellish each school's experience, followed by some observations about each site's emergent accountability culture.

\section{Mariposa's M. A. P. to Success}

If you're going on a trip, where do you begin? At Mariposa Elementary, you start by drawing a map. The M. A. P. -Mariposa Accountability Plandelineates the route for the school's journey toward student achievement accountability. Staff members defined where they wanted to go, determined the appropriate vehicle, planned the route, kept a record along the way, and evaluated each stage of the journey to inform their subsequent trips. The M. A. P. forms the heart of Mariposa's story.

Mariposa Elementary, located in a primarily middle class suburban community, housed 1080 students in 1995-96. The ethnic distribution is approximately 32 percent Filipino, 31 percent White, 15 percent Indochinese, 10 percent Hispanic, 6 percent African-American, and 6 percent Asian and Pacific Islander. While the population numbers have remained relatively constant over the past 10 years, the ethnic balance has shifted with an increase in Filipino, Indochinese, and Hispanic students and a corresponding decrease in White students. Approximately 20 percent of the students have limited English language proficiency. (See Appendix F for a complete profile.) 
Student academic performance at Mariposa is generally above district and national averages on standardized norm-referenced tests, particularly in mathematics. Despite these test scores, however, the administration and teaching staff have continued to investigate ways to improve student learning outcomes and measure student progress. Thus they joined the Leadership in Accountability Demonstration (LAD) School project.

\section{Becoming a LAD School}

I saw the opportunity to apply to become a Leadership in Accountability Demonstration School as a kind of catalyst that would move Mariposa into the modern thinking of the rapidly changing educational community of the 21 st century. It would give us a chance to improve our programs for students while at the same time develop a team of staff, teachers, and parents that would focus that energy toward better student achievement.

Carl, Mariposa's former principal, wrote those words at the end of the first year of the LAD project. These points were echoed by one of the lead teachers, who said that the principal "wanted a program that would focus on student achievement, but we really didn't have anything in mind until the district offered the LAD program." So when the opportunity presented itself, Carl pulled together a team of eleven people-the two site administrators, eight teachers, and a parent-to attend the district training. This group became the school's LAD leadership team. As Carl commented, "that was significant because it sort of solidified a small group of trainers." 
Steps to success. Figure 1 outlines the process that unfolded beginning with the principal's spring 1993 vision:

Step 1: Administrator provides leadership, vision, guidance, and buy-in to the development of an accountability system.

Step 2: A core group of teachers (LAD Team) receive training and district support to examine 'key' reform documents and develop understanding of terminology and develop a common philosophical base of 'accountability'.

Step 3: Core group provides identical support and training to the total staff.

Step 4: Core group and selected members of the total staff provide identical support and training to parents and community members.

Step 5: A needs assessment is conducted involving all stakeholders and an academic area is decided upon for focus in developing an accountability system.

Step 6: An accountability plan is created based on the academic area which addresses district goals, standards, learner outcomes, benchmark indicators, rubrics, key observable behaviors, recognition and intervention strategies, and public reporting ideas. (This process involves all stakeholders.)

Step 7: Documentation method and assessments are developed to ensure practice of key observable behaviors and ensure progress towards learner outcomes.

Step 8: Grade-level folders are developed to house all assessments, rubrics, reporting documents, and accountability process instructions. This includes a menu of essential assessment items as well as a timeline for implementation of the accountability system. Dates and deadlines for reporting of assessment results to the governance team are also included within the timeline.

Step 9: Begin implementation of accountability system.

Step 10: On-going reflections on the process in order to make improvements and develop innovations.

Figure 1. Steps in the Mariposa Accountability Process. (From An Exhibition Presentation: Accountability in Action, May 24, 1995.) 
Implementing an accountability system-drawing this M. A. P.proceeded through an iterative process, moving back-and-forth among the LAD leadership team, grade level teacher teams, and the whole staff. Gloria, one of the LAD team members, recalled that "every time we went to a LAD training, we came back and completely trained our staff in every single thing that we did there.... From there, we just developed a plan and it became intensive grade level development."

Steps five through eight were the most extensive. Chris, the former vice principal, described a cyclical process that began with teachers working as grade level teams, then meeting across grade levels, to identify the key elements that students should know and be able to do. He prompted them to "focus and narrow: what is it in language arts that we really want for children to be able to do in the area of reading? What is it that we really prioritize and value in the area of writing? What is it that we really prioritize and value in listening and speaking?"

"Once they had defined those three areas-comprehension, writing process, and formal and informal oral presentations," Chris continued, "then it was much easier to say, now we can develop assessments." The processgrade levels teams to cross-grade groups back to grade level teams-thus repeated itself for the creation of assessments for each grade level. Then, teachers had to match the assessments with scoring rubrics, which led to further revision of both the assessments and the rubrics. Finally, teachers realized they wanted a schoolwide portfolio system, and the cycle repeated. 
"This process of development was not easy," wrote former principal Carl. "In fact, it was very painful at times, but immensely rewarding."

Bringing parents on board. Staff at Mariposa felt it essential to let parents know what this work was all about, since they also share in the responsibility for improving student achievement. So once teachers became more comfortable with the terminology and the concepts, they initiated step four in the spring of 1994, to repeat key elements of the LAD training for parents and community. Staff members conducted a series of four evening sessions which introduced the state frameworks and the concepts of accountability, reviewed standards and performance assessments, provided an overview of the school's language arts plan and student portfolio system, and concluded with a discussion of how parents can be part of the accountability process.

More than fifty parents attended the first set of training sessions in March 1994. With that success, staff repeated the series in 1995 . Evaluations of these sessions were extremely positive, with parents indicating that they better understood the idea of accountability, what Mariposa was doing with staff and students, and their role as parents in the process.

Making it ours, letting it grow. The key to their work, Carl said in our interview, was making the accountability system and the action plan the basic program at the school. The result, he added, was one of the school's greatest successes: "We're able to go through this for four years, three and a half, and have something evolve that is an actual document, an actual plan, an actual 
system that is in operation. ... We have a system in place that we are using and it's a total school thing."

As step ten indicates, the journey does not end with the creation of the system. Reflection, refinement, and continual evolution are essential. Chris, the former vice principal, identified several works in progress at the end of the 1995-96 school year, or proposed for 1996-97. These include refining the scoring rubrics to better align with the specific assessment tasks; creating grade level menus of learning experiences and teaching practices based on the learner outcomes and assessments; and designing an accountability newsletter to report out to parents and the community. As Tina, one of the teachers, summarized, "it's got to develop into more. (We need to) continue to look at it, to revise it, to make changes."

\section{Teaching and Learning}

An accountability system, in isolation, will not change the teaching and learning process. Critical to improving student achievement, then, is connecting that work to the classroom, using it to refine teaching strategies and focus instruction. Has this happened at Mariposa? Two themes emerged from the interviews and observations: Teachers are teaching other teachers, and teachers are at least beginning to use assessment content and results to inform the instructional process.

Teachers teaching teachers. Teaching is changing, according to staff members, because teachers are talking about teaching and talking about student work. The key is the grade level collaboration. Chris, the former vice 
principal, observed that "it was very natural for the teachers to begin to share strategies, to begin to see who was doing things that were positive models and who was doing things that could be improved. As a grade level, they themselves began to improve one another." Gloria, one of the LAD team members, echoed the same theme: "Now, at grade level meetings ... we talk about teaching strategies and stuff." Carl, the former principal, concluded that "it was sort of like a staff development kind of thing with each grade level, and I think when teachers are teaching themselves it's as good as going to a workshop." Mark, the new principal, added that "compared to prior schools ... I hear teachers talking curriculum and what works in the classroom. They have conversations about academic issues."

The content of what teachers share has changed and evolved, noted Nancy, one of the LAD team teachers:

In the past, when we'd go to mentor teacher demonstrations, we focused on the cute part of teaching ... but we've never really looked at how did you get your student to write a paragraph with a topic sentence, we've never sat and shared instruction or strategies that really improved the basics of what we should be teaching children... . (Now) it just works across the board where people are kind of indirectly sharing their expertise-there's a lot of modeling. Chris agreed: “It was an excellent staff development piece because some teachers were no longer concentrating on just having the nice bulletin boards but talking about what children were doing and how they can improve it." 
My observations at grade level scoring sessions confirmed these comments. Teachers were, indeed, engaged in substantive conversations about teaching and learning. Fourth grade teachers, while talking about student performance on the end-of-year post-assessment, identified areas that needed improvement in both the assessment tasks and the scoring process. They also discussed what type of responses would rate the highest scores, and suggested elements they might include in lessons the next school year. First grade teachers were engaged in sharing their initial assessments of student performance, collaboratively rescoring selected papers, and entering results in student portfolios. One teacher, reflecting on this process, said "when have we ever had time before to sit together and talk about student work?"

Using assessment results. Another step in changing the teaching and learning process involves using results from the student assessments to focus and inform the instructional process. This, it appears, is still a work in progress at Mariposa. Some teachers, primarily at the intermediate and upper grade levels, are using the site-developed assessments to structure their curriculum. Joanne, an upper grade teacher, commented that "we know the areas that we need to teach so sometimes it directs what we will teach between now and the end of the year because it's expected at that grade level." Terri, another teacher, noted that "I have changed the way I do some of my weekly assignments so that the children will be more directed to do the kinds of things that they will be required to do. I think it has focused me on what my objective is in the product I expect from the children." 
But my observations at governance team meetings and a conversation with the new vice principal led to the conclusion that this is not yet a widespread practice. At the October governance team session, where grade level representatives were sharing pre-assessment results, the new principal and vice principal continually probed: "When you look at results, does this help you know what to do instructionally?" "What happens next? All this data is nice to report, but how does it inform instruction?" Mayra, the new vice principal, observed in a subsequent interview that the assessment data may serve to validate teacher impressions about student performance, but the assessments "are not yet fully seen as a helpful tool for instruction." One focus of the new administration this year is to help solidify those connections. Decisionmaking and Governance

Site-based governance and shared decisionmaking are integral parts of the San Diego City Schools restructuring process, and central, as well, to the process of site-based accountability for student achievement. As noted in Chapter Two, restructuring involves increased site-level autonomy and decisionmaking authority in exchange for accompanying accountability and responsibility. Within the school, in exchange for greater involvement in the decisionmaking process, teachers are being asked to accept the accompanying responsibility for the outcomes of those decisions.

Governance structure. Figure 2 illustrates the basic governing structure at Mariposa, with the primary power currently resting with the school governance team and the grade level teams. 


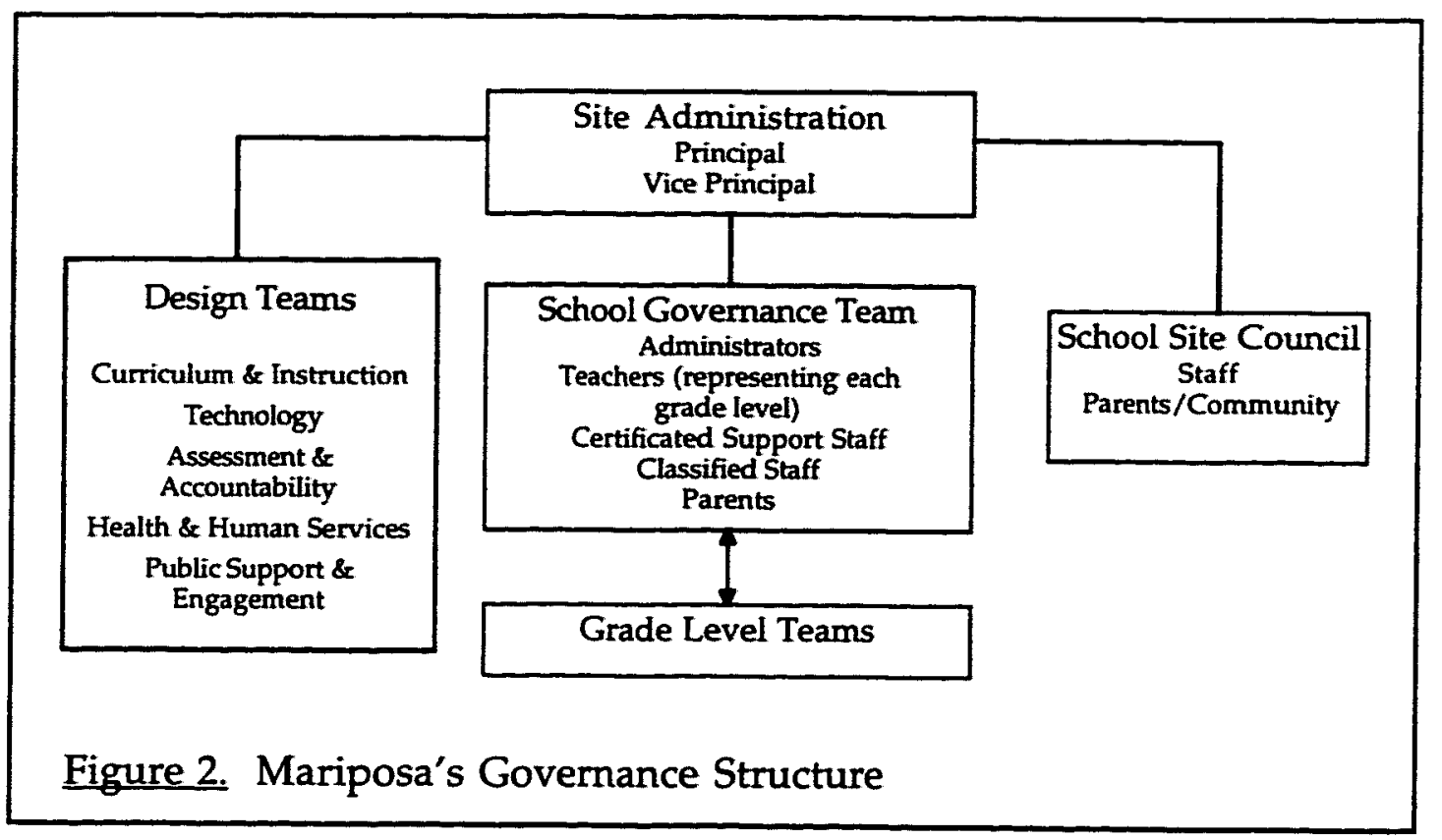

The governance team, consisting of teachers, the principal and vice principal, classified staff representatives, and parents, meets monthly to address issues of schoolwide concern. Each grade level has a teacher representative on the governance team. Information and discussion flow back and forth between the governance team and the grade level teams.

Grade level teams have considerable influence in the decisionmaking process. Issues such as staff development, revision of assessments and portfolios, student class assignments, even procedures for Open House or parent conferences, are first discussed within each grade level team. Ideas, proposals, and recommendations are then taken forward to the governance team by the grade level representatives.

However, the governance team's scope of decisionmaking authority is tempered by the frequent desire of all teachers to have their voices heard.

"Traditionally," commented Nancy, "major decisions have been made by the 
whole group ... here we all like to have our input.... When something comes up at this school, everybody does like to be involved." Tina concurred: It's supposed to work where the grade level teams vote on something and the representative will share (at governance team) what the team came up with and then from there it's decided on. Many of our big decisions haven't necessarily been made that way.... The governance team is made for making the decisions, although I think all they do is talk about it and anything that everybody needs to have a say on does go to the whole staff.

For the 1996-97 school year, the new vice principal, with agreement from the teachers, has just reinstated design teams, which have existed on paper but have not been operational. This governance concept was brought into the district through the National Alliance for Restructuring Education, which identified five key design areas that encompass essential elements of the educational process: curriculum, instruction, and technology; assessment and accountability; health and human services; public support and engagement; and high performance organization. The Alliance proposes that schools organize their work around these design tasks.

For Mariposa, the design teams will provide an opportunity to increase teacher input into the decisionmaking process around particular issues that cross grade levels, without waiting for the monthly governance team meetings or whole staff meetings. Rather than set up a regular meeting schedule, however, teams will meet as needed based on issues. As a subject 
comes up which relates to one of their areas of focus, the administration will present the issue and relevant information to the design team chairperson via a folder. The chairperson will then call the team together at a convenient time, raise and discuss the issue, and return feedback to the administration in the folder. As appropriate, the discussion may be brought to the governance team, grade level teams, and/or the whole staff at a future time.

Input, involvement, decisionmaking. The decisionmaking process at a school site flows along a continuum, from autocracy to input to participation to representative democracy to full democracy. The district's governance guidelines offer two fundamental questions to separate true shared decisionmaking from input (San Diego City Schools, 1990, p. 4):

- Does the shared decisionmaking group have the authority and the responsibility to make decisions?

- Does the shared decisionmaking group have access to the resources necessary to implement their decisions?

Teachers and administrators presented somewhat different pictures of the level of shared decisionmaking at Mariposa. Carl, the former principal, commented as follows:

This program (the accountability system) evolved to a point where teachers were making so many decisions about curriculum and about learning and about outcomes and that sort of thing. ... It's almost like having a tiger by the tail now-if you do not let them make the decisions they are going to be very upset. 
Chris, the former vice principal, echoed a similar idea, saying "maybe it's just the culture of the particular site, for the most part the teachers have always been part of all the decisionmaking things at this school."

Teachers, however, expressed somewhat different points of view. Nancy, while commenting that everyone liked to be involved in decisions, also questioned which decisions are truly open to teacher determination. She observed that "I don't think our staff has really made major decisions ... the district has made decisions on curriculum (and) the principal has pretty much made the budget. ... There are certain factors that we don't think that we, in reality, have control over." Terri, another teacher, brought up a related point:

I think we have a lot of say in decisionmaking (but) we are often directed in the decision that should or could be made. . . Having become somewhat empowered, I think we often feel, well, we know what we are doing and we should be able to make these decisions. I think sometimes we may even expect to go beyond our limits.

In the best interest of...? Another key point raised in the interviews relates to the nature of the decisions being made. Are they reflecting the best interests of the whole school, or the desires of individuals or small groups? Tina commented:

I think a lot of people are resistant to change and they make decisions based on them rather than the whole picture. So I think there needs to be someone who continually reminds everyone who is making the decision that we're not talking about what's best in your room or for 
you, we're talking about what is best for your students and also your students when they are going to be in grades above and below.... I think some people still see it as what's best for me.

Chris did feel that this area was improving as a result of the LAD experience: The decisions that they are making are more valid ... are wiser ... for the good of student achievement and learning.... A lot of those decisions are many times me, me, me-decisions just to make it easier for me. Now the decisions are more about improving quality. Teachers and decisionmaking. It appears that teachers at Mariposa do have many opportunities for active participation in the decisionmaking process, particularly through grade level teams and whole staff meetings. As they have become better informed through their work with the LAD project, they have demanded more discussion, and focused those discussions more around issues of teaching and learning. But, some teachers acknowledge, they do not yet have full control over many of the final outcomes. The Challenges of the LAD Project

While the Mariposa teachers and administrators, for the most part, were extremely positive about their experience with the Leadership in Accountability Demonstration School project, they admitted to some challenges as well. Their comments revolved around four themes: the difficulty of building and maintaining commitment, frustrations with time, confusion about direction, and concern about the future. 
Commitment and confidence. "Why are we doing this-why don't you just leave us alone and let us be in our classrooms and do our own thing?" In sharing this comment heard from teachers, Carl, the former principal, identified one of the major challenges to school reform-gaining commitment from the stakeholders. Terri echoed the same refrain, saying that one challenge was "getting all the teachers to buy into it." Nancy observed that "the biggest challenge is overcoming negative energy."

Complementing that challenge is the need to build confidence. Chris remarked that it was "very delicate to work with staff members who are now coming together to work with each other who never had to before ... some feel threatened and some feel insulted ... (it was difficult) to keep the peace and the harmony." He also recalled that, as teachers proceeded deeper into the process of creating a system, "they began to doubt themselves. Did we really do the right thing? Is it really valid? ... . They don't really know if they really have that much knowledge, background or information." Joanne, one of the teachers, added that "we felt pretty ineffectual when we thought we'd come up with one thing, and then we used it and we went, oh well, these aren't the results we were expecting, back to the drawing board."

Even when all stakeholders are confidently on board, it remains a challenge to keep the flame burning and the work growing and evolving. Carl worried that, while a strong core of teachers retain the vision and the motivation, they might not be able to carry it on if they don't receive support from the new administration. Chris added that "the momentum of 
excitement sometimes gets stopped," and noted that someone has to continually build morale and build motivation. Terri observed that "we need to be renewed, refreshed ... this will work for a number of years (but) we have to continue to grow in other directions."

Time, time, time. "Time, time management ... it's a very time consuming process when you consider the other things you have to do as well," observed Joanne, an upper grade teacher. Her colleague, Melinda, concurred: "It turned out to be a much greater task than we ever guessed at that time. I don't know if, as a site, we would have gotten into it had we realized in advance how much work it was going to be!" Nancy, one of the LAD team members, commented that "there were days when we talked and we went into our classes without a single lesson plan written down because we were maxed to the limit."

The teachers unanimously reported that, individually and collectively, they invested a huge amount of time in the development of their assessment and accountability system. This was time taken from classroom preparation, staff development, and even teaching, since substitutes were brought in to cover classes so teachers could attend training sessions and meet together. While teachers recognized the value of this work, they also bemoaned what they may have lost in the process.

Does anyone know what we're supposed to do here? "I think that when we signed on as a staff, we were expecting a lot more direction from somebody," expressed Gloria, one of the teachers on the LAD leadership team. 
"We were pretty much left on our own to figure it all out." The LAD team members reported that the initial training was often confusing, and sometimes they felt they were floundering without direction. "In the beginning," commented Nancy, "a lot of it didn't make sense and the preliminary guidance was less than good." Gloria added that "I don't feel they knew what they wanted quite at that point so we did a lot of flip-flopping around. We would spend a whole day organizing something and then we would go to another meeting and be told that we were totally wrong, on the wrong track."

In addition, some of the teachers expressed a little annoyance about having to start nearly everything from scratch, from structuring the system to designing their own assessments. While they do recognize and acknowledge the value of being involved in the development process, Joanne, one of the teachers, summed up some of these feelings:

We're tired of developing things. ... Why should we have to go through the time and effort to reinvent the wheel if we can look at something that someone else has taken the time to develop and decide whether or not it applies to our situation and can be adapted easily? . . . Being told, no, think about it on your own is just frustrating. Will the district come in and tell us...? Now that they have spent more than three years on this tremendous task of development and implementation, the fear arises among the Mariposa teachers that the district 
will change direction and come up with some conflicting requirements that will negate their work. As Nancy remarked:

We are going to be pretty unhappy if the district comes up with something that is real different and says, well, gee, that was nice three years ago, but now it's out.... We put a lot of effort into it and I would be indeed very discouraged if the district tells us, oh, this is no longer the in thing. ... That just frustrates people so much, it almost makes them not want to try a new thing when the district comes up with it.

\section{The Successes of Being a LAD School}

Despite the hard work, despite the challenges, despite the frustrations, Mariposa teachers and administrators were unanimously positive about the LAD experience and what it brought to the school. Three key points emerged: the benefit of increased staff collaboration, the value of discovery, and the accomplishment of having an actual system in operation.

All together now. Each of the interview participants independently commented on how the teachers have come together and built strength first as grade level teams then as a whole staff. Joanne remarked that "it's developed a cohesiveness within the grade levels," while her colleague Melinda commented on "grade levels talking to each other or discussing problems and ways to resolve issues ... you really do develop a different feeling or a different respect for the people you work with." Nancy said that "the very best thing of the whole program was having teachers at grade levels thinking along the same lines and comparing student work and also then 
keeping in mind what the next grade level is expecting." Former principal Carl noted that "it brought grade levels together," while vice principal Chris added, "we're very proud about our collaboration in grade levels."

The grade level collaboration has extended to a sense of camaraderie and cohesiveness as a whole teaching staff. "The biggest thing is the collaboration of teachers," observed Tina. "The process of ... getting together and coming up with things as a school-grade level teams and as a whole school-really helped, and I probably see that as the biggest benefit." Mark, the new principal, observed that "the quality of the staff is reflected in the quality of the teaching. They have high expectations for themselves, collectively. They have an ability to work together cooperatively for common goals." Gloria added her thoughts:

The end product was that the teachers became much better in working with each other. They had a stake in the plan and I think the morale of the school generally rose and in addition, now, I think the staff is much stronger as a staff.

Discovery. Despite the frustrations expressed by teachers about starting from scratch, staff members do recognize the value of discovery. Chris, noting that the staff was on the verge of taking a next step with assessments and scoring rubrics, commented that "I was just waiting for that to happen. I tried to push it at first and talk to them about it ... we can't push and enforce it until they are ready for it." Terri, an experienced teacher, similarly observed that "if you didn't make your own wheel you just don't tend to use 
it, or you don't know how to use it. ... It helps with your direction to have been involved with putting the spokes on."

I addressed this point when I was called on to give some observations at the May governance team meeting. During this session, each grade level representative reported the end-of-year assessment results; as these reports proceeded, teachers began to develop new insights and raise some important issues about how the assessments were administered and scored, and how the results could be used. I talked with them about the difficulties inherent in struggling through something new. But I also noted that the experience had obviously led teachers to internalize major issues and concepts, ones they might have disregarded had they simply been told.

Mariposa's discoveries have resulted from, and also enhanced, the staff collegiality and collaboration. Through working together and engaging with difficult tasks, discoveries have emerged and camaraderie has developed. This process has involved hard work and frustration, but it has also been of great value.

Accountability in use. Carl, the former principal, was excited about the evolution of Mariposa's work. Many schools, he mentioned, have created some of the individual pieces-learner outcomes, rubrics, assessments, action plans. But Mariposa's work evolved into "an actual system that is in operation... We actually have a system in place that we are using and it's a total school thing." He felt this was what moved them beyond many of the other LAD schools. 
Nancy, from the LAD leadership team, extended this thought: "Teachers started saying ... this was actually something that we were going to use." Chris concluded that Mariposa is most "proud of the actual consistency in our implementation of the program.... It's become a part of the staff's repertoire ... now it's part of the culture of the school."

\section{Variation: A Model Program}

Beyond the common themes that structured the interviews, two other points emerged from my conversations with Mariposa staff. The first involves the area of public recognition from the district and the larger educational community for their model program; the second relates to using that model, and the work of the LAD schools, across the district.

Mariposa's work has generated recognition for the school and the staff, but not as much as they would like or believe they deserve. The LAD leadership team members have presented their M.A.P. at a district accountability fair and to other schools in their surrounding area. They also partnered a Phase II LAD school and assisted two neighboring sites last year with their needs assessment and planning processes. But Mariposa has received the greatest recognition from outside the district; teachers and administrators have been invited to present their work at conferences and staff development workshops across the state. It's a bittersweet feeling, note Nancy and Gloria, to receive so much attention outside the district and very little from within. They commented that "what would be nice . . . would be 
some little pat on the back from someone in the district.... We think we are doing something a little special ... there should be recognition."

Carl would like to see the school pursue a different type of recognition as well. He reflected that "I don't know if it's a legacy but it's something that I've dreamed about for a long time. I wanted to stay with it and take it further. ... I wanted to apply for a Golden Bell award or something ... it is something for the future of education." He hopes that school staff will pursue such formal recognition in the near future, and of course would like the school to invite him back to share in the celebration.

Staff members also believe that the district has not fulfilled the promise of the LAD concept. The Leadership in Accountability Demonstration School project was created to "provide leadership in developing an accountability system model for the district" (Student Achievement Accountability Committee, 1993, p. 4). The accompanying circular that announced the opportunity to participate in the pilot stated that “this project will serve as a prototype system for understanding, developing, and reporting accountability in student achievement across the district" (SAAC, Appendix D, p. 1).

Yet Mariposa teachers do not feel the project achieved that purpose. Nancy, from the leadership team, asked "let's say that three or four schools have really developed this now. Why aren't these three or four schools getting together and developing a model for the district?" The work of the LAD schools has not been brought together, she observed, nor shared widely 
across the district. The district reports that the key elements of accountability have now been subsumed into the new school site planning process.

However, Nancy and Gloria note that, while some schools continue to work on their own, many others have not even begun to consider the critical idea of demonstrating accountability for student achievement through standards, assessment, recognition and intervention, and public reporting. These schools, they feel, could benefit from the work of the LAD schools.

\section{Mariposa's M.A.P.: An Accountability Culture in Action}

Mariposa seems to embody an emergent schoolwide accountability culture. In the school office, a large scroll calls out-for staff, parents, community, visitors-their Proclamation for Student Success (Figure 3).

It is hereby proclaimed that the students, parents, staff, and community of Mariposa Elementary dedicate themselves to providing a quality education through the four elements of an accountability system: 1) High Standards; 2) Meaningful Assessments; 3) Recognition and Intervention; and 4) Public Reporting.

Mariposa School guarantees that children will achieve grade level expectations and standards as measured by learner outcomes and assessed through benchmark indicators, so long as strong, ongoing support is provided to the children by the following important stakeholders: parents, teachers, school staff and community.

Only through consistent support, as evidenced by the key observable behaviors outlined for each stakeholder in Mariposa's Accountability Document, will this guarantee be in effect.

Figure 3. Mariposa's Proclamation for Student Success 
At Mariposa, teachers regularly sit together in grade level teams to evaluate student assessments and engage in professional discourse about student work and student learning. Governance team members share the results of student assessments and brainstorm implications for schoolwide strategies, stimulated by probing questions from administrators. Students' cumulative portfolios include a report on their academic accomplishments as well as a summary of interventions, with annotations for the next teacher on which activities were effective and which were not. A site-developed guide presents parents with Mariposa's belief system about language arts; the accountability plan; the grade level rubrics; and suggestions to support reading, writing and oral language at home. It asks parents to sign a contract of understanding regarding accountability, grounded in the proclamation for student success.

Student achievement accountability, at Mariposa, is embedded into the everyday way of doing things. The route is planned, the vehicle is fueled, the map is drawn, the camera is in hand ... the journey continues.

\section{Sierra's Saga}

Sierra's story begins several years before the Leadership in Accountability Demonstration School project, starting with a change of principal and a new school focus in 1990. The story has also extended on after the LAD project formally ended in 1995, with work which continues to grow and evolve. Thus, while the LAD program itself forms the main chapters, 
the prologue and epilogue are essential as well, to tell the whole story of how Sierra has worked to demonstrate accountability for student achievement.

Sierra is a relatively new school, opening in 1986 to serve the children of a rapidly growing bedroom community. The 1995-96 enrollment of 1419 culturally and ethnically diverse students makes Sierra one of San Diego's largest elementary schools. The student population is 38 percent Filipino, 24 percent White, 18 percent African-American, and 17 percent Hispanic. About 24 percent of the students are limited English proficient. The poverty rate has increased steadily, with the percent of students eligible for free and reduced lunch increasing from 26 percent in 1992 to 38 percent in 1996. (See Appendix F for a complete profile.)

To house this burgeoning population, Sierra operates on a multitrack year-round schedule. Students and teachers are divided into four groups or tracks; one group, or about one-fourth of the population, is out on vacation at any time. Tracks proceed through a staggered series of nine week sessions followed by three week vacation periods. Teachers often come in during their breaks to work as substitutes or assist with curriculum writing projects.

Sierra staff members have focused extensively on building student academic skills and knowledge in language arts and mathematics, and standardized test scores have shown improvement at most grade levels from 1994 to 1996 . The school also operates a highly successful visual arts magnet program which integrates the arts across the curriculum in support of academic learning; this program attracts students from other areas of the city 
who may attend Sierra through the district's integration program. In 1993, the school was selected as a California Distinguished School, with an extension granted through 1997.

\section{Becoming a LAD School}

Sierra's work began, as noted, well before the LAD project itself. This work continued to grow and evolve throughout their association with the program. And although the project formally ended in 1995, Sierra did not stop there, as the story shows.

Prologue. "I'm going to go back about five years because that led up to the three year participation (in LAD)," reported Sylvia, Sierra's principal. When she came to the school in 1990, she found the teachers embroiled in controversy around the whole language reading program. Mayra, the former site resource teacher who was a classroom teacher at that time, recalled:

We were no longer teaching using the basal readers and so it wasn't specific anymore as to what you were supposed to teach through the school year. We weren't all using the same materials so that's when it became really important that we at least begin to focus on the same skills, output that we expected from the students.

So the teachers sat down with the state curriculum frameworks, the state reform document It's Elementary, and the district course of study. Mayra continued:

The administration was leading us through discussions about what we expected from the students that we currently had and what we expected 
from the students as they enter our classroom. ... We started discussing first of all within grade levels what it was that we expected that we were going to be teaching consistently throughout each grade level. And once we decided that, we met with the grade above us and the grade below us to talk about the articulation.

This process, remarked both Sylvia and Mayra, helped them begin a needs assessment based on the state curriculum guidelines and reform recommendations, focus staff development around their needs, and prepare their application for California Distinguished School. By 1993, when the LAD opportunity presented itself, Sierra teachers were quite familiar with the state Language Arts framework and with It's Elementary; they had also developed a K-6 written language continuum and some grade levels had delineated specific learning expectations.

Chapter 1: Beginning the LAD project. "The LAD proposal came out and we felt that since we were already starting this process, it would be wonderful to gain some district support for continuing." With these comments, Mayra reported on why Sierra volunteered for the pilot project. LAD, added Sylvia, appeared to be "the vehicle for putting it all together." The first chapter in Sierra's accountability story thus began with a team of ten staff members-five classroom teachers, two special education teachers, two site administrators, and one parent-attending the five days of training in the spring of 1993. This training helped them start "talking about needs assessment, site decisionmaking, accountability," Mayra noted. Kent, one of 
the LAD team members, added that "I just remember getting together as a group and sitting down and talking about where we were, what we were doing, what we thought was important, where we wanted to go."

Following the initial training, the LAD leadership team brought the information back to the whole staff and engaged teachers, schoolwide, in similar conversations. As Kent recounted, "after we had some of these discussions ... it came time to bring things back to the staff and tell them what was coming down the road." Sonia, another LAD team member, mentioned that "each time we presented to them it was only a small portion. It wasn't that we presented the whole bailiwick at the beginning. We said, this is where we want to get to, but today all we're working on is...."

The first year's work focused on three areas: learning new terminology such as learner outcomes and observable behaviors; converting the beginning site work on grade level expectations into language arts standards; and developing an assessment correlated to those standards. As Mayra recalled, "we would focus our staff development on language arts, developing standards and then looking at trying to develop an assessment that would try to measure whether we were accomplishing the standards." Sylvia, the principal, expressed that it took "a lot of team work, a lot of grade level meetings, a lot of triads and discussion."

By the end of the 1993-94 school year, Sierra produced its first Literacy Standards Notebook. Through intensive work that year, teachers developed or adapted from other sources the following materials to describe and assess 
student performance in language arts: content, performance, and program standards; developmental continuums; essential portfolio items; reading assessments and intervention sheets; writing performances and anchor papers. The process, particularly developing the reading assessment, involved a great deal of research and coordination which fell under the supervision of Wendy, one of the classroom teachers. As she related:

I took the standards and I created a format for the assessment. I coordinated going back and forth between the staff, having them include the kinds of areas that they wanted to assess according to the standards. My job was to oversee K-6 to make sure that there was consistency from one grade level to the next ... to do a lot of research into different kinds of assessment.

She also acknowledged that, while this process was incredibly time consuming, it paid off in teacher commitment:

Each grade level would meet and, coming from different teaching philosophies, it created lots of wonderful discussions. .. I I think after going through that process the teachers became more receptive to it because they were involved in creating it.

Chapter 2: Implementing, refining, growing. Following that first year of intensive development, the process of implementation and refinement began. During the 1994-95 school year, teachers administered the newly developed reading assessment for the first time. In addition, the school participated in a Program Quality Review focusing on mathematics, which 
initiated another process of looking at student work in relation to standards and identifying student needs. Year two of the LAD project thus addressed the implementation of intervention strategies in reading using assessment results, the revision of the reading assessments based on teacher feedback, and the creation of a math assessment.

During this second year, a group of Sierra teachers continued attending monthly district focus group sessions, often acting as presenters to share their work with standards and assessment. In addition, they served as partners and mentors to two of the schools entering the LAD project under Phase II.

Chapter 3: Institutionalization and evolution. Kent, one of Sierra's original leadership team members, observed that "I have always seen this as an evolution, starting slow, growing and changing." Although the funding and formal support from the LAD project ended in June 1995, Sierra's work did not. Teachers have continued working on further refinements to the assessments and the assessment process. And staff, particularly administrators and resource teachers, have also worked to further embed accountability into the basic school operations and the school culture.

Over the past year and a half, Sierra teachers have refined the reading assessments, begun revising the math assessments, and integrated science and the visual arts program into the accountability process and the school action plan. Academic interventions have been expanded, with students identified based in part on their performance on the site assessments. The monthly 
grade level meetings have also become better structured to focus discussions on teaching and learning, assessment, and accountability.

Epilogue. Sierra's story does not stop with the formal end of the LAD project, nor does it stop at the school boundaries. Several site teachers have worked as consultants to other district schools, helping them organize their staffs, identify needs, focus on standards, personalize assessment processes, and develop site plans. They have also shared their work by presenting at conferences, at school districts around the state, and at many local school sites.

Kent shared an observation from a recent conference where he and other members of the LAD leadership team made a presentation: "It was amazing to me to see the reaction of the other educators there. People were just blown out of the water by what we'd done and people were dying to buy our program." Sierra staff are very pleased with their work, and with the associated recognition that they have received.

Teaching and Learning

Sierra's teachers have been talking about teaching and learning since they began their work on grade level expectations back in 1990. But has their work with standards and assessments actually influenced teaching practices? I asked that question during the interviews.

Talking teaching. One way to influence change in the classroom is to encourage teachers to talk about teaching. Yet at most school sites there are few structured opportunities for teachers to come together and converse about instruction. At Sierra, in the early years of the accountability process, 
this was a central element of the site's work. Sylvia, Sierra's principal, commented that "during this process we spent the first two or three years talking about teaching strategies and instructional techniques. We also built in where teachers share instructional techniques that work for them." Mayra added that, "within our staff development calendar we have days that are called teaching practices, where teachers will share their teaching practices with other teachers, whether it's within the grade level or across grade level." What this has done, Mayra observed, is "give teachers permission, basically, to talk about student work." Sylvia noted that teachers now share informally throughout the year, making comments such as, "almost all of my first graders are reading, and this is what they are doing," or "I've learned so much from this person."

Now that the standards and assessments are developed, fewer formal occasions have been set aside for instructionally-focused conversations. Sonia, one of the LAD team members, commented that she'd like to see staff development days become more of a true opportunity for teachers to learn about teaching strategies and share successful practices. In an effort to refocus teachers on instructional discussions, Wendy reported that the monthly grade level meetings have become more structured for the current school year. These meetings are now guided by agendas that lead teachers to address instructional activities such as those called out in the school action plan.

Connecting assessment to instruction. Sierra's accountability work seems to be best connected to instruction via the site-developed reading and 
math assessments. First, many teachers said that the assessments provide for early identification of needs, especially in the primary grades. Wendy remarked that "teachers can diagnose students much better than they could previously," while Paula, a primary teacher, noted that "once I gave the math assessment, I saw everything they needed to know." As first grade teacher Virginia said, the assessment "gives me a very clear idea of what they know and what they don't know."

As a result of the opportunities the assessments provide for early diagnosis, interventions can also be targeted early in the school year. Sonia, a special education teacher, reported that now, "because there is a pre-test, we identify our kids who are at risk during the first two weeks of school.... We've set up many more intervention programs and, because we have a post-test, I can tell if the intervention programs are working."

In addition to interventions, some teachers use the assessments to inform instructional practices in other ways. Wendy observed that "it has turned some teachers into assessment maniacs ... they are so excited about the growth they are seeing and are so rewarded by the growth that they saw at the end of the year that they want to see it from week to week." She also related the following about her work last year as a classroom teacher:

I was able to diagnose what was going on with their reading. I was also able to individualize their education more based on what their needs were from what I discovered from the assessment. I also changed the way I taught my reading program as far as comprehension. . . . And on 
the math, I used my pre-assessment results to completely revamp my math program.

Olivia, a primary teacher, commented that she has taken the concepts as they are introduced on the reading assessment and integrated those into her regular lessons. "After every book my kids read, I create a comprehension test for them ... so they're trained in the mode of what they're going to do.... I bring that type of assessment into my own curriculum." Virginia added: I make up several packets with similar concepts as the assessments. I give the similar concepts to the parents so that way they can have an overall view and they know the direction we are going.... I go through these concepts and I make sure that these are the concepts that I'm bringing into my homework packet. ... Everything I do really is tied around the assessment.

This practice is somewhat less widespread at the upper grade levels, it appears. First, noted sixth grade teacher Grace, "you usually don't see the growth in the upper grades as you see in the primaries." She also added that, "I can guarantee you that we assess, and we see who is low, but the individualization of the program is not a reality-bound thing, considering all my material is in sixth grade vocabulary." However, Wendy had the following response:

We've discovered that the upper grades really are on their own, and don't have any type of intervention program, so we've just come up with ... a third through sixth program where (teachers) just identify 
the frustration-level kids in the class (from the pre-assessment) and they will be working with aides.

Kent, a fifth grade teacher, expressed that giving the pre-assessment helps confirm his initial judgments about students and also helps identify those quiet ones who may get lost in the shuffle:

I'm always afraid as a teacher that I'm going to let a kid slip through the cracks. I'm looking around the room and I'm thinking, you know, he needs help with math, he needs help with reading and I'm keeping them in the back of my mind.... But what about the student who is real quiet behind me that I never notice? ... The assessment gives it to you in black and white and you can go back to it and say, where are we all at, is there anyone I've forgotten?

Reflecting on teaching. There is another area in which assessments such as those developed by Sierra teachers have a great deal of potentialusing the results to reflect on teaching practices themselves. Kendra, a mentor teacher, observed that the assessment process can "help the teacher look back on their teaching ... to reflect on yourself ... and say, where did I start with this group, where am I ending, and how effective have I been and how do I need to modify?" Sonia similarly commented that, "I see a lot of teachers also taking the test and saying okay, my class did terrible last year on this part so I need to do more teaching and I need to do more explanation and practice for that." 
Wendy proposed that the assessments could be very valuable to site administrators. She suggested, for example, that principals could "use this to work with teachers who are not achieving with their students." She also thought that administrators could have meetings with teachers at the beginning of each year, "looking at the pre-assessments and asking the teachers to mark on the graph where they thought they could get that student by the end of the year, hoping, again, that the teachers would internalize and focus on getting the students what they really needed."

\section{Decisionmaking and Governance}

When I asked teachers in the Assessment and Accountability Team group interview about decisionmaking, one of them laughingly commented, "we have to form a committee to discuss this." Tongue-in-cheek, yes, but the element of truth in this statement captures both the strength and the challenges of Sierra's governance process.

Governance structure. In 1993-94, concurrent with the first year of the LAD project, school administrators completely restructured decisionmaking and governance processes, adding design teams under the National Alliance model but adapting them to encompass Sierra's unique programs and needs. The schoolwide governance groups-School Governance Team, School Site Council, and Principal's Advisory Council-include administrative staff, classroom teachers, certificated support staff, classified staff, and parents. The design teams are comprised of certificated staff, with all teachers serving on at least one of the teams. Figure 4 illustrates the Sierra governing structure. 


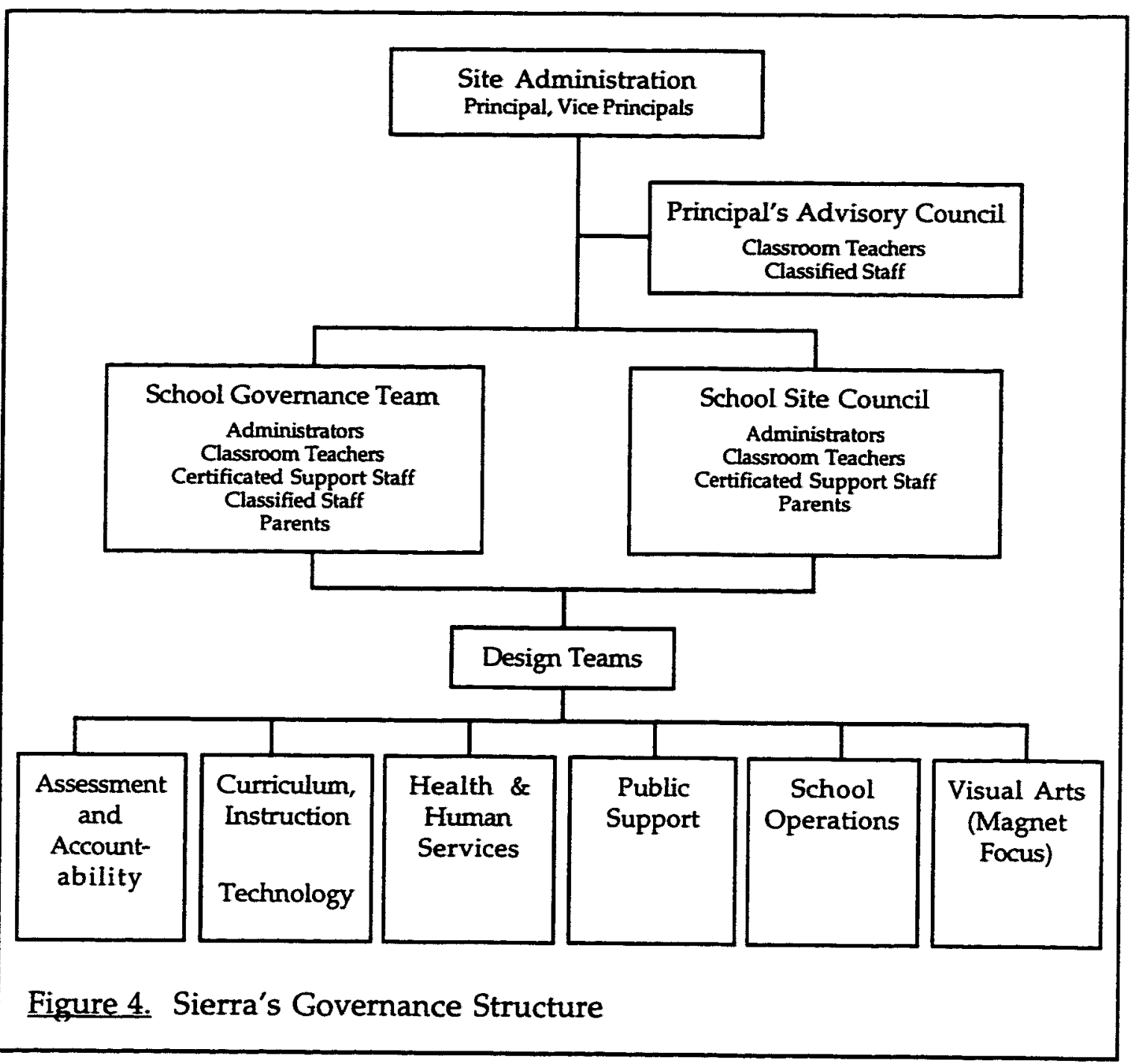

During the 1995-96 school year, the staff outlined the roles and responsibilities of each governing body in the organizational structure:

- School Governance Team serves as the High Performance Organization and is responsible for ensuring the implementation of the district's expectations and overseeing the design teams.

- School Site Council will be responsible for state requirements of the School Improvement Program and assist with the development and monitoring of the Annual Action Plan. 
- Curriculum, Instruction, and Technology Team will monitor the learning environment where students learn and demonstrate through exhibitions and portfolios knowledge that is valued in the real world and meets high standards of quality.

- Assessment and Accountability Team will ensure that all students master a core curriculum which emphasizes high standards.

- Health and Human Services Team will ensure the health and welfare of our students and maintain a clean and safe campus.

- Public Support Team will oversee that the parents and community are actively engaged in the educational process through involvement in all school activities to promote optimal education for all children.

- School Operations Team will actively engage in enhancing the capacity of the school for beneficial change.

- Visual Arts Team will work together to enable each child to achieve full potential and self worth through an integrated visual arts curriculum.

Governance process. How is this governance structure supposed to work? According to Sylvia, Sierra's principal, "each design team is a decisionmaking team. If they feel it is something that will totally impact... the site, either they will say, let's take it to governance or let's take it to total staff." In addition, she continued, "because governance and the design teams meet once a month, and SSC is once a month, and staff meetings are every week, we have an opportunity for a lot of ongoing communication." Mayra, former resource teacher, extended this: 
Each design team is a decisionmaking team within itself. But that's not to say that some of the schoolwide big issues, controversial issues, will be discussed at a design team and brought forward to governance to make the decision. But some of the day-to-day operational decisions, some of the program decisions, the design teams are empowered to make the decisions....

With everyone assigned to at least one design team, people feel when they have discussed the topic, collected information ... and made the best decision that they can, they don't want necessarily another group to begrudge them their decision.... I think it's dangerous in a sense to have one team, such as governance, hold the decisionmaking power. I think the design teams give the ability for more people to have their voices heard.

When it works = teacher power. When this decisionmaking structure works as intended, teachers hold a great deal of power. One example is the creation of the assessments. The Assessment and Accountability Team coordinated an interactive process among teacher grade level groups, whole staff meetings, and committee meetings, to draft, review, create, implement, and revise the reading and mathematics assessments. The decisions about the content and format of the assessments rested completely within the teachers' hands. As Virginia observed:

The teachers' role has been really important because the teachers themselves were the ones... given the power and told, you are 
expected to come up with an assessment. So we put our heads together and we did it, and it was a gradual development but we were expected that we were going to do it and we did.

In another example of the decisionmaking capabilities of design teams, Kendra described the scope of authority of the School Operations Team on which she serves: "We've come up with job descriptions and things for hiring new teachers, and that group designed the entire summer program when we went from year-round July to year-round September . . . we filled classes and did a whole ton of decisionmaking."

When it doesn't work = teacher frustration. Unfortunately, in many instances this complex system of committees does not seem to work as intended. As Kent, one of the LAD team members, expressed, "I think there is a lot of frustration, decisionmaking wise, because we have a wonderful system of committees and a chain of command and powers and so forth, but somehow or another, things always end up different." Olivia, another Assessment and Accountability Team member, added that "we always come up with these wonderful ideas that we think will be positive for the school, but ... they don't usually make it into reality."

Complicating the process is the large size of the school and the multitrack schedule. Wendy commented that "it's the communication that is so hard at this school, being multitrack. We're not all here, so you don't know why some of these decisions are made... . We're not all on the same track, and I mean that in more ways than one!" 
Getting appropriate and comprehensive information into the hands of teachers is another challenge. "We don't always have all the information," remarked Grace. "You can't make an intelligent decision unless you have information." Sonia concurred, noting that "when we're making a kind of important decision, you really do need all the information.... And it would be nice if the information was presented ahead of time."

One reason decisions don't hold up, suggested Grace, might be that "you're on a committee that interests you ... (but) we're dealing with the fact that maybe your passion is not somebody else's passion." Thus, the priorities decided by a particular design team may not hold up under discussion at the governance team or with the whole staff. And that, explained Kent, is a significant problem: "That's the frustration, we had discussed something, made a decision, this is what we wanted, and it got changed." It shouldn't be "they decided," he continued. "They don't have to decide, we decide."

For shared decisionmaking to work.... Sierra's teachers do have some suggestions to help the school's shared decisionmaking process work more as it is intended. Sonia proposed, for example, that the decisionmaking process needs to "become more focused on kids-I don't think that most of the teachers really believe that most of the decisions ... are what is the best expectation for the kids in the classroom."

Sylvia, the principal, observed that "probably the most challenging is to gain trust, not just from them with me, but among each other. Most importantly, trust in allowing others to make decisions for them." Kent 
added that it's important for teachers "to feel empowered, that they're going to make an impact and have an effect.... There has to be the responsibility of saying, okay, if it's a problem we need to fix it-how are we going to fix it, and who's going to fix it."

\section{The Challenges of the LAD Project}

Over the past six years, Sierra's teachers and administrators have put a tremendous amount of time and energy into becoming accountable for improving student achievement. This effort has not been without difficulty. During interviews, concerns were raised around three themes: building and maintaining teacher commitment, dealing with frustrations related to time, and getting direction and support from the district.

Bringing everyone on board. One issue cited by Kent is getting "teacher buy-in ... to make the program work, you have to have teacher buy-in and getting them to take it seriously." Mayra noted that "it took several years to develop the capacity of our teachers to understand the LAD vision." She also commented that, "you have people in different categories of willingness to change, and you have different degrees of people finding something valuable versus something not valuable. So the staff dynamics is a challenge ... to bring this into a schoolwide process."

This capacity-building process, hard enough at any school, was complicated by Sierra's multitrack schedule. Mayra reported that "it's difficult to get consensus on things that are really, really important to the success of this program" when teachers go on and off track during the development. As 
Kendra expressed, "not having everyone on site at the same time so decisions are made ... you're like, whoa, I didn't know about that, because you were on vacation." Sylvia added:

You still will have teachers who will say they aren't sure what is going on, or decisions are made without them.... At some point when they are on track, they are involved in decisionmaking, but when you go off for three weeks, and then all of a sudden you are back and things have changed, they think, oh, what happened?

Time, time, time. Sierra's work involved, and continues to ask for, a tremendous time commitment on the part of teachers. They spent hours in staff meetings discussing what students should know and be able to do at each grade level, then spent more time writing the standards and creating the assessments. As Mayra reported, "time is a challenge. People need time to discuss on an ongoing basis the school programs and what's working and what is not." Sonia commented on "the amount of time that we put in on our own, outside of the classroom and everything else.... We spent hundreds and hundreds of hours on our own."

Now, teachers are also asked to commit classroom time twice a year to administer and score the reading and mathematics assessments. Thus it was no surprise that Kendra said, "it's too much-it's incredible-we have a lot of work that we have to do." Virginia exclaimed that "it takes ... enormous amounts of time." And Kent added that "it's just a fact of life that the teacher 
is expected to do more and more and more in the classroom these days, and there just isn't the time."

Starting ahead of the crowd. Another frustration, expressed primarily by the LAD team members, resulted from the fact that Sierra had started work in these areas before the LAD project began. Staff members felt at times that they were ahead of the rest and thus out on their own. As Sonia described:

The hard part was that we had already been working on it for two years and so our school was actually ahead of most of the district.

Sometimes it got frustrating because we were actually doing more teaching than learning at some of the presentations.

Many teachers felt that the district has not been fully supportive of their work, particularly in terms of recognition and funding. Wendy asked, "where is the support, where is the value from the district? ... If you want us to buy into it, then the support needs to be there." Another Assessment and Accountability Team member added, "it should not just be a passing whim or a drive-by program." As Sonia summarized: "At the beginning I really liked it, because I felt we were supported by the district as far as giving us time to actually meet. I think that, as it went on, then those that were leading kind of said, you'll do it on your own time."

Now faculty members are wondering whether the district really values the work accomplished by the LAD schools. They also query whether appropriate direction and support will be extended to other schools as the accountability process is operationalized districtwide. 


\section{The Successes of Being a LAD School}

Despite the challenges and the frustrations, Sierra's teachers and administrators clearly feel there are many positive outcomes from their involvement with the project. First and foremost is the creation of their assessments and the accompanying feeling that "we did it." Second comes the feeling of working together and moving the school in the right direction.

It's the assessments! The number one success cited by Sierra faculty is the creation of the reading and mathematics assessments and the consistency of expectations that has resulted from that work. Resource teacher Mayra remarked that "I think the best thing that we have done is come to some clear, consistent guidelines of what we are expecting of students at each grade level." Kendra, a classroom teacher, said the greatest success is "definitely, the assessments, which give us a pretty clear goal of where we should be going and what should be covered."

One of the primary grade teachers commented: "I have seen so many fads ... I see this (the assessments) as something that is a safeguard." Virginia added that the assessment "doesn't leave anything up to the imagination. ... we made sure we're not missing any of the major concepts." Wendy similarly sees their assessments as a safety net for students. "I can envision the ideal state that we would like to be in," she expressed. "I think that we are going to be able to catch every student."

We did it! Teachers believe that the assessments are particularly powerful because they are built on the experience and expertise of teachers, 
and include the ideas of many. As Virginia remarked, "it wasn't as if one person did everything." The teachers all had opportunities to provide input into both the development and revision, and thus have a great deal of ownership in the final products.

Kent, one of the original LAD team members, commented that "we talked about having the teacher feel empowered, and part of that is having them start from the beginning and having them feel part of the process." As Sylvia, the principal, noted, "nothing we have done or have accomplished here (came) without teachers saying 'we did it'."

Moving in the right direction. Sierra's work has taken the school and its teachers well down the road of educational reform. Wendy, the resource teacher, noted that schools like Sierra are really research bases for the district and for the larger educational community. Her lament is that the district does not choose to use what Sierra teachers, and those at other schools, have created. She commented, "we're the professionals. ... They've got to know what's going on out here."

During the Assessment and Accountability Team group interview, Sara, an upper grade teacher, seemed to surprise everyone with the following insightful observation:

I'd like to say something in terms of positiveness from LADs and the creation of these programs. What I'm seeing is finally, in education, that there's change, and people are willing to change in their teaching strategies and techniques and look towards the future.... It has to be 
given to a lot of teacher credit that they want to go forward and be productive members of the educational community.

As Kent concluded, "it's moving in the right direction."

\section{Variation: Bringing It All Together}

It would be easy, especially at such a large school with the complication of the multitrack schedule, for this work to become diffused and subsequently lost in the day-to-day operational realities of running a school and teaching children. But Sierra staff have found a way to tie all the accountability elements together and infuse them into the basic school operating structurethe district's comprehensive planning process and the Annual Action Plan.

During the 1992-93 school year, at about the same time the Student Achievement Accountability Committee was completing its work and proposing the Leadership in Accountability Demonstration School project, a second district task force was investigating a new site planning process. The prior structure was compliance-bound and cumbersome; it produced a document that met categorical funding requirements but had little utility in the everyday life of a school or a teacher. What the task force delineated instead was a comprehensive site planning process that revolves around an annual cycle of needs assessment, plan development, implementation, ongoing monitoring, end-of-year evaluation, and accountability. At its heart is a core document-the Annual Action Plan-that focuses school efforts on selected standards, benchmark assessments, and key observable behaviors in 
each of the four district goal areas: Learning Outcomes, Teaching Practices, Integration, and Governance and Collaboration.

The task force proposed that all district schools be phased into this new planning structure over a four-year period, based on the state Program Quality Review cycle. However, because the process was so closely aligned with the accountability policy guidelines and terminology, LAD schools were offered the opportunity to voluntarily enter into the new planning structure during the first year in 1993-94, regardless of their scheduled cycle. Sierra was one of the schools that accepted that offer. Staff developed the first Annual Action Plan for implementation in the 1994-95 school year; the school is now into the third year of this new planning process.

The action plan, observed Mayra, is "the product that we needed, the organization that we needed to keep changing and keep revising what we do at Sierra in the area of assessment and accountability." Sylvia, the principal, more strongly asserted that "I think the Annual Action Plan is probably ... the number one best instrument any school can have for accountability." In a recent letter to one of the school board members, she wrote, "The Annual Action Plan holds our school accountable for what is taught and for what students learn."

At the school retreat I observed in July, one teacher commented that the Annual Action Plan is a positive method for embedding accountability into the system-it's not just on paper, but something that can be done. 
When someone complained about the extra work, another staff member responded:

In one way we're asking them (teachers) to be accountable and it hurts a little, because it's another task. But in another way, teachers are having conversations about student progress and valuable learning is going on about changing teaching.

Accountability at Sierra is fully integrated into the annual planning cycle illustrated in Figure 5. All governing groups at Sierra, and thus representatives of all stakeholders, are involved at various points in this process of analyzing site needs, developing and revising the plan, monitoring its implementation, and evaluating the results at the end of the school year.

The plan is based on district standards, and Sierra's site-developed assessments are used as measurements for the language arts and mathematics benchmark indicators. Key observable behaviors in the academic components identify basic learning experiences for all students, interventions for students in need of assistance, and essential support activities for staff and parents. Other sections address site needs relative to staff development, integration, and governance. Procedures for ongoing monitoring are built into each section, with oversight by design teams, grade level teams, the governance team, and support staff. The end-of-year evaluation process includes the identification of areas for recognition and intervention, and reporting out the results to staff and community. Thus, the Annual Action Plan is truly Sierra's site accountability document. 


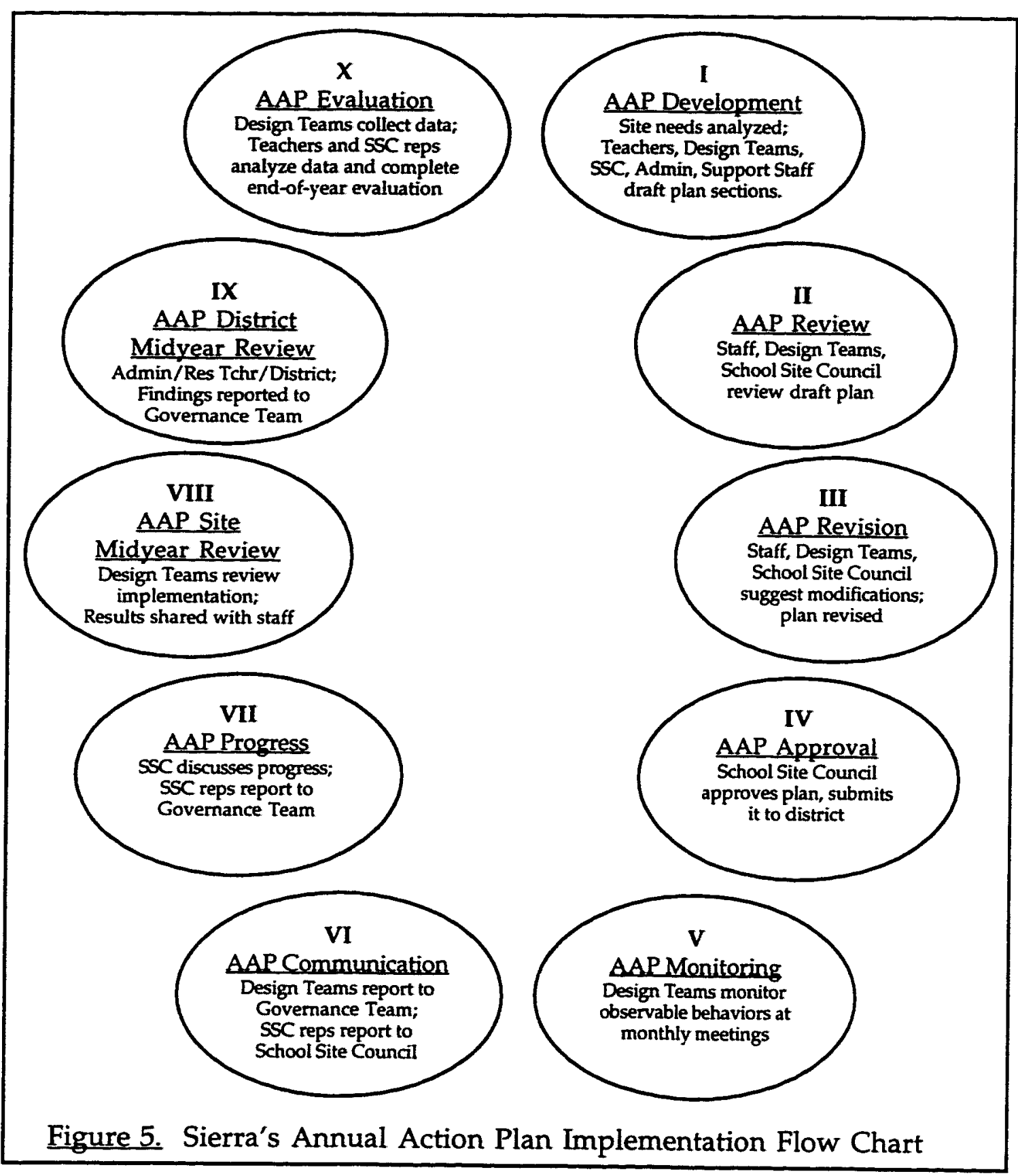

\section{Sierra: A Continuing Saga}

In January 1995, in an open letter to the board of education and the superintendent, Sierra's principal expressed the following:

We have been fortunate to be affiliated with the Leadership in Accountability Demonstration (LAD) Program. Through the LAD 
experience great insight has been gained in the areas of standards, assessments, recognition and intervention, and public reporting. The LAD program has provided us with the support, guidance, and resources needed to accomplish this endeavor.

In November 1996, Sylvia wrote another letter to the president of the school board and senior district staff, promoting the developments in assessment and accountability that have taken place at Sierra over the intervening years. This letter also announced that the school is turning its attention next to the intervention process, including determining rewards and consequences for teachers and students relative to student progress.

Despite the school size, despite the complexities of schedule and organizational structure, Sierra Elementary has completed a tremendous amount of work over the past six years-before, during, and since the LAD project. Sierra staff members have created a school culture that expects and supports student achievement through an integrated approach to curriculum, instruction, and assessment. Teachers have been encouraged to use their professional knowledge and skill to develop the site assessments; make presentations to other teachers both on- and off-site; and engage in ongoing, informal conversations about student work and about teaching. Accountability appears to be embedded into daily activity even when the word itself never appears in the conversation.

What will be next for Sierra? As Kent said, "it is a process and an evolution." We will simply have to wait until a sequel is written. 


\section{Paloma: Reform Meets Reality}

"Expect Excellence," declares Paloma's school motto, and make decisions "in the best interest of children." Those philosophies seem to be embedded into the school's approach to the educational process, and have thus carried it through significant changes over the past few years. Paloma's story tells what can happen when the drive for school reform runs headlong into the harsh realities that may enter the educational arena.

Paloma is one of many aging schools in the San Diego district; it opened forty years ago in what was then a baby-boom community of small homes and apartments. Over the past ten years, however, the surrounding neighborhood has changed significantly, with the multiunit structures swelling with immigrant and refugee families. In concert, Paloma's student population has ballooned as well, growing from 550 students in 1986 to more than 850 students in 1996.

The current ethnic distribution includes about 39 percent AfricanAmerican, 34 percent Hispanic, 18 percent Indochinese, and 6 percent White. This represents a major change from the 1986-87 school year when the student body was 22 percent African-American, 17 percent Hispanic, 29 percent Indochinese, and 27 percent White. Hidden in these numbers is an even more significant figure: Of the current 39 percent African-American students, about one-third are Somali refugees who arrived in the country and at the school within the past three years. With these new Somali students, combined with an increase in Hispanic immigrant students, there has been a 
corresponding growth in the percent of students who are limited English proficient: from about 44 percent in 1990-91 to more than 70 percent in 199596. Paloma's students speak more than 20 languages, with Spanish, Somali, Cambodian, Hmong, Lao, and Vietnamese the most predominant. (See Appendix F for a complete profile.)

This multiracial, multiethnic, multilingual student population led to the recognition that new ways were needed to organize and manage the school, involve parents and community, teach children, and document student learning. The usual classroom structures, standard curriculum materials, traditional instructional practices, and typical ways of measuring student academic achievement simply did not match the unique needs of Paloma's educational community. Thus, when a new principal came on board in 1990, the time was ripe for change.

Becoming a LAD School: Reform Times Three

The Leadership in Accountability Demonstration (LAD) School program came along when Paloma was already well into a process of school reform. Reform \#1 brought the Comer School Development Program to Paloma, Reform \#2 linked Paloma with the National Alliance for Restructuring Education, and the LAD project became Reform \#3. Why reform times three for Paloma? Clark was the former principal who initiated these reform efforts; he subsequently left the school in October 1995 for a position at the central office. He commented, during our interview, that "I went into the school with a vision and didn't want to fix the school 
piecemeal-I wanted to restructure the whole school." Helen, one of the teachers, remarked that he was "one of the forerunners, leaders, always looking for programs that would address the needs of the children."

Reform x 1: The Comer School Development Program. In 1988, when Clark was vice principal at another district school, he had an opportunity to hear James Comer speak. Comer's philosophy, grounded in the belief that quality relationships among students, school staff, and parents are essential to school success, seemed to be exactly what Paloma needed. Thus, when Clark became principal at Paloma in 1990, he brokered the process of adding the school to the district's group of Comer sites.

The Comer program, noted Clark, is a "management model but more importantly it's a model that brings all stakeholders together, specifically parents and community and teachers ... to really build strong relationships around a positive school climate." Nine components comprise the Comer model: three mechanisms, three guiding principles, and three school operations (see Figure 6). As described in Paloma's school brochure:

The Comer School Development Program (SDP) uses principles of child development and relationships as a basis for school management. School staff and parents combine talents and interests, forming a balanced group that develops policies, procedures and programs.... The result is a focus on the child as the center of the educational process, and a friendly, caring and nurturing environment for teaching and learning. 


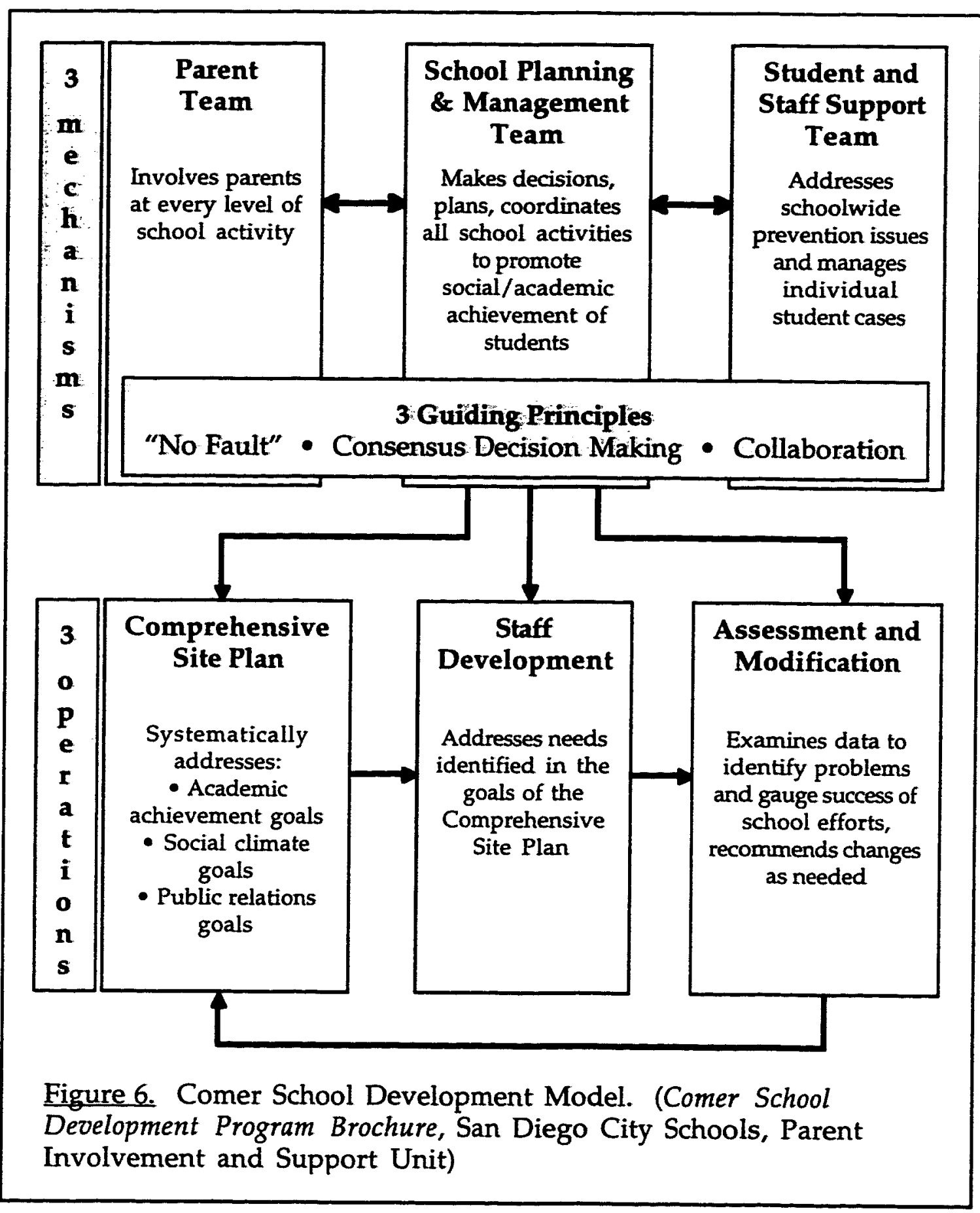

Clark reported that the Comer guiding principles became ingrained at Paloma. "You operate with collaboration, and the no fault policy would get us ... into a problem-solving mode. We really were able to stay focused on 
what needed to be done, and that all decisions are made in the best interest of the children."

The Comer model also led Paloma to focus on the critical involvement of parents and family in the education of children; and helped the staff create structures and processes to meet the very complex personal, social, and academic needs of the student population. Toni, a parent leader who has been active at the school for many years, commented:

I'm in love with Comer.... It's been the glue that has held the students, parents and staff together.... It's just that extra kindness and consideration in looking at the whole child, understanding their home environment has something to do with what they bring to school.

Helen, who has been at Paloma only four years but has taught for twenty-five, added that, "I think Comer for one thing had a big impact. . . . I think everybody has that 'it takes a whole village to raise a child' attitude."

Reform $\times$ 2: The National Alliance for Restructuring Education. In 1991, not long after Clark brought the Comer program to Paloma, he heard about another opportunity to involve the school in a cutting-edge reform effort. The district, with several of its schools, joined the National Alliance for Restructuring Education. What did that offer to Paloma? First, noted one of the lead teachers, it allowed a group of classroom teachers to join educators from across the country in "professional discourse about what we are in the business of doing. ... They need to get us engaged at that level of discourse if they really want educational reform." 
Second, it provided an organizational structure that could be integrated into the Comer management model to further involve staff in focused decisionmaking. As a result of the direct involvement with the National Alliance, Paloma was one of the first district schools to organize teachers into decisionmaking teams around the Alliance's educational design areas: curriculum, instruction, and technology; assessment and accountability; health and human services; public engagement; and high performance management. (Paloma's use of the design teams will be discussed in the section on decisionmaking and governance.)

Finally, the National Alliance also offered a set of content standards and benchmarks to the teachers at a point when they felt they did not have the time or energy to create their own. As Clark reported, we "didn't think it was necessary to reinvent the wheel so we basically adopted the language arts, math, and school-to-career standards to start giving us a feel of-here are the content standards, what does this mean and what's the next step?"

Reform x 3: The LAD Program. In 1993, when the Leadership in Accountability Demonstration School program appeared, Clark knew their "plate was full." But he also saw one significant hole that neither Comer nor the National Alliance had filled: assessment appropriate to the special needs of Paloma's limited English speaking and highly mobile student population. Comer, he observed, was primarily a management model; besides, its origin on the east coast with predominantly white homogeneous student populations led to a focus on using data from norm-referenced assessments 
in the decisionmaking process. Yet a significant portion of Paloma's students do not even take standardized tests due to their limited English proficiency. The National Alliance offered content standards, but Clark still felt that the school needed support with alternative assessment, particularly as the teachers had just begun to tinker with portfolios.

So in the spring of 1993, Clark sent the Assessment and Accountability Team members to the district orientation on the LAD program. He reported that "they came back and said we definitely need to be involved in the LAD program" to take advantage of the opportunities for training and support. An eight member leadership team-the principal, four teachers, two classified staff members, and a parent-attended the spring 1993 training and started Paloma off as a LAD school. Andrea, one of the teachers on that team, commented:

The first few meetings they were talking about teachers are going to have to be accountable for student achievement-what a concept! ... But if you're going to take responsibility for their achievement, you have to look at the whole picture.

Thus a primary focus for Paloma, with the LAD project, became student portfolios-how could they expand and refine their fledgling system into one that would authentically assess student performance and progress? Under the guidance of the Assessment and Accountability Team, teachers developed menus for student literacy portfolios in alignment with developmental literacy continuums the school had adapted for use with both 
fluent English speaking and limited English proficient students. The portfolios would be able to reflect student capabilities in both the acquisition of language as well as the development of literacy. This expanded the next year into guideposts for student-led portfolio conferences. The idea was to ultimately have portfolios where teachers could document student progress, as well as actively involve children in the process of selecting work, reflecting on that work, and using the portfolio to show their teachers and their parents what they have learned.

Paloma's Assessment and Accountability Team also became interested in a related arena while working on recognition and intervention, a difficult element of accountability for many schools. Most schools had in place various mechanisms for student recognition and intervention, but applying those concepts to teachers was much more difficult. Paloma chose to investigate the idea of professional portfolios as a way to recognize teacher strengths and identify areas that need support. This led to the Professional Development and Accountability Model (PDAM), which became an option for the teacher performance evaluation process. Teachers who chose to participate would maintain a professional development portfolio with three exhibits-student learning, teacher learning, and professional outreachdocumenting accomplishment of selected professional standards. At the end of the school year, they would present the portfolio at an assessment center to a panel of trained staff and community members who would evaluate the presentation and the portfolio using a site-developed five point rubric. 
The PDAM model was field-tested in 1994-95, with several teachers developing professional portfolios; however, the assessment center was not put into operation. More teachers indicated an interest for the 1995-96 school year, and the assessment panelists had been identified but not trained, when Clark left the school. With the change in administration along with an influx of new teachers, the process was never completed. However, those teachers who prepared teaching portfolios found them extremely valuable. As Andrea, who chose to leave Paloma this year, commented, "a lot of us put our portfolios together and went around the district, and when we were looking for jobs at the end of the year, people's mouths just dropped open." Teaching and Learning

Paloma's story of reform thus incorporated the LAD project into a series of events that led to significant changes in the way the school was organized and managed, the expectations for student learning, and the assessment of student progress. So what actually changed at the level of teaching and learning? According to a poster prominently displayed around the school, Paloma underwent a paradigm shift (see Figure 7).

From isolation to collaboration. "Paloma went from a school where teachers worked in isolation," commented Clark, to one with "a lot more collaboration." When he came to Paloma, classrooms were separated by program with little cross-communication or integration of students and teachers among the fluent English, sheltered, and Spanish bilingual programs. To break down those invisible walls, Clark said he "started by 


\begin{tabular}{|c|c|}
\hline FROM & TO \\
\hline Individual subjects & Integrated learning \\
\hline Textbooks, dittos, worksheets & Manipulatives, references, videos \\
\hline Competitive learning & Collaborative learning \\
\hline Curriculum-centered: & Student-centered: \\
\hline Student fits the mold of the school & School meets the needs of the child \\
\hline Memorization & Understanding \\
\hline Hands-off: passive & Hands-on: active \\
\hline Quiet, in seats & Noisy, in communication \\
\hline Tracking, ability grouping & Heterogeneous grouping \\
\hline Grade reporting: A, B, C & Portfolio conferences \\
\hline Teacher rules & Class rules \\
\hline Teacher: Sage on Stage & Teacher: Guide on the Side \\
\hline Three Rs driven: & Three Cs driven: \\
readin' - 'ritin' - 'rithmetic & curiosity, creativity, communication \\
\hline
\end{tabular}

\section{Figure 7. Paloma's Paradigm Shift}

identifying grade level coordinators and holding grade level meetings that were across teaching assignments."

Within two years, after many teachers had participated in training on developmental learning, the school was restructured into a primary school (grades $K, 1,2$ ) and an intermediate school (grades 3, 4, 5). "Out of that," Clark noted, "came the cluster concept ... where children were mixed for portions of the academic day and academic week around strategies that really embraced academic learning." He also commented on the benefit to teachers:

There was planning time for teachers to look at student work and plan thematic units and to just talk and reflect about what they were doing, what worked and didn't work.... It became contagious because 
teachers would share their successes.... It's much more fun to teach together than to teach in isolation, and I think teachers were seeing that. They were sharing ideas and expertise.

Benefits to teaching and learning. Currently, classes at Paloma are organized according to language fluency for the portions of the day that focus on literacy and mathematics. There are classes for fluent English proficient students, students who need sheltered English instruction at different levels, students who need primary language instruction in Spanish, and newcomer students who speak no English and have little or no prior schooling. Through the clusters, however, teachers team together in groups of three to four, and for several hours a week they mix students from the different language fluency levels for instruction in areas such as science, social studies, art, and music.

The cluster approach provides several benefits to the teaching and learning process. First, it supports English language development by providing limited English students with the role models of other teachers as well as fluent English students. Second, noted Helen, "it allows you to have integration. ... As a cluster, we work together to try to get the children to get along with each other and to integrate, something where they have to interact using cooperative group strategies and try to get them to communicate with each other." Toni, the parent leader, loves the "cooperative learning (that) is going on ... they are learning how to get along with one another and how to work in a team and not so much individualism." Third, as Andrea observed, 
the cluster mixing process allows students to experience different teaching styles, teacher personalities, and teacher instructional strengths.

From teacher development to student development. The various reform projects also provided a variety of opportunities for training and professional growth, which further impacted teaching and learning. Many teachers were able to visit other schools in the district, travel across the country to receive training and attend conferences, and engage in conversations with other educators. Through the Comer project, several teachers visited schools and attended training on the east coast; through the National Alliance, teachers participated in major national conferences with teams of classroom teachers and district personnel; and through the LAD project, teachers met in focus groups with their colleagues from other schools. Barbara, one of the Alliance lead teachers, mentioned that "often times we go to teacher supply stores and we grab those advantages, and we never have the opportunity to have the philosophical discussion on which to base our teaching." Paloma's association with these various reform efforts, along with encouragement by the site administration to seek out professional development opportunities, allowed classroom teachers to feel valued and to grow personally and professionally.

Clark, former principal, said that he encouraged teachers to "be risktakers ... I saw teachers trying things, bending procedure a little bit, trying different things to see if they would work." Many teachers were trained in developmental learning, which had a major impact on both school 
organization and classroom practices. Andrea observed, for example, that "I found out that noise in the room actively engaged learning." Barbara added that the developmental model meshed well with Paloma's philosophy and with the unique student population:

What's important ... is where you started and where you ended up, was there progress? ... I think it took a lot of pressure off the teacher, I think it took a lot of pressure off the children, and I think as a result, people loved learning more and loved teaching more and I think more learning and teaching was going on.

Authentic assessment, authentic learning. Finally, the focus that LAD brought to authentic assessment through portfolios also began to carry over into the teaching and learning process. As noted, a major impetus for Paloma's involvement in this program was the recognition of a need to find different, more authentic ways to assess the progress of the highly mobile, mostly limited English speaking students. The portfolio process has been developmental over the past several years, moving from general collections of student work toward a defined menu of elements. Allison noted that, for this year, a collection schedule has been delineated, and Helen explained that they are working on rubrics for consistent schoolwide scoring. The portfolio process has also included student reflections and student-led portfolio conferences with teachers and parents.

Having structured student portfolios directs teaching and learning to at least some degree; teachers have to provide instructional experiences that 
give students the opportunities to produce the designated products. Since a primary focus at Paloma is English language development, Helen noted that this year portfolios will include videotapes of student oral presentations. Therefore, classroom lessons must give students practice in oral language and in presentation skills. At the upper grades, she noted, students must write a research report to include in their portfolio, so teachers must organize instructional units to help students learn research and report writing skills.

Engaging in a portfolio conference is another significant learning experience for children, particularly those who have had limited opportunities to be actively involved in their own learning. Andrea commented that, "it really made them aware of their own successes ... you want to put things in this portfolio that any stakeholder, any person could come in and say, show me who you are, show me what you do in the classroom, and you'd be able to show that off just by opening your portfolio." Clark observed that, "at the portfolio conferences, you know kids are learning when you sit down and watch a child lead a conference, and be able to talk about his or her learning, and show examples that really show progress."

Professional portfolios can also influence the teaching and learning process. According to site documents, teachers were told that "the teaching portfolio should accurately depict teaching and learning in your classroom." These portfolios could include assignments, lesson plans, and student work samples. They were expected to address literacy instruction; illustrate how students are involved in integrated, cooperative, multi-ability groupings; and 
show how students demonstrate knowledge in ways other than traditional tests. In addition, teachers were asked to complete reflective writings about the lessons and activities conducted in the classroom. Preparing this type of portfolio is bound to influence classroom instruction. If Paloma returns to the Professional Development and Accountability Model, or at least to having teachers maintain professional portfolios, there are inherent opportunities for further changes in teaching and learning.

\section{Decisionmaking and Governance}

"This is our school," asserted intermediate grade teacher Marie, "and we have a right to make part of the decision." With this philosophy echoed in other interviews, it appears that teachers feel they have significant opportunities for involvement in decisionmaking at Paloma. Along with that involvement, however, come the trials and tribulations of the shared decisionmaking process.

Governance structure. Paloma's governance process melds the Comer management model, the National Alliance design tasks, and the teacher clusters into an interactive system of communication and decisionmaking. Figure 8 illustrates the basic structure.

- School Planning and Management Team. The SPMT has responsibility for broad, schoolwide issues. Marie, the current chairperson, indicated that the "SPMT is basically for deciding curriculum, and health and safety issues at the school," things that have schoolwide implications. Allison observed that "I see that the SPMT is really starting to focus on the 


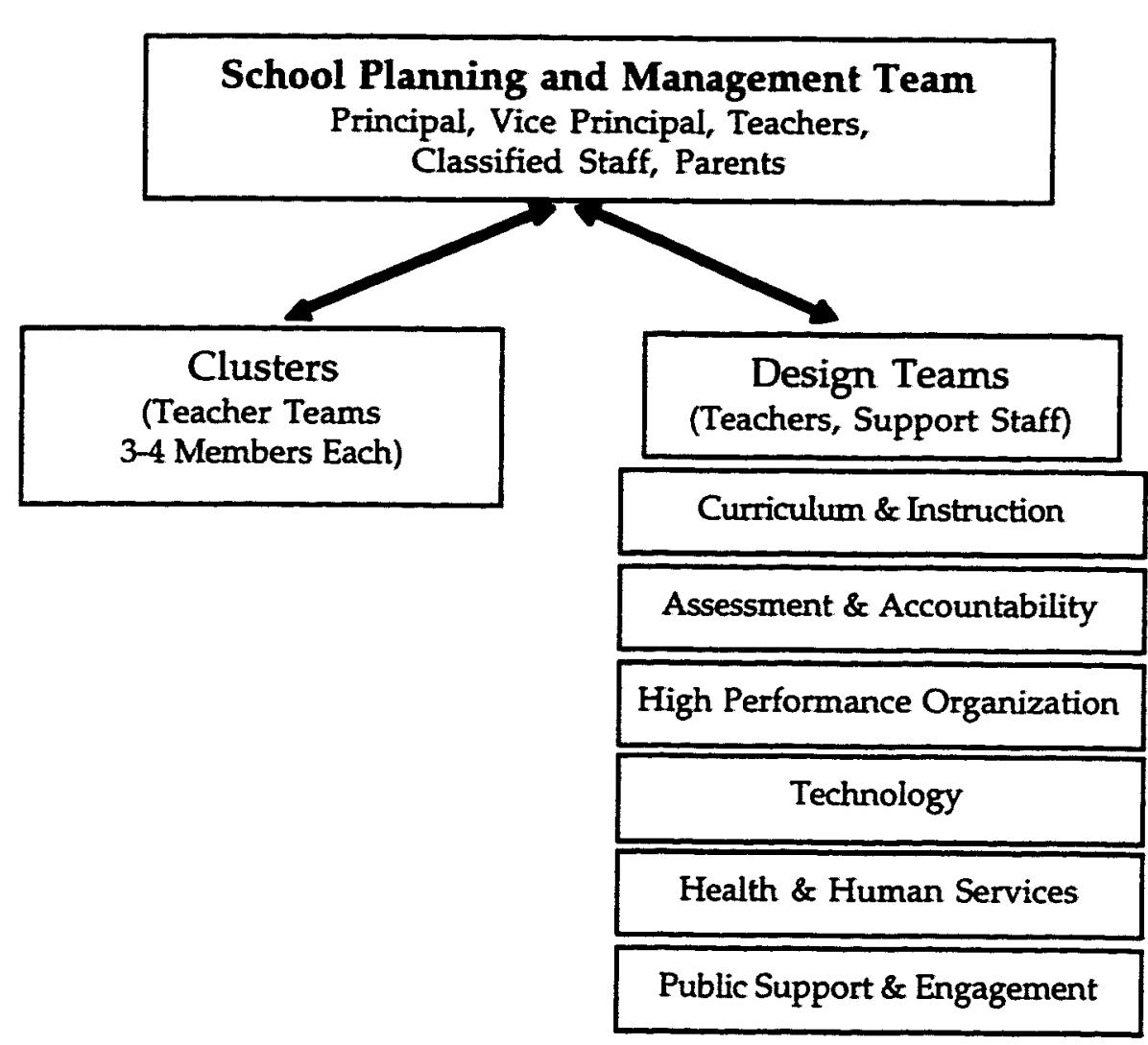

Figure 8. Paloma's Governance Structure

crucial issues of curriculum and instruction and student achievement, whereas before, I think a lot of time we were off track with that and we were going to other issues other than the crucial, most important ones." To help focus the group's attention, anyone who has an item for SPMT consideration must submit a concern form to the chairperson, who meets with a small group to set each meeting's agenda. Items submitted may be addressed by the SPMT, or may be referred to another forum such as a design team, a particular cluster, or the administration.

The SPMT has teacher representatives from each cluster and design team, as well as classified staff and parents. Toni, the parent I interviewed, 
was a former co-chair of the SPMT. She felt that the current committee is very active, noting "there must be at least fifteen teachers that attend each meeting, and then the administration is there ... and we're getting a nice group of parents, finally." However, Vicky, the current principal, and Marie, teacher and current chairperson, both commented that getting parent representation on the committee has been difficult and complicated by issues of language and culture.

The School Planning and Management Team operates under the guiding principles of the Comer model: no fault, consensus decisionmaking, and collaboration. This encourages a solution orientation to problem solving; rather than spending time assigning blame, ideas are proposed until a resolution is reached that people can live with. Teachers I interviewed indicated that the process works well. Toni, former co-chair of the group, commented that "there is a lot of respect, collaboration. ... Consensus works as far as our team goes in making a decision. ... There are no winners, there are no losers, and I think that's real important." Tammy, a teacher and former co-chair with Toni, concurred: "I could say, that's right ... we're going to arrive at consensus and we aren't going to vote on it. And no fault is brought up often."

I saw the process and the philosophy carried out in practice during the SPMT meeting I observed. Throughout the meeting, the fourteen teachers, support staff, and parents present were attentive, respectful, and on task. At one point, an issue of obvious concern was under consideration. The 
discussion proceeded, however, without blame and with a solution orientation. Someone suggested, "can we help out, think of some ideas?" Members admitted there was a problem, suggested ideas and solutions, decided on a course of action, and volunteered to take responsibility for what needed to be done.

- Design Teams. Paloma has taken the five National Alliance design tasks and used them to organize teachers and support staff into six design teams. In order to direct their efforts, the design teams select an area of focus each year, then do research, discuss ideas, propose solutions, and ultimately present suggestions to either the whole staff or to the SPMT.

Sandra, who is on the Health and Human Services Team, commented that her committee worked on a safety issue-gates in the kindergarten area-which involved going to get financing information, then presenting a proposal to the SPMT. She added, "I think ... it gives you a better idea of what is involved" in the decisionmaking process. Tammy recalled that last year the Curriculum and Instruction Team organized the training on portfolios, pushed for getting a schoolwide math program, and arranged to have a variety of books made available to teachers for check out. As indicated previously, the Assessment and Accountability Team served as the leadership team for the LAD project and coordinated site work on both student and teacher portfolios.

The ups and downs of shared decisionmaking. Paloma, like Mariposa and Sierra, has also discovered that participatory decisionmaking has its good 
points and its difficulties. On the down side, shared decisionmaking can be a slow process. Andrea expressed considerable frustration with the fact that "nothing ever happened fast enough." Helen remarked that, "I like site-based decisionmaking but I can't stand these meetings ... you want to have input on the decision (but) some of the meetings just seem to drag on and on and on, and you have to revisit issues." Vicky, the principal, added that reaching consensus sometimes takes a great deal of time and patience.

On the positive side, shared decisionmaking engages teachers in the process of influencing their working environment. Barbara, a former teacher, indicated that "I knew my input was meaningful and was listened to. ... I liked finding information and bringing it back to the other teaching staff." She concluded that the work of teachers was indeed influential, saying "I saw too many changes happen as a result of the input of my committees." As Marie, the SPMT chairperson, commented, "if I'm not involved in the decisionmaking, I can't bitch about anything that is happening." And she also feels that the School Planning and Management Team does "a good job of making decisions. We don't have a lot of stuff that comes around and around. ... I think we are good at making decisions. It's easier to do that because of our investment in the kids."

\section{The Challenges of School Reform}

Paloma has encountered multiple challenges over the past several years. Student demographics have changed significantly. There were perhaps too many new programs in too short a time. Teacher turnover has meant 
continuing staff have to revisit their work to bring new teachers up to capacity. Together, these issues have challenged the school's attempts to engage in, and maintain, systemic reform efforts.

A new kind of newcomer. The Paloma community has been home to many immigrant populations over the past ten years, but none so demanding as the recent arrival of Somali refugees. When asked about the major challenges facing Paloma, interviewees responded:

- "It's the change in population, the big influx of Somalians in the last three years, had an enormous effect on this school. There are so many special needs that we were totally unprepared for.... They are refugees, they've gone through things that we have no concept of, they have lived through trauma, living in refugee camps where family members have been killed."

- "Getting war refugee children ... suddenly this child who has been stepping over dead bodies turns up on your front porch and is punching the hell out of everybody else."

- "We would find incredible things in these students' lives which really impact their achievement."

- "The influx of Somali students changed the complexion a lot.... I used to think there is somebody in Somalia standing there with a sign saying, go to San Diego and when you get there go to Paloma."

The arrival of this new kind of newcomer brought challenges of culture and language complicated by exceptional emotional issues and needs. It has resulted in major classroom reorganizations, changed the nature of the 
cluster mixing and integration activities, even led to the creation of new lessons on things such as bathroom hygiene. There have been more frequent playground altercations, including racial conflict between the AfricanAmerican and Somali students. The counseling and administrative staff have spent a great deal of time dealing with discipline as well as with the psycho-social needs of the students and their families.

With all these issues, it's not surprising that, to many teachers and staff, "some of the big reform issues are really hard to grasp and follow through on because you don't have the time and energy." As Marie continued, "I guess what I'm saying is, reform takes a back seat. I mean, reform is happening, but there are other things happening too."

Too many programs, too much confusion. "Let's just not do so many things," requested Sandra. "We don't need to do everything, just a few things and do them very well and thoroughly and with quality." "Just focus on certain areas," echoed Helen. "Start with one area that needs reform and work, and stick with it." Another significant challenge of Paloma's engagement with school reform was the multiple projects themselves. Teacher leaders were pulled in many directions, and other staff were often confused about exactly what the focus was supposed to be.

Those directly involved in each project saw the value and benefited personally from the experience of attending training or visiting other sites. But they often struggled to translate their enthusiasm and their ideas to the rest of the staff, who were trying to learn about the various projects, connect 
them together, and make them meaningful in the context of their classrooms. As Helen commented, "I think part of our problem is a lot of people didn't have time to research and read and study whatever it was that we were meeting about that particular day because they had five other things going on. ... Comer, what are we doing today, developmental learning, what are we doing today?"

With the LAD project, the leadership team expressed frustration with the lack of clarity at some of the training and the confusion over terminology. Andrea commented that "even the LAD trainers seemed to be struggling." Gene added that "we wanted to bring LAD back to the school (but) we didn't have the time or the expertise to explain what it was ... people didn't really understand because we barely understood it ourselves." Clark, the former principal, summarized the frustrations:

A challenge that we felt with the LAD program (was) there were so many changes in terminology for the longest time. There were times when we thought we had it and we didn't ... and that kind of slowed work and understanding, and it probably impacted the enthusiasm for a while. ... We felt like people that were telling us and giving us guidance in the LAD program weren't quite sure either because things were changing so much.

Teachers come, teachers go. Complicating the efforts to embed reform work into the basic operation and culture of the school was the significant annual teacher turnover. Following the 1993-94 school year, more than a 
third of the teaching staff changed, and each of the next two years brought from fifteen to eighteen new teachers to the school. Many of these teachers were inexperienced and unfamiliar with Paloma's situation. Former principal Clark observed, "that just kind of put our work back, put our work at a standstill ... trying to bring them up to capacity on what was happening." Helen echoed that thought, saying "it's kind of like we started off in full motion and all of a sudden we had to back up a little bit."

In addition, those who left were often teacher leaders who were feeling the burnout of spending many hours above and beyond the call of duty, complicated by a difficult student population; they were ready to move on to new experiences. Clark, the former principal, thought that he created many teacher leaders who "would hold on to the beliefs that we created years ago, and that were connected with the national initiatives enough to know where to go with them." But he added "my next thought ... is the burnout of these teacher leaders ... the burnout to sustain the systemic change at a school." $\mathrm{He}$ also noted that, "most significant is teachers who were trained in developmental learning and Comer and National Alliance and LAD and had professional portfolios . . became very marketable." Indeed, by the 1996-97 school year, none of the teachers from the original LAD leadership team remained at the school. "There aren't," Clark observed, "a lot of incentives to keep teachers at a school like Paloma."

Where's the support? Paloma teachers asked about district support, just like their colleagues at Mariposa and Sierra. But at Paloma, the requests 
include not only support for LAD and the other reform projects, but also assistance in dealing with the daily realities at the school.

Several of those interviewed questioned the follow-up for the early reform projects in which Paloma participated. While they believe the Comer project has continued strongly, and there are ongoing opportunities for training and support, they feel like the district dropped the ball relative to both the Alliance and to LAD. Toni, the parent leader, commented on the National Alliance: "I don't hear anything from them (for) probably two years. .. They worked with us for a short while and we have heard nothing." Barbara echoed those feelings, saying "I felt very bad that nothing more has been done. Apparently the association was put on hold, the district didn't sponsor anyone to go to last year's conferences, or at least anyone at the classroom level.... I felt really bad that the National Alliance connection was broken."

Through the LAD program, the school team attended training and received considerable support during the first year, but team members also noted that they had to immediately turn around and act as trainers for the second group of schools the next year. While leadership team members noted that this helped them internalize some of the ideas, Clark also observed that "teachers feel that was really a lot on them to prepare to do that." In addition, when the program ended after the second year, the support system that had helped to maintain some of the energy and effort ended as well. 
But beyond the reform projects themselves, many of those interviewed questioned where the district was as they faced the influx of refugee families and where the district is now as they deal with an overcrowded and deteriorating physical plant. Sandra noted, during our interview, that "I don't think very many people from the district come out here to see what it looks like." Marie added, "Why isn't anyone from the district interested enough to come down here and spend the morning?" Their issues and calls for help range from assistance with primary language instruction and translation to the need for more social services and improved facilities. Toni, the parent leader, added that "I don't think the district really understands what's happening.... There is no one on any level that I could go to who would tell me, everything is going to be okay ... we know what we're doing."

Facilities are a particularly touchy issue at Paloma. It is an aging school that was built to house a much smaller student population. The lunch area and cafeteria are too small; more than half the students are in portable classroom buildings with no water access and only one nearby bathroom facility; the teachers' lounge cannot even hold the entire teaching staff for meetings. As Clark concluded:

(There need to be) set standards of equity for all schools.... The whole facility plant (should be) something that first of all is safe and a healthy place for kids and staff to be, attractive and a focal point of the community, and teachers can have buy-in in being there and spending their professional life there. 


\section{The Successes of Paloma's Involvement in School Reform}

Despite these significant challenges, Paloma staff found many positive things to share about their engagement with school reform in the face of adversity. The reform projects gave staff time and opportunity to talk about educational issues and to network with colleagues across the district and the country. Teachers are energetic and dedicated, and always looking to help the students, their families, and the community. Above all, they feel they make things work for the kids.

Time to learn, time to share. As reported previously, through their involvement with projects such as LAD, the National Alliance, and Comer, many teachers had opportunities to talk together, converse with other educators, and visit around and outside the school district. For teachers who have traditionally been isolated within their own school, and often their own classroom, this is a significant change. Tammy commented that, "I don't think we could have had these discussions at the level that we had them at without the people who had gone through the training." She also added, "I didn't realize how much I had picked up (until) I realized half way through a meeting that year, I've been working with this and this is now something that is part of my knowledge."

Barbara, as I noted earlier, was highly positive about attending National Alliance conferences and engaging in dialogue with national leaders as well as principals and classroom teachers from across the country. Andrea loved having the opportunity to attend conferences and visit other schools 
through her association with the Comer project. And Clark said that "one of the key things with LAD was the ability to talk to other schools and to laugh with them and cry with them and share your frustrations, but also to really learn from them."

Again, these opportunities had many influences on the school: they led to structural reorganizations as well as changes in the teaching and learning process. They also created a strong core of teacher leaders, building capacity from within the staff to carry on the visions and the work.

It takes a pioneer spirit. When asked about the strengths of Paloma, new principal Vicky responded, "the biggest strength is the staff. ... (They) are extremely dedicated, extremely committed individuals and they have sort of a pioneer spirit about them that says we're here for the kids and we'll do anything it takes." Tammy added that "the people ... have the energy and enthusiasm, we actually have lectures by the VP about not working from dawn to dusk." Helen, a teacher for 25 years, perhaps summarized it:

I see people willing to share and reaching out to help each other when there are problems.... We've moved from teachers who aren't willing to go out of their way to do extra things for kids and now we're seeing more people willing to give an extra hand beyond the regular work day to help involve the parents, involve the kids, and meet the needs of the kids. ... I think everybody has that 'it takes a whole village to raise a child' attitude. 
Paloma's greatest success, observed Allison, has been "making a campus with this many students from so many backgrounds work as well as it does." She added, "I've just seen a real pulling together. ... I think there is hope for Paloma." Andrea simply concluded, "I think we were all really good for the kids. We gave them stability and mutual respect and love." Paloma staff members are often blazing new trails, under difficult conditions, but their desires and hopes for the children give them the energy and motivation to keep moving forward.

\section{Variation: It's the Vision Thing}

Paloma had many experiences that were unique among the schools in the LAD project. They were engaged in several simultaneous reform efforts. They also had the significant challenges of student demographics and changing teaching staff. What led to the success of some of their efforts and the discontinuation of others? It appears to be that vision thing.

"I went into the school with a vision," recalled Clark. "I didn't want to fix the school piecemeal, but I wanted to restructure the whole school." It was that vision that led to Paloma's engagement with three major reform efforts. As Barbara said, "he went out there, he sought out the programs, he went to the conferences, and came back with the vision and sold it to us." "He knew where he wanted us to go," added Andrea, and "he was going to allow us to figure how to get there."

Some "real changes happened," remarked Barbara, because teachers internalized that vision, took on the challenges, influenced the process, and 
maintained the focus. The School Planning and Management Team from the Comer model and the design teams from the National Alliance became part of the basic school governance structure. The Comer principles of collaboration, no fault, and consensus, as well as the basic philosophy of actions in the best interest of children, became embedded into the school's belief system and its decisionmaking processes. Student portfolios, nurtured by the LAD project, became a part of every classroom.

Why didn't some of the other significant work continue, such as the Professional Development and Accountability Model and the professional portfolios? Again, it may be the vision thing: Some projects and philosophies, while close to the souls of a few, were not diffused enough among a critical mass of teachers, were not embedded into the culture of the school. So when particular key staff left, the vision-and the associated project-faded away. Andrea hated to see these things happen; she remarked wistfully, "it just seemed like we were on the verge so much of being great, of coming to incredible decisions and really being that school that stood out."

\section{Paloma: When Reform Meets Reality}

Paloma Elementary exudes dynamism; there is a sense of excitement and an energy on the campus. Staff members face significant challenges everyday: refugee students, language confusion, cultural conflicts, new teachers, dry dirt fields, inadequate facilities. Their best intentions clash with daily realities. But they continue to carry on, working together to solve problems in the best interest of children. It was energizing to attend the 
school's third annual literacy and mathematics exhibition last May-to hear the incredible babble of languages, to see children in shorts and T-shirts next to Somali girls covered in clothing from head to toe, to see students pulling their parents and friends along to see where their work was displayed, and especially to see children's academic achievement as the focus of a celebration.

Staff may not see Paloma's current culture grounded in their reform efforts; indeed, as Marie commented, sometimes "reform takes a back seat." But consciously or subconsciously, staff have drawn from each of the reform projects, and from deep within themselves as well, to demonstrate their personal and professional commitment to improving student achievement. Teachers strive to take the children from wherever they enter, and push and challenge them to reach as far and as high as they can. Andrea recalled her last class of students, some of whom she had for three or four years: "I got to see them start here and make it to there, and watch them struggle but to actually want to get there, and want to succeed, and do the best they could." That is an accountability culture in action.

\section{Summary}

Mariposa, Sierra, and Paloma Elementary Schools each took part in an adventure-the quest to establish a culture of student achievement accountability. At times their paths crossed while at others they branched off in different directions. This chapter told their individual stories which, while woven around common themes, vividly illustrate each school's unique experience. 
Central to these stories, whatever their differences, was one common thread: teachers coming together around an issue critical to their professional lives and the lives of those they touch every day. These teachers did research, engaged in discourse, created assessments, made decisions, evaluated results, faced challenges, and celebrated successes. Becoming accountable for student achievement, they found, is a process. It moves forward, it steps back, it goes off on side roads, it sometimes requires rest and reflection. It takes time, it takes energy, it takes nurturing. The entire educational community must commit to a great deal of effort, but all members of that educational community - teachers, administrators, staff, parents, students-also have a great deal to gain. 


\section{CHAPTER FIVE}

\section{CROSS-CASE ANALYSIS}

\section{RESTRUCTURING, ACCOUNTABILITY, AND SCHOOL SITE LEADERSHIP}

\section{Introduction}

Mariposa, Sierra, and Paloma Elementary Schools were three of the original ten schools in the Leadership in Accountability Demonstration (LAD) School project. These ten sites volunteered to help design a "prototype system for understanding, developing, and reporting accountability for student achievement across the district" (Student Achievement Accountability Committee, 1993, Appendix D, p. 1). The LAD project provided them with a sketch, but not a detailed blueprint. Each school had to use the knowledge and strength that came from the individual and collective experience of teachers and administrators to create their own plans, draw their own maps, and thus proceed on their adventures. In doing so, the schools engaged in a process which exemplified the intersection of school restructuring, accountability, and leadership.

The literature on school restructuring and educational accountability laid the groundwork for this investigation. The study's methodology-openended interviews supplemented by participatory observations-evoked a wealth of data that led to the creation of rich descriptions and interpretations. Chapter Four told the schools' individual stories around six themes: how 
they progressed through the project, changes that emerged in teaching and learning, the decisionmaking and governance processes they embraced, the challenges they dealt with, the successes they celebrated, and the accountability cultures they created.

This chapter now presents integrative interpretations which weave together those individual stories with insights gained from the literature. It also introduces a discussion of school site leadership as conceptualized and practiced at three schools engaged in educational reform efforts for the improvement of student achievement.

\section{Becoming Accountable for Student Achievement}

On March 31, 1993, the Leadership in Accountability Demonstration (LAD) School project formally began with the first of five introductory training sessions for site leadership teams. District materials indicate that these initial workshops aimed to introduce LAD schools to the accountability process and help them begin to plan for implementation at their school sites.

The training built on current educational research relative to restructuring, accountability, shared decisionmaking, professional development, organizational development, and change. The first two sessions introduced participants to research on accountability, and discussed school reform, the change process, and communication structures. Days three and four focused extensively on the first two accountability elements: academic standards and student assessment. Day five addressed the final two elements of recognition/intervention and public reporting. Throughout the 
five days, school teams analyzed their sites' current status in relation to each aspect of accountability, and identified their site needs and organizational capacity to implement change.

\section{The Adventure Begins}

With this initial training, the adventure was underway. The Mariposa, Sierra, and Paloma leadership team members returned to their sites, talked among themselves, met with school staff, and began integrating the training direction into their own school cultures and prior work. As they set off on the accountability quest, their subsequent paths converged and diverged, but always wove around the basic guiding principles, the project sketch.

Becoming accountable for student achievement begins with the identification of what students should know and be able to do, followed by the determination of how well students are, indeed, demonstrating their acquisition of those knowledge and skills. Mariposa, Sierra, and Paloma engaged in different processes to address these two elements. All three found the direction and their efforts relative to the first-standards-both confusing and frustrating. But all three also honed in on the second-assessment-as the foundation of their work and ultimate success with this project. What Should Students Know and Be Able to Do?

"Standards-based reform requires that considerations of what students should know and be able and disposed to do should be placed at the center of reform efforts" (Lemahieu \& Foss, 1994, p. 17). San Diego's Student Achievement Accountability Committee identified standards as the first 
element of accountability, based on their research and on the district's association with various local, state, and national projects. At the time the LAD program began in 1993, a great deal of work was taking place relative to academic content and performance standards: The New Standards Project worked with teams from states and districts across the country; subject matter groups like the National Council of Teachers of Mathematics were disseminating standards for their content areas; the state of California had produced reform documents and curriculum frameworks.

The direction given to the LAD schools, at the beginning of the project, was to use these sources to guide their work at the school sites; indeed, most had already begun working with documents such as the California task force reports and curriculum frameworks. But suddenly they were also being introduced to a host of new terms: learner outcomes, benchmark indicators, observable behaviors. What, exactly, was the difference between standards and learner outcomes? What was to be consistent across the district and what were they supposed to develop for their school sites? What about the work already done at schools-where did that fit in? Many of the school leadership team members expressed frustration at what they felt were conflicting guidelines and confusing terminology.

Nancy, from Mariposa's leadership team, said that "in the beginning, a lot of it didn't make sense and the preliminary guidance was less than good." Gloria, one of her colleagues, added, "I thought it was very unclear in the beginning. We would come and go to these meetings and just look at each 
other and go, what are we doing?" Clark, Paloma's principal at the time, observed that "there were so many changes in terminology for the longest time-there were times when we thought we had it and we didn't, or we did. ... We felt like people that were telling us and giving us guidance in the LAD program weren't quite sure either because things were changing so much." Barbara from Paloma, who attended one of the early training sessions, was the most blunt. She recalled one session where two district staff members, both with doctoral degrees, reached a difference of opinion about one of the terms being used in the training:

These two doctors are arguing over the definition of what the hell a learner outcome or a benchmark or whatever it was-they're arguing over these terms, and those of us who are grunts who have been working away all day just tore up our papers and threw them in the air. ... (If) the experts can't agree, how can we be expected to do it? ... It led to a lot of frustration and hard feelings.

So the school teams struggled somewhat, especially the first few months. The terminology was new for everyone, even district training staff; thus it was hard to clearly articulate what, exactly, schools were to do and equally hard for anyone to know when it was right. But the struggle had a benefit: out at the schools, as they grappled, teachers and administrators began to internalize key concepts, and ultimately come together around what it is they thought their students should know and be able to do. They used national materials and state frameworks; they delved into reform documents; 
they integrated their previous work. From that developing awareness came, naturally, their steps into assessment, the next element of accountability. Assessment at the Heart of Accountability

It was the process of translating their ideas about what students should know and be able to do into ways of determining when students had acquired those knowledge and skills that seemed to center accountability in the school cultures at Mariposa, Sierra, and Paloma. All three schools placed assessment at the heart of accountability and focused much of their energy during the project in this area.

"The accountable school," notes Wiggins (1994, p. 17), "requires a credible approach to assessment." These three schools sought, with support from the LAD project, to find authentic ways to assess student achievement, based on what they want students to know and be able to do. Mariposa teachers spent a great deal of time working within and across grade levels to identify and prioritize what they really value in the areas of reading, writing, listening and speaking. Then, they worked to integrate those valued skills and attitudes into assessment instruments that would allow students to demonstrate their abilities through meaningful performances.

Sierra teachers, independently, went through a similar process of coming to agreement on grade level expectations then translating those expectations into assessment instruments, first in reading then in mathematics. Sylvia, principal at Sierra, recently wrote to a school board member that "what we assess shows what we value, and what we value we 
assess." The Sierra teachers feel that their assessments are excellent indicators of the content and skills they think are important for students to know and be able to do. Their assessments look different from Mariposa's, yet each address, according to staff members, important skills and knowledge. The assessments at both schools are administered and scored twice a year, by teachers, to help inform instruction and to document accountability for student progress.

Paloma teachers recognized that their unique student population required a different approach to assessment-a single instrument would not meet their needs. Thus they devoted their energies toward the development of a portfolio system which, through collected samples of student work, would allow children to demonstrate what they know and can do, and how they have progressed. This type of system allowed them to be sensitive to the documentation of student achievement across multiple levels of English language proficiency. It also helps them be accountable for student learning even when children may be at the school only a short time; portfolios align with a value-added approach to education which focuses on taking students from where they are and moving them along a learning continuum.

Sierra and Mariposa also have portfolio systems which build from their site-developed assessments and add other indicators of student performance. All three schools continue to work on refining these systems so that they better reflect important knowledge and skills, articulate from grade level to grade level, and illustrate and document student growth over time. 
Thus the LAD adventure began at these schools by addressing two critical elements of accountability-standards and assessment-which are central to its nature in the 1990s. The next question then becomes, what does this mean to teaching and learning? Were there changes in these core processes of schooling?

\section{Teaching and Learning}

Teachers were at the center of these schools' work with standards and assessment. They actively engaged in the experience of identifying what students should know and be able to do, and determining how to assess the acquisition of those knowledge and skills. It was through this activity that teachers took ownership of both the process and the products. But to change teaching and learning, and thus improve student achievement, this work must become directly and explicitly connected to the classroom. It must help teachers to refine teaching strategies and focus instruction.

Looking across the findings from these three schools, two common themes emerge relative to how their accountability efforts have influenced teaching and learning. First, staff at each school reported that the opportunities teachers have had to talk together about teaching and about student work have begun to impact what goes on in the classroom. Second, at these schools, it appears that assessment is no longer a practice divorced from curriculum and instruction, but one which is starting to be used to inform teaching and learning. 


\section{Talking Teaching}

Building practitioner knowledge and skills through collegial interaction is a critical concept in the professionalization of teaching. "True colleagues," observe Garmston and Wellman (1995, p. 11), "develop teaching materials together, plan together, seek one another's help, watch one another teach, and reflect together about their students and their teaching." DarlingHammond $(1988$, p. 39) thus comments that an essential task in a professional accountability model is to "create a professional culture within schools that will seek, transmit, and use knowledge as a basis for teaching decisions, that will support inquiry and consultation, and that will maintain a primary concern for student welfare."

One of the main values of the LAD project, according to teachers and administrators, was the opportunity it provided for collegial interaction, where teachers could talk together as professionals. Teachers, frequently, have been isolated in their classrooms; when they do come together it has often been to share horror stories about student behavior, swap art projects and worksheets, or bemoan a lack of instructional supplies. They have not been encouraged to share practices; indeed, it has often been threatening for them to do so (Hargreaves, 1995; Wasley, 1995).

Substantive conversations about teaching and learning require opportunity, safety, and rationale; the LAD project offered all of these. Teachers at each of these schools highly value the interactions they were able to have through their work with this program, whether with colleagues from 
across the hall or from across the district. As these opportunities began to build their sense of professionalism, they began to have some positive effects on the teaching and learning process as well.

Chris, former vice principal at Mariposa Elementary, noted that conversations among teachers, particularly during their grade level discussions, grew beyond focusing on things like bulletin boards to "talking about what children were doing and how they can improve it." Nancy seconded that idea, stating "in the past ... we focused on the cute part of teaching. ... Now it just works across the board where people are kind of indirectly sharing their expertise-there's a lot of modeling." At Sierra, even before the LAD project started, time was built into the staff development calendar for teachers to share teaching practices. The principal and the former resource teacher commented that this gave teachers both permission and stimulation to talk about student work and to focus on teaching strategies. And Paloma, noted the former principal, "went from a school where teachers worked in isolation ... to a lot more collaboration." Teachers had time, he added, "to just talk and reflect about what they were doing, what worked and didn't work... They were sharing ideas and expertise."

At each of these schools, teachers promote the continuation and expansion of the structures and practices which allow them to share and consult with their colleagues about student performance. This plays out through Mariposa's grade level teams and governance team meetings, Sierra's design teams and grade level meetings, and Paloma's teacher clusters 
and School Planning and Management Team. Through the discussions of teaching and learning they have in these settings, it appears that teachers have begun internalize a sense of professional accountability where, according to Darling-Hammond and Ascher (1991, p. 29), "practitionersindividually and collectively, through inquiry and consultation-continually seek to discover the most responsible course of action."

One element of the San Diego City Schools' definition, which grew from the work of Darling-Hammond and Ascher, states that accountability seeks to "ensure that students are exposed to good instructional practices in a supportive learning environment" (Student Achievement Accountability Committee, 1993, p. 2). Teacher isolation is contraindicative to building teachers' repertoires of good instructional strategies. Mariposa, Sierra, and Paloma found that, by bringing teachers out of isolation and building cultures of collaboration, teachers can, indeed, learn from each other through the process of talking teaching.

\section{Connecting Assessment to Instruction}

"In a sound assessment system," believes Wiggins (1994, p. 18), "no gaps occur among what you assess, how you assess it, and your priorities in curriculum and instruction." Since each of these schools focused extensively on assessment, can a connection be made between their assessment activities and corresponding instructional practices? While still a work in progress, it appears the schools and teachers are moving in that direction. 
At Sierra, some teachers, particularly at the primary grades, have taken the concepts covered on the site-developed assessments and integrated them into regular classroom lessons. This serves two purposes, they note: helping students learn and apply the needed skills, while also building comfort with the format of the assessments. Teachers also report that pre-assessment results are used formally or informally by many classroom teachers, as well as by non-classroom support staff, to diagnose student needs and determine appropriate interventions.

Some teachers at Sierra may also be reaching the point where they use assessment results holistically to reflect on their teaching practices. One first grade teacher commented that the assessment process can "help the teacher look back on their teaching ... and say, where did I start with this group, where am I ending, and how effective have I been and how do I need to modify?" This study's methodology did not allow for determination of the degree to which this is actually happening. However, the ongoing professional conversations among teachers that occur during grade level meetings and design teams, along with the knowledge and comfort teachers gain through continued administration and scoring of the assessments, should help stimulate this type of reflection, leading, hopefully, to both improved instructional practices and better learning results for children.

Some teachers at Mariposa reported that they do connect the sitedeveloped assessments to instruction, focusing teaching activities on the types of products students are expected to create and the skills they will be 
expected to demonstrate. At this time, it appears that these primarily relate to lesson content and format. If what is assessed is what teachers believe students should know and be able to do, then, commented the former vice principal, "we should be comfortable about teaching to the test." Thus, he said, teachers were beginning to develop menus of learning experiences, increasing their repertoire of high quality instructional practices.

Talking with Mariposa's teachers, it does not appear that results from individual student assessments are necessarily used to make instructional decisions such as those beginning to occur at Sierra. This is something the new administrators hope to encourage. Both principal and vice principal probe into this at meetings and work sessions, asking, for example, "when you look at results, does this help you know what to do instructionally?" and "what happens next-how does this inform instruction?"

At Paloma, the portfolio system is still in the process of refinement and full implementation, but it holds great potential for changing instruction. By specifying the types of products that are to be included in student portfolios, teachers are also, by implication, specifying learning experiences they value. Thus, teachers have identified that upper grade students must be able to do a research report and all students should make oral presentations. Authentic assessments require authentic curriculum and stimulate authentic instruction. And while it is difficult to place your instruction in public view through student portfolios, the atmosphere of trust and collegiality that 
continues to evolve from their work together in clusters and design teams makes this not only easier, but more valuable for students and teachers alike. The Core Processes of Schooling

Lieberman and Miller (1990, p. 763) note that "few schools have ways to encourage discussion about approaches to teaching and learning or to enable the teachers themselves to learn and grow." Building on the LAD experience, Mariposa, Sierra, and Paloma are all actively working to engage teachers in substantive conversations about teaching and learning. Through these efforts, they are bringing teachers out of isolation and creating cultures of collaboration and professionalism.

Placing their collaboratively-developed assessment practices at the center of this process, teachers have also begun to show an understanding of the essential integration among curriculum, instruction, and assessment. Many are beginning to use assessment to inform instruction, based on both the content, which reflects their expectations for student performance, as well as the results. As a result of talking teaching and focusing on assessment, it appears that changes are starting to occur at these schools in the core processes of schooling-teaching and learning-in connection with their efforts to demonstrate accountability for the improvement of student achievement.

\section{Teacher Empowerment and Shared Decisionmaking}

Central to the restructuring movement is the concept of site-based management, central to site-based management is the concept of shared decisionmaking, and central to shared decisionmaking is the concept of 
teacher empowerment. How have these concepts played out at these three schools, and what is the connection to their efforts to become accountable for student achievement?

At all three schools in the study, teachers are prominent in the school governance structures; they cited this involvement in governance and decisionmaking as both a source of strength and a source of frustration. At times, teachers felt truly influential in making changes happen at their school sites. At other times, however, they felt bogged down in the process and frustrated that either they did not truly have decisionmaking power, or their decisions were not supported or upheld.

The Values of Shared Decisionmaking

Hill and Bonan (1991, p. 4) note that "site-based management is frequently paired with another term, shared decisionmaking. The latter represents a shift in the balance, in an individual school, from control of all important issues by the principal to some degree of open discussion with the staff." In San Diego City Schools, the definition goes even farther, calling shared decisionmaking "an empowering joint planning and problem-solving process that seeks to improve the quality of education and working life" (San Diego City Schools, 1990, p. 3). These are powerful words. And when it works, teachers at these three schools reported, shared decisionmaking is indeed a powerful process. What makes it successful, it appears, are two key elements-involvement and influence. 
Each of these schools has in place a governance structure strong on teacher participation. At Paloma, teachers are active members of the School Planning and Management Team, and they have opportunities to research and address critical areas through their design teams. At Mariposa, teachers make their voices heard from grade level teams to the governance team to whole staff meetings. At Sierra, teachers have opportunities to impact decisionmaking through their design teams as well as through their representation on the governance team. At all three schools, teachers felt that, in many instances, they truly wielded influence through these various structures and opportunities.

A primary example of teacher influence occurred with the development of the site assessments that form the core of their accountability work. At each school, teachers were given the power to extract, from various source documents and their own experience, what students should know and be able to do at different grade levels and within different programs. They then translated that information into assessment processes that would work for their school sites. As Virginia, one of the Sierra teachers, observed, "the teachers themselves were the ones ... given the power and told, you are expected to come up with an assessment."

Teachers at each school also cited other examples of ways they had been involved in decisionmaking and thus exerted control over their own working conditions and the learning environment for their students. At Paloma, teachers were the ones who grouped students into classes and 
formed classes into clusters. At Sierra, teachers on one design team planned the transitional summer program when the year-round school schedule changed. At Mariposa, through grade level teams and the governance team, teachers determined staff development needs and formats, and proposed options for student interventions.

Key to shared decisionmaking in an accountability culture, however, is focusing the decisions on students and the improvement of student learning. Darling-Hammond (1988) notes that keeping the welfare of the clientsstudents-as the primary concern is an essential element of professional accountability. Tina, one of Mariposa's teachers, acknowledged that "I think there needs to be someone who continually reminds everyone who is making the decision that we're not talking about what's best in your room or for you ... we need to look at the whole picture ... (and) make decisions for the good of our students at our school." At Paloma, the Comer philosophy constantly helps orient staff that decisions should be made in the best interest of children. While that statement has sometimes been abused, commented some of the teachers, for the most part it focuses them on why they're there. As Tammy, teacher and former SPMT co-chair recalled:

I remember the very first time everyone got all heated up on the first discussion I was at, which was probably my first staff meeting too. It was wild ... and someone just said, wait a minute, what's in the best interest of the child? ... It made everyone stop and think. 
Participatory decisionmaking can be a powerful process when teachers truly feel they not only have opportunities for active involvement, but for influence. It appears that, at these three schools, the process has moved in that direction around a focus on improving the achievement of students. The Pitfalls of Shared Decisionmaking

Participatory decisionmaking also has its challenges which temper the strengths: it takes commitment to the philosophy and the process, it takes the true devolution of authority and responsibility, it takes true empowerment, and it especially takes time. Each of these carried associated frustrations for the schools and teachers.

It is a time-consuming process to research issues, talk about all sides and perspectives, and reach consensus. Teachers must commit hours beyond the instructional day to sit on committees, to gather and internalize new information, to share and discuss and argue often complex issues. Vicky, the new principal at Paloma, recalled that one decisionmaking process had taken so much time that "it was like people just wanted to get on with it, let's make a decision and move on." Schedules must be redesigned to allow teachers the time to participate in decisionmaking. Schools must also invest in professional development to expand both organizational and individual capacity to engage in the process effectively and efficiently.

When decisions involve multiple or nested committee structures, other problems may arise. First, it takes time for a committee to research and discuss issues, propose solutions, then share those recommendations with 
other governance groups or the whole staff. In addition, as proposals move through the chain, decisions made by one group may be revised or overruled by the next. Also, the process is defeated if teachers do not fully trust the members of other groups or committees to make decisions in their collective interest, and thus insist that the discussions and decisions be revisited at whole staff forums.

Another downside to shared decisionmaking is the question about what decisions schools and teachers really have under their control. Malen and Ogawa (1992) observe that, often, site-based management processes tend to shift task responsibility, but not delegate decisionmaking authority. In addition, they add, site participants in shared decisionmaking arrangements rarely address central, salient policy issues. Nancy and Gloria, teachers at Paloma, echoed this concern. They noted that teachers have many opportunities for involvement in site decisionmaking; but major decisions about curriculum, instructional materials, school calendar, and budget are often made by the district, not the school. Sierra teachers expressed similar frustrations, especially in relation to decisions that have ties to budget. As Grace complained, anytime they hear "OK, we have a lot of money," it immediately seems to be followed by something prefaced with but.

To support their accountability cultures, these schools want site-based control over critical areas that influence their ability to improve student achievement. In conjunction, however, they must also have structures which provide stakeholders with the time, knowledge, training, and 
resources to actually make and implement the decisions over which they have control. These schools are still struggling both internally, and with the district, in these two areas.

\section{Empowerment}

"Where there is no responsibility for shaping practice," comments Darling-Hammond (1988, p. 40), "there can be no accountability for appropriate practice." Teachers, she notes, need to be empowered to participate in professional decisionmaking in order to be professionally accountable for both practice and results. What empowers teachers? Midgley and Wood (1993, p. 251) propose that teachers "who are examining and changing school policies and practices ... feel empowered."

Based on the experiences cited by teachers and administrators at Mariposa, Sierra, and Paloma, it seems that empowerment is key to shared decisionmaking. When teachers did not feel empowered, when they felt decisions were not truly under their control or their voices were not being heard, the frustrations of the process seemed to overwhelm its benefits. But when teachers felt empowered, when they felt valued and enabled, they were willing to commit the time and energy to engage in substantive discussion and make meaningful decisions focused on students.

\section{Challenges and Successes: Worst of Times, Best of Times}

Education is a complex process, and, as Brown $(1990,2)$ notes, "accountability ... remains a slippery concept." At Mariposa, Sierra, and Paloma, staff members encountered challenges as they worked to create and 
implement site-based systems to demonstrate their accountability for student achievement. Key among these, as cited by teachers and administrators, were problems related to time, direction, and support.

But these three schools experienced success in their endeavors as well. Darling-Hammond (1993) reports the following from a 1930s study of progressive schools:

The most successful schools were characterized not by the particular innovation they had adopted but by their willingness to search and struggle in pursuit of valid objectives, new strategies, and new forms of assessment. It was the process of collective struggle that produced the vitality, the shared vision, and the conviction that allowed these schools to redesign education in fundamentally different ways. (p. 761) The schools in this study found, as Fullan and Miles (1992, p. 749) suggest, that "change is learning-loaded with uncertainty." But while facing and working through the challenges, they found their staffs coming together and they rejoiced in the sense of ownership and success that comes from creating and implementing something yourself.

No One Said School Reform Is Easy

From the educational literature to the daily newspaper, there seem to be as many stories of the failure of school reform efforts as there are tales of success. What are some of the challenges facing schools like these three that are trying to engage in systemic reform? Teachers at Mariposa, Sierra, and Paloma identified frustrations with time, confusion about direction, and lack 
of sustained support as key issues they faced during their involvement with the LAD school project. Paloma, in particular, added another: the clash of reform efforts with day-to-day realities.

Never enough time. Donahoe (1993) writes about the challenge of time in the process of school restructuring:

This was the source of the stress: we could buy time for the school staffs, but they had no space to install it.... It wasn't just a matter of finding time for meetings; there had to be time for all the additional interaction, assignments, and emotional energy that stitch an organization-a culture-together.... We were crowding the time they would otherwise have spent thinking about their children and their classrooms by giving them the additional responsibility of thinking about the whole school. (p. 300)

Time, similarly, was a factor cited by Mariposa, Paloma, and Sierra teachers as one of the major challenges of the LAD project. Individually and collectively, teachers at these schools, especially those on the leadership teams, invested huge amounts of time in the process. This included time to attend trainings; time to prepare for staff development; time to engage in substantive discussions about research and educational theory; time to identify essential student learning outcomes; time to create assessments; time to make decisions; time to plan, implement, review, revise, expand, modify.

Nancy, one of Mariposa's LAD team members, commented that "there were days when we talked and we went into our classes without a single 
lesson plan written down because we were maxed to the limit." At Sierra, Sonia stressed "the amount of time that we put in on our own, outside of the classroom and everything else.... We spent hundreds and hundreds of hours on our own." "It was a time issue," decided Gene, one of Paloma's leadership team. As Joanne, from Mariposa, probably concluded for them all: "It's a very time consuming process when you consider the other things you have to do as well."

Where are we going? Beyond the challenge of time lies the difficulty of proceeding forward with a project when direction is unclear. As reported earlier in this chapter, school leadership teams experienced some confusion early in the project. Clark, former principal at Paloma, recalled that "we felt like the people that were telling us and giving us guidance in the LAD program weren't quite sure either because things were changing so much." Gloria, who was on Mariposa's leadership team, summarized this perception in saying, "I think that when we signed on as a staff, we were expecting a lot more direction from somebody. We were pretty much left on our own to figure it all out."

"Change is a journey, not a blueprint," note Fullan and Miles (1992, p. 749). "What is needed," they continue, "is a guided journey." These schools embarked on their accountability adventures without a map, without a blueprint, with only a sketch. It appears that this sketch did not provide quite as much guidance, especially at the beginning, as the school leadership teams felt they needed. 
Where's the support? Yes, they all did figure it out-quite successfully, it seems. However, some of these same teachers also felt the district later abandoned the project, leaving the schools to proceed on their own and ignoring their valuable work that might inform others. Sonia, one of Sierra's leadership team members, reported that "at the beginning I really liked it, because I felt we were supported by the district as far as giving us time to actually meet. I think that, as it went on, then those that were leading kind of said, you'll do it on your own."

"We feel like the district dropped the LADs concept," concluded Mariposa leadership team members Nancy and Gloria. As Wendy at Sierra asked, "where is the support, where is the value from the district?" Staff at each school bemoaned the fact that the work of the LAD schools, especially those that put together significant products or systems, has not been acknowledged or shared across the district.

Reform meets reality. Reform efforts are not easy; they require vision, commitment, energy, direction, support, time. But when day-to-day reality includes difficult issues that take up these valuable resources, then the school faces the double challenge of dealing with those daily situations while also trying to sustain the reform efforts. Paloma exemplified this struggle when faced with an influx of refugee students and significant annual staff turnover. As Paloma teachers Marie and Sandra observed, "some of the big reform issues are really hard to grasp and follow through on because you don't have 
the time and energy.... (Sometimes) reform takes a back seat. Reform is happening, but there are other things happening too."

Time, direction, support, and daily realities all influenced the ability of staff at Mariposa, Sierra, and Paloma to engage in systemic reform for the improvement of student achievement. Yet despite these issues and problems, teachers and administrators still found ways to move their reform efforts forward, and to struggle through the challenges to find success.

\section{Nothing Breeds Success Like Success}

"Nothing we have done or have accomplished here," observed Sylvia, principal at Sierra, came "without teachers saying we did it." That sense of participation in significant accomplishment permeated teachers' conversations across the three schools when they talked about the benefits and successes of their involvement with the LAD project.

Sierra's teachers cite their assessments-researched and created by teachers-as their most significant accomplishment. Accompanying that is the sense of empowerment teachers have gained from that experience. "I think the best thing that we have done," noted resource teacher Mayra, "is come to some clear, consistent guidelines of what we are expecting of students at each grade level." These expectations are reflected in the assessments, which then provide a common language to talk about student achievement. The assessments are powerful, observed teachers, because they are built from their own experience and expertise. "It has all been teacher driven and 
teacher generated," concluded the principal. Teachers "can experiment with just about anything to improve what they are doing."

"The biggest strength is the staff," observed Vicky, new principal at Paloma. "They are extremely dedicated, extremely committed individuals." That strength was forged through difficult times but has proved to be one of Paloma's success stories. Clark, the former principal, noted that the school created many teacher leaders-ones who knew the research, who had internalized the philosophies, who could be mentors and change agents. While many of those teachers moved on, those that remain and new teachers that have arrived seem to have the energy and enthusiasm to carry on in the face of significant daily challenges. "I see people willing to share and reaching out to help each other when there are problems," said Helen, one of the teachers. "Everybody has that 'it takes a whole village to raise a child" attitude." Their efforts, expressed Allison, have made a school with so "many students from so many backgrounds work as well as it does."

Mariposa's teachers and administrators are particularly proud that they came together and created what they feel is an operational accountability system. Teachers "had a stake in the plan and I think the morale of the school generally rose," reflected Gloria at Mariposa. "I think the staff is much stronger as a staff." Carl, the former principal who led the school into the program, was pleased to be able to say that they had "something evolve that is an actual document, an actual plan, an actual system that is in operation." 
His vice principal, Chris, added that "it's become a part of the staff's repertoire ... it's part of the culture of the school."

These three schools found various challenges associated with the accountability demonstration project, but they also found success. Staff members came to recognize that change processes are complex and chaoticthey require learning; they require patience; they require time, energy, and resources; they require commitment (Fullan \& Miles, 1992; Garmston \& Wellman, 1995). Teachers and administrators at Sierra, Paloma, and Mariposa took the sketch provided by the LAD project, as limited as it may have been in their eyes, and set off on their accountability journeys. They struggled through the challenges, but also proudly celebrated their successes.

\section{Accountability and School Site Leadership}

Leadership is a term intimately associated with this program, starting with its name: Leadership in Accountability Demonstration (LAD) School project. The final evaluation study of the LAD program also reported that "site leadership, from administration and among staff, was identified by many of the study participants as central to the success of the school efforts" (Bennett, 1995b, p. 25). This study, therefore, included an investigation of how leadership was conceptualized and practiced within three of the pilot schools. To explore this idea, teachers were asked to "describe leadership at your school-what does leadership look like?" The purpose of this openended question was to elicit a conversation about school site leadership in connection with their schools' reform work. 
The comments were both interesting and informative. Leadership itself, as a concept and practice, appears to be something that is rarely discussed or articulated. When asked this question, teachers were often nonplused, inquiring what do you mean? But they thought about and reflected on the question. Some then responded first with a direct association between leadership and the position of site administrator, while others instead began with the idea of shared leadership or leadership opportunities for teachers. As introduced in Chapter Two, the literature on educational reform and restructuring has begun to make a transition from school site leadership associated solely with the principal to the concept of relational leadership, collaborative among the school community. So too, it appears, have the teachers out there on the front line of these particular educational reform efforts in San Diego.

School Leadership in the Modern Context

About half the teachers who responded to this interview question first connected leadership with the school site administration, which is common in the modern-era view where leadership is frequently associated with the traits of an individual person or with a position of organizational authority. When asked to describe leadership at their school, these teachers made comments such as the following:

- The principal ... is the leader, there is no doubt about it. ...

- Starting from the top down, if you want to talk about (name) as a principal. ... 
- I guess right now, it's just the administration....

- (Principal) was the most incredible leader I have ever worked for. . . .

In addition to connecting leadership directly to the administrator, these teachers also tended to introduce the idea of leadership style into the conversation, proposing that the personal characteristics of the leader/ administrator need to match those of the followers/teachers for leadership to be effective. Thus, remarked one teacher, "I like (the principal's) leadership style ... (it) is more or less laid back... Some people get frustrated with that." A teacher at another school, referring to a change in the school administration, commented that "it was a big switch in leadership styles." School Leadership in a Postmodern Context

Yet other comments indicated that many teachers view leadership in a different way. More than half the teachers addressing this question about leadership responded through a participatory or relational perspective, connecting leadership not with the position of administrator but with a process which occurs in a community. Even some of the teachers who had first equated leadership with the administration subsequently continued on to talk about leadership in a collaborative sense. Leadership, to these teachers, is something that is available for many members of the educational community. These schools seem to provide an environment that enables those who are interested to participate in the leadership process.

Participatory democracy. "I sort of think leadership at this school is voluntary," observed one teacher. "It's very, very much shared." Another 
teacher at the school added "I believe that we have really strong teachers and teacher leaders at varying grade levels.... I do think that we have a good deal of leadership here." From another school, one teacher commented that, "I think we are all involved with the leadership process." One of her colleagues concurred, reporting that "we have within our staff, leaders who are leaders in different areas." At the third school, one teacher noted that "I think leadership is available to those who will take it." Or, as another suggested, "there are lots of opportunities for leadership."

Leadership, in the perspective expressed by these teachers, is a collaborative relationship, a participatory experience, a democratic process. It does not reside in one individual or with any particular position, but instead exists within the community as an opportunity tied to context, interest, influence, knowledge, and skill. There is, as one teacher commented, "a potential for anyone." Angus (1989, p. 88) connects this view of leadership with the idea of empowerment, and notes that "many school participants have access to forms of self-determining power within a context of participative democracy." Or as Rivzi (1992) conceives it:

Leadership should be seen as located neither in individuals nor in institutional positions, but in particular acts.... Thus viewed, leadership may originate with any person within a community, and not just those who have been officially designated as leaders. (p. 163) 
These teachers also cited, either directly or by implication, the same three elements identified from the literature on leadership and educational reform: vision, collaboration, and transformation.

Vision. As reported in Chapter Two, vision is often associated with educational reform; its power to change schools derives from its firm grounding in the educational community rather than in an individual. "Shared vision," declares Senge (1990, p. 206), is "a force in people's hearts, a force of impressive power." Although the vision for school reform may begin at a personal level, personal visions must become shared visions to provide the power to which Senge refers, the power to create change. As Chance (1992) reports:

One thing the visionary leader knows for sure is that the journey to actualize the vision cannot be made alone.... The vision provides the ultimate destination, and when a visionary leader collaborates with the stakeholders of the school, the trip can be an exciting and rewarding one. (pp. 111-112)

It appears that, at these schools, a key process involved first building a shared vision, then empowering others to take responsibility for actualizing the vision within the school community. Thus, at Mariposa, Step One of the M.A.P. says, "Administrator provides leadership, vision, guidance, and buyin to the development of an accountability system." But the principal was firm in reporting that, for the work to continue, the vision must be maintained and teachers must be empowered to keep going. And at Paloma, 
one teacher commented that the former principal "was the vanguard. . . He came back with the vision and sold it to us, but we bought into it." Another teacher added that the principal "knew where he wanted us to go, (but) he was going to allow us to figure how to get there. He gave us so much freedom to decide how we were going to do all the little things."

Collaboration. Leadership, suggests Carlson (1996, p. 192), should be seen "not as an act but as a process in which the dynamics permit multiple levels of exchange and participation. It is through these interactions that necessary change becomes articulated by vision, charisma, trust, and empowerment." My conversations with teachers and my observations of their school environments led me to conclude that leadership is becoming a highly collaborative experience at these schools.

Leadership does not reside solely with the principal, with certain key staff, or with specific positions. It is, commented one teacher, "very, very much shared." Leadership at these schools, it seems, is evolving into a communal endeavor which occurs, as Foster (1986) suggests, within the context of democratic participation. As another teacher summarized, "I think we're all involved with the leadership process."

Transformation. As noted in Chapter Two, leadership is also connected in the educational reform literature with the concept of transformation-the transformation of schools, and the transformation of the leadership process itself. At all three schools in this study, the efforts of teachers and administrators engaged in leadership relationships led to 
transformations in the schools themselves-their activities, their attitudes, their cultures. In interaction with the process of school transformation, the perception and practice of leadership began to undergo a transformation as well. From roles and responsibilities based on traditional hierarchical arrangements, the teachers and administrators at these schools moved toward the view and practice of leadership as a participatory experience in which they all have opportunities to be engaged, to exert influence, and to promote and achieve change.

This was not an automatic evolution. As one teacher commented, at first "it was a little bit difficult to get people to start taking leadership roles because traditionally, that's not what we were used to." But now, through the process of engaging as professionals in significant school reform work, teachers are also much more comfortable with their opportunities to participate in the leadership process. There is, as one teacher said, "a potential for anyone," and many teachers seem to not only recognize that potential, but also realize it. At these three schools, transforming the school and transforming leadership seem to be mutually influential processes. Empowering Leadership

Ricoeur (1992) proposes that self-esteem, to be realized, requires the mediation of others. It thus has a dialogic dimension-it cannot be grounded in oneself alone, but is achieved through placing oneself in relationship. It appears that, at these schools, leadership also has a dialogic dimension. Engagement with others is required to actualize the leadership relationship 
itself; engagement with others is also required to bring the experience which that leadership strives to enact-school reform and accountability for student achievement-from capacity to realization.

By empowering teachers to participate in leadership relationships, these schools are exemplifying empowering leadership. This concept integrates two complementary ideas. First, the process of school restructuring empowers a new form of leadership-one that is participatory, relational, democratic, collective. And second, that new form of leadership is itself a process of empowerment wherein participants engage in collaborative, mutually influential relationships to enact change.

\section{Building an Accountability Culture}

The final evaluation report for the LAD school program indicates that "the primary result of the schools' two years of work with the LAD project has been the establishment of site 'accountability cultures' wherein stakeholders recognize, accept, and perform their responsibilities and associated accountability for student achievement" (Bennett, 1995b, p. 25). These cultures emerged from concerted efforts to establish structures for communication and collaboration, build site empowerment and ownership of the process, work together on the articulation of standards and the identification of appropriate assessments, and focus on student needs.

Each of the three schools in this study has a unique culture which reflects the special relationships that have formed among those in the educational community within and around the school. Mariposa's 
accountability culture is embodied in teacher's professional conversations and collaborations. It is exemplified by the Proclamation for Student Success, the school community's dedication to provide a quality education through a supportive climate grounded in the four elements of accountability: high standards, meaningful assessments, recognition and intervention, and public reporting. Sierra's culture expects and supports student achievement through the professional integration of curriculum, instruction, and assessment. Accountability, at Sierra, is embedded into daily activity, school decisionmaking structures, and the annual planning process. At Paloma, the culture of accountability has been forged in hardship, and is manifested in the pioneer spirit and dynamism exhibited by staff, parents, students, and the surrounding community. The underlying philosophy, in the best interest of children, drives teachers to take students from wherever they enter, with whatever challenges they bring, and push them to reach as high as they can.

To what degree are these accountability cultures embraced and enacted by all members of the educational community? "In most contemporary organizations," writes Senge (1990, p. 219), "there are relatively few people enrolled-and even fewer committed." He calls enrollment the process of becoming part of something by choice, while commitment adds to enrollment the feeling of full responsibility for making something happen. A challenge faced by these three schools on a continuing basis is the need to build and nurture commitment to the vision and culture of accountability. All three schools have done a great deal of work with teachers, creating 
environments which foster commitment by allowing them time to engage in meaningful conversations as professionals; by making teachers part of the process, they become part of the solution as well. However, teachers and administrators noted that they must continually renew their efforts with new teachers and with those who may remain resistant or reluctant; they also acknowledge there is still work to be done with other staff, parents, students, and members of the larger educational community.

"Culture-the values, beliefs, behaviors, rules, products, signs, and symbols that bind us together-is not something we can change like a flat tire. Culture is organic to its community" (Donahoe, 1993, p. 302). Building these school accountability cultures did not come easily. It took vision, it took time, it took negotiation, it took two steps forward and one step back, it took leadership. In an accountability culture, stakeholders accept that accountability rests with the school and the members of the school community. Stakeholders within these three school communities, at least the professional staff, seem willing to put accountability into action. Their payoff comes from the engagement in the process itself and from the ultimate outcome as well-improved student achievement.

\section{Summary}

Since the spring of 1993, faculty at Mariposa, Sierra, and Paloma Elementary Schools have discussed what students should know and be able to do, created ways to assess those knowledge and skills, begun changing the teaching and learning process, embraced participatory governance and 
collaborative decisionmaking, faced challenges, and celebrated successes. They found that leadership is essential for change in the educational context and they began to reconceptualize leadership, building opportunities for those within their professional communities to enter into leadership relationships.

Their courses through the accountability adventure converged and diverged; they moved in concert at times while at others they went off in different directions. It hasn't been easy, but, as Kent from Sierra expressed, "there is a certain bond with all of us having gone through it." Each school's path ultimately led to a stronger sense of community within the school, a cohesiveness and collaborative relationship among the teaching staff, and a growing commitment to accepting accountability for the improvement of student achievement. Through empowering teachers and empowering leadership, these schools exemplified the emerging postmodern perspective of school restructuring, educational accountability, and school site leadership. 


\section{CHAPTER SDX}

\section{SUMMARY, IMPLICATIONS, AND RECOMMENDATIONS \\ WHAT CAN WE LEARN FROM WHAT WE HAVE LEARNED? \\ Introduction}

The demand for accountability is ubiquitous in the 1990s-it appears in newspaper editorials, business meetings, campaign pamphlets, school board discussions, graduation speeches, even dinner table conversations. As the twentieth century draws to a close, it is one of the prevailing social, economic, political, and educational issues.

In education, accountability stands at the intersection of public outcry for improved educational results with school site demands for increased autonomy and flexibility. The San Diego Unified School District has exemplified this interplay among school autonomy, public pressure, and accountability. In the late 1980s, the district began pursuing school reform through restructuring efforts that focused on participatory site governance processes. In 1993, facing both external and internal pressure to demonstrate improved student outcomes overall, as well as close the achievement gap exhibited by certain student groups, the school board approved a student achievement accountability policy along with a recommendation to implement a pilot program to develop an accountability system model for the district. This Leadership in Accountability Demonstration (LAD) School 
project was funded and supported from the spring of 1993 through June 1995, during which time the participating schools investigated and modeled different ways to put the district accountability policy into practice. In 1996, work began in earnest on the process of operationalizing the accountability system districtwide.

The LAD project was embraced by teachers and administrators at three elementary schools in particular as an opportunity to make some significant changes in the way they do business-to investigate standards for student performance and ways to assess progress toward them; to actively participate in school governance, decisionmaking, and leadership; and to engage the school community in demonstrating accountability for improving student achievement. This study delves into the work of these three schools in order to see what educational practitioners and policymakers, locally and generally, could learn from their efforts, their challenges, and their successes.

This chapter first presents a summary of the study's purpose, methodology, and key findings. It then explores some implications of this research for educational policy and practice, and presents recommendations for policymakers and practitioners as well as for further research. The chapter closes with remarks about the intersection of my personal odyssey through doctoral study and this dissertation, the San Diego school district's odyssey through restructuring and accountability, and our collective odyssey into a new century and a new millennium. 


\section{Summary of the Study}

As presented in Chapter One, the purpose of this study had three interrelated elements: to investigate the issues, challenges, and successes involved in engaging teachers in school reform efforts around the implementation of a student achievement accountability policy; to identify what kinds of site governance and leadership have been most embraced by schools accepting site accountability in exchange for increased flexibility and autonomy; and to discuss implications for policymakers and practitioners relative to student achievement accountability, restructuring, and leadership.

Following is a review of the methodology used in the study and a summary of the key findings from my analysis of the rich data that were collected and interpreted. This section concludes with a discussion of two themes that emerged from interrelating the findings of this study with the literature on restructuring and accountability: change in perceptions, actions, and culture; and the nature of educational accountability in the 1990s as demonstrated by these schools through this project.

\section{Summary of Methodology}

Qualitative methodology is grounded in the belief that "there are multiple realities-that the world ... is a function of personal interaction and perception. It is a highly subjective phenomenon in need of interpreting rather than measuring" (Merriam, 1988, p. 17). The educational enterprise itself, and the implementation of educational policy therein, play out in a realm of multiple realities. Just as teachers interact uniquely with each 
individual student and with each class of students, so too does each educational policy interact uniquely with each context to create situations that must be approached not as objective events to be defined but as subjective experiences to be discovered.

This multisite case study investigated three unique but interrelated settings-cases "rich in the sense that a great deal can be learned from a few exemplars of the phenomenon in question" (Patton, 1987, p. 19). Since the concept of culture permeated the LAD schools' work, the case study approach was overlaid with an ethnographic orientation to look into site accountability cultures. The three elementary schools involved in the study, called Mariposa, Sierra, and Paloma in this report, serve as rich exemplars of the pilot project to implement the district accountability policy. The inclusion of three sites provides both variation and a broader base for potential transferability. As illustrated in Chapter Four, these three schools represent distinct areas of the district, serve varied student populations, and exemplify different governance structures and leadership approaches. They took their own paths through the demonstration project and created unique school accountability cultures.

Data collection focused on viewing each school's experience through the eyes of key participants-teachers and administrators-who were intimately involved in the schools' work with the pilot program. Thus interviews formed the heart of the data collection process. As Seidman (1991, p. 4) comments, "the primary way a researcher can investigate an educational 
.. process is through the experience of the individual people." And, add Brenner, Brown, and Canter (1985, p. 3), individuals are "the heroes of their own drama (and) valuable sources of particular information." These interviews were contextualized and augmented by observations of site decisionmaking forums and staff workshops, along with a review of relevant site and district documents. Data analysis then allowed the rich data obtained through the interviews, observations, and document reviews to be integrated, synthesized, and interpreted around individual school and cross-site themes. Summary of Key Findings

Chapter Four reported the schools' individual stories according to five common themes: how they engaged in the demonstration project itself, what changed in teaching and learning, the decisionmaking and governance processes they embraced, the challenges they dealt with, and the successes they celebrated. It also presented the unique variations that embellished each school's experience, along with some observations about each site's accountability culture. Chapter Five subsequently wove those individual stories together, first around the common themes that crossed the sites, and then around discussions of school site leadership and the process of building school accountability cultures.

What are the major elements of the individual school and cross-site themes that emerged from this study? The following sections summarize key findings from this research. 
Common paths, divergent branches. Teams of teachers, support staff, parents, and administrators from Mariposa, Sierra, and Paloma Elementary Schools (along with teams from six other elementary schools and one middle school) attended the same Leadership in Accountability Demonstration (LAD) School introductory training in the spring of 1993. But each individual and each team interpreted and internalized that training through the filter of personal experience, prior work, and school culture. Thus, the subsequent paths taken by the schools as each attempted to implement the district accountability policy were directed by the unique interaction of policy and context, as defined by individual and collective experience. At times the schools moved along a common path, but at other times they branched off in unique directions.

Two elements directed the initial work at each of these sites during the LAD project: a focus on academic standards and an investigation into the related assessment of student performance. Teachers at the schools engaged in substantive conversations about student achievement and about teaching and learning. It was the process of translating ideas about what students should know and be able to do into ways of determining when students had acquired those knowledge and skills that seemed to center accountability in the school cultures at Mariposa, Sierra, and Paloma.

The results of these events, however, were unique to each site. What emerged at each school came about from the interaction among the knowledge and experience of teachers and administrators, their collaborative 
efforts, the special characteristics and needs of the student populations and school communities, the site governance structures and approaches to decisionmaking, and the leadership relationships.

The core processes of schooling. Teachers were the heart and soul of these schools' work with the LAD project. They actively engaged in the experience of identifying what students should know and be able to do, and determining how to assess the acquisition of those knowledge and skills. They talked extensively about student work and about teaching and learning as they identified standards, developed assessments, and made decisions about materials, school operations, professional development. Did these conversations and this work influence teaching and learning-the core processes of schooling? It appears that changes are beginning to occur, but the classroom connection is still a work in progress.

First, the LAD project not only enabled but encouraged teachers to move from isolated individuals in separate classrooms toward professional collaborators in the educational enterprise. As such, grade level and staff meetings began to become safe environments where, formally or informally, teachers could share instructional strategies. Indeed, one of the values cited by many teachers in the study was the opportunity this project provided for collegial interaction where teachers could talk together as professionals. And according to administrators and some of the teachers, these professional discussions began to have some influence on instructional practices. 
In addition, some teachers began to make the explicit connection between assessment and instruction by integrating concepts from their site assessments into their classroom lessons, introducing students to both format and content. Others reported that assessment results are used to diagnose student needs and determine appropriate interventions. And a few teachers were also aware of how assessment results might be used to reflect holistically on the effectiveness of their teaching practices.

Teacher empowerment and shared decisionmaking. As reported in Chapter Two, the literature indicates that site-based management is central to the restructuring movement, shared decisionmaking is central to site-based management, and teacher empowerment is central to shared decisionmaking. How did these three schools approach governance and decisionmaking? What is the connection to their efforts to become accountable for improving student achievement?

At all three schools in the study, it appears that teachers are prominent in governance and decisionmaking through structures such as site governing groups, design task committees, and grade level teams. Participants in the study were able to cite various circumstances where teachers had been truly influential in making decisions and in making changes, most particularly around their work to develop the site assessments that form the core of their accountability efforts. However, teachers also reported on difficulties and frustrations associated with the process of participatory decisionmaking-it takes time, it needs the true devolution of authority and responsibility, it 
requires access to knowledge, and it needs a commitment to see the process through as it is intended.

At these schools, the philosophy of participatory governance, at least in terms of teacher involvement, became a central part of their accountability cultures. A sense of empowerment was essential, however. When teachers felt decisions were not truly under their control or their voices were not being heard, the frustrations of the process seemed to overwhelm its benefits. But when the teachers felt truly valued and enabled, they seemed willing to commit tremendous time and energy to engage in substantive discussion and make meaningful decisions focused on improving the learning environment and the achievement of their students.

The challenges and successes of engagement in school reform. Staff at Sierra, Paloma, and Mariposa Elementary Schools were engaged in school reform adventures. They worked to change the way they do things as educators, in the classroom and across the school, in order to improve student learning. As they created and implemented site-based systems to demonstrate their accountability for student achievement, they encountered challenges while they also experienced successes.

Two challenges cited repeatedly by participants in this study were time and support. Teachers found they needed to carve out time and find the energy to attend trainings, prepare for staff development sessions, engage in substantive discussions about research and educational theory, identify essential student learning outcomes, create assessments, review and reflect on 
their work, and just make decisions. This is a great deal to ask of people who are already engaged in the exhaustive process of teaching a classroom full of children each day. While teachers generally felt that the additional time requirements were both essential and valuable, they also felt divided, stressed, and often overwhelmed. This was complicated by a perceived lack of support from the district. Teachers, especially those on the accountability leadership teams, reported that there was confusion and misdirection at the beginning of the program. They also expressed concern that the district abandoned the project just when it was beginning to be effective, and felt that their work has been neither acknowledged nor appreciated.

But despite the problems of time and support, a sense of participation in significant accomplishment permeated teachers' conversations across the three schools as they talked about the benefits and successes of their involvement with the project and with school reform work. In particular, teachers and administrators were proud of the products they developed and implemented-their site-developed assessments and portfolio systems, their processes for teacher communication and collaboration, and their structures for teacher participation in decisionmaking and governance. They emerged from this work with the sense that we did it.

Leadership in accountability cultures. Participants at each school discussed school site leadership in connection with their work in restructuring and student achievement accountability. At these schools, the concept of leadership appears to be evolving from a modern construct where 
leadership is associated primarily with the person and position of school administrator toward a postmodern construct oriented more toward leadership as a process that occurs within a community.

Some of the teachers responding to the interview question on school site leadership made an immediate connection with the site administrator, and also tended to focus on particular acts or on personal characteristics. However, many teachers responded from a relational perspective, describing leadership as a participatory experience open to any and all who are interested. Leadership, to these teachers, is a collective endeavor that does not reside in any one individual, but exists within the school community as an opportunity tied to context, interest, influence, knowledge, and skill.

Leadership, in these schools, is empowering. Their restructuring efforts empowered a new form of leadership, and that new form of leadership in turn empowered the participants to engage in collaborative, mutually influential relationships to enact further change.

Change and Educational Accountability

Following a holistic review and analysis of the findings from this study in relation to the educational literature, two themes now seem to emerge that summarize and interconnect many of the elements. The first is change and the second is the emergent postmodern nature of educational accountability.

Change. In a discussion of systemic educational reform, Fullan (1994, p. 2) observes that "there is an overwhelming amount of evidence that educational change is inherently, endemically, ineluctably non-linear." Any 
educator, I am sure, would emphatically concur. As Paloma, Sierra, and Mariposa Elementary Schools engaged in a school reform process through the Leadership in Accountability Demonstration School project, they took steps forward, backward, off to the side, and around in circles. But whether it happened slowly or quickly, directly or around and about, change did occur at these three schools-in perceptions, in actions, and in culture.

It appears that teachers' and administrators' perceptions-of themselves, their schools, the educational process, and the idea of accountability-did indeed change as a result of their work with school reform. At Mariposa, Sierra, and Paloma, teachers began to see themselves differently; they developed a new sense of themselves as professionals, as colleagues, as decisionmakers, as leaders. Administrators and teachers began to regard their schools as collaborative communities rather than a collection of isolated classrooms. Staff began to view the educational process as a continuum along which everyone has a place, and where communication and articulation are essential. And student achievement began to be seen not as your responsibility but as our responsibility.

Along with the change in perception came corollary changes in action and in culture. Feeling more like professionals and collaborators, teachers began to engage in collegial conversation about students, learning, and teaching. Feeling more like decisionmakers and leaders, teachers and administrators created governance structures, decisionmaking processes, and leadership practices that are increasingly democratic and participatory. And 
feeling a more collective sense of responsibility, the members of each school community translated their emergent understandings and beliefs into school cultures which both value and promote individual and collective contributions toward the improvement of student achievement.

The nature of educational accountability. Chapter Two presents a discussion of the nature of educational accountability as described in the current educational literature. In the 1990s, it appears, accountability is evolving toward a multidimensional approach that is based on a democratic tradition of participatory governance, on complementary ideas of responsibility and responsiveness, on multidirectional relationships, on a performance and outcome orientation, and on a constructivist conception of teaching and learning. As accountability becomes intricately interwoven with restructuring, the focus is at the school site level with the expectation that, in exchange for increased autonomy and flexibility, there will be an associated acceptance of accountability for improving achievement.

How does this view of the nature of educational accountability compare to what I found by talking to teachers and administrators, by observing staff interactions, and by reviewing site documents at three San Diego school sites? At Mariposa, Sierra, and Paloma Elementary Schools, governance and decisionmaking are becoming more democratic and participatory for teachers and administrators; the educational process and professional development are building on the view that both students and teachers construct their own knowledge tied to their own experiences; 
instructional strategies and assessment practices are becoming more outcomeoriented, and responsive to changing student and school needs and environments; roles and relationships are becoming more supportive and multidirectional; and leadership is evolving into a communal endeavor shared at least among professional staff. Thus, it does appear that the emerging conceptualization of educational accountability described in the literature is supported by the evidence from this study of three elementary schools engaged in a process of school restructuring for the improvement of student achievement.

\section{Implications}

What can we now learn from what we have learned about restructuring, accountability, and leadership at these three schools? How might this study and its findings be applicable or transferable to other settings? In other words, what implications can be drawn from these data and interpretations to inform educational policy and practice?

Eisner (1991, pp. 203-204) notes that, "in conventional statistical studies in the social sciences, the construction of a generalization is left to the researcher. ... In qualitative case studies, the researcher can also generalize, but it is more likely that the readers will determine whether the research findings fit the situation in which they work." With this study, I believe it is the joint responsibility of the researcher and the reader to find which processes and outcomes might be applied to other settings, and to determine how the findings might inform educational policy and practice. To assist in 
this endeavor, I have presented a rich, contextualized description in Chapter Four, painting a picture of the settings, processes, and results using the words of the participants to the fullest extent possible. In Chapter Five, I have added a thoughtful, interpretive analysis of the experiences and themes which crossed the three sites.

What do I, as the researcher, think we might be able to learn from what we have learned from these schools? In Chapter One, I commented that restructuring-decentralizing authority and accountability to the local school site level-has multiple implications for the teaching and learning process, for school governance and decisionmaking, and for school site leadership. In this section I discuss implications for policymakers and practitioners relative to the link among restructuring, accountability, and the core processes of schooling; site-based management and shared decisionmaking at school site levels; the conceptualization and interconnection of accountability, restructuring, and leadership; and the complexity of translating policy into practice in a culture of restructuring, site-based accountability, and empowering leadership.

Restructuring, Accountability, and the Core Processes of Schooling

Restructuring is not a simple process-it involves fundamental reconceptualization and redesign of schools and schooling. Thus restructuring must affect the teaching and learning process; school structure and organization; governance and decisionmaking; roles and relationships 
among staff, parents, and community; and school site leadership practices. It must also be intimately interrelated with student achievement accountability.

This study found that roles and relationships among teachers and administrators were indeed changed as the schools engaged in their work with the Leadership in Accountability Demonstration (LAD) School project. These changes might not be obvious to the casual visitor but they emerged through my conversations and observations. It was evident that teachers' roles evolved professionally both within the classroom and within the school organization. In addition, relationships among teachers, and between teachers and administrators, began to be reexamined and reordered, moving from isolation and hierarchy toward collaboration and collegiality.

Some of the rules and practices for doing the business of education were also reconsidered and revised by teacher groups and governance teams at these three schools. These schools began to first connect restructuring with accountability through their assessment systems, which evolved toward a standards-based approach to the evaluation and reporting of student performance, and which led to some changes in school structures and in teaching and learning. Governance practices also changed, becoming more inclusive and participatory for teachers, and more focused on issues related to the improvement of student achievement.

The LAD project seemed to open the door to significant changes in the teaching and learning process through its emphasis on the identification of standards and the examination of student work. Indeed, some teachers did 
begin modifying their teaching practices. However, the basic instructional delivery systems and organizational structures at these schools remain essentially the same. In addition, roles and relationships involving other school staff (such as classified and clerical support personnel), as well as parents and community, have undergone much less examination and reconceptualization. There also appears to be little change, and much tension, in the relationships between these schools and the school district.

To support schools and staffs in taking the next steps toward the more fundamental redesign of the core processes and practices of schooling, educational practitioners and policymakers should:

- allow, support, and encourage true innovation as applied to the basic structures and organization of schooling;

- explicitly address how the process of restructuring, and the acceptance of accountability for the improvement of achievement, can and should translate into changes in the teaching and learning process-an implicit expectation does not automatically equate into actualization; and

- provide support and build capacity for the professional and organizational development needed to change instructional practices, school structures, and governance processes.

Site-Based Management and Shared Decisionmaking

Site-based management and shared decisionmaking involve devolution of authority from the district to the site level, and the engagement of site stakeholders in decisionmaking based on that devolved authority. 
These concepts also encompass acceptance of accountability for the process of site governance, the actions taken as a result of the decisions made, and the improvement of student achievement based on those decisions.

In San Diego City Schools, with participatory decisionmaking as the primary focus of district restructuring efforts, guidelines have been developed for school governance teams and training has been offered on everything from conducting effective meetings to conflict resolution to using quality tools for continuous improvement. The schools involved in this study, who were recognized as out in front of others in their commitment to the process of becoming accountable for improving student achievement, were also among those schools that first initiated participatory governance structures.

This study reported that each of these schools significantly involves teachers in governance and decisionmaking through various structures and processes that include grade level teams, design task committees, and school governance groups. In particular, teachers took control of decisions relative to the identification of standards, and the development and implementation of related assessments. They are also actively involved in other discussions and decisions about issues such as staff development and school operations.

There were, however, various comments made by teachers and administrators about the content of the decisions open to these groups. They feel there are still a great many strings attached to budget and resources; they often have limited access to essential knowledge; and the district still 
maintains at least partial control over things such curriculum, assessment, staff development, and the selection and placement of personnel.

On the positive side, these schools provided teachers with extensive opportunities for meaningful involvement in school governance. However, they also found that time, knowledge, resources, structures, and authority influenced their ability to engage in significant decisionmaking, and to move beyond merely making decisions to actually achieving results.

Thus, in the area of site-based management and shared decisionmaking, educational policymakers and practitioners must:

- clearly define the locus of accountability, identifying the actual accountability and associated responsibility of each level of the system, and of each stakeholder group, within the intricate and complex web of roles and relationships that form schools and school systems;

- promote the autonomy of school sites by allocating significant authority with accompanying knowledge and resources to school site stakeholders, and broadening to the extent possible the schools' scope of decisionmaking responsibility;

- address explicitly the conflicts which may arise among site-based decisionmaking, contractual issues, and policy and programmatic mandates;

- help school stakeholders determine who should be involved in making which decisions, and how to increase involvement in decisionmaking processes (particularly beyond teachers and administrators to the inclusion of other school staff, parents, and community); and 
- build capacity at school sites for stakeholders to engage in responsible, meaningful, effective, student achievement-focused decisionmaking processes within their scope of authority.

\section{Accountability, Restructuring, and Leadership}

Leadership is being reconceptualized in the educational reform literature yet it is still barely mentioned in much of the literature on accountability. There are challenging issues which must be addressed relative to school site leadership in the context of school restructuring and educational accountability, including: integrating the concepts of participatory leadership, autonomy, and accountability; promoting and practicing shared leadership and communal responsibility within bureaucratic systems and traditional views of school administration; and providing training for participatory leadership roles and relationships.

In San Diego City Schools, leadership appears to be viewed from a predominantly modern perspective; it is connected to position, person, management, and administration. Thus a quarterly get together of the superintendent's leadership team means a meeting of all district management and supervisory personnel. Leadership professional development conferences involve management-oriented workshops for school site and central office administrators. A call for a change in school site leadership translates into transferring the principal.

At the school sites involved in this study, however, the conceptualization and practice of leadership seems to be evolving toward a 
postmodern construct embedded in democratic relationships, dialogue, collective learning, and the pursuit of change. Teachers connected leadership with something that was open for their participation; involved vision, collaboration, and transformation; and existed within the school community as an opportunity tied to context, interest, influence, knowledge, and skill.

To promote significant school reform as society moves into the postmodern era, educational policymakers and practitioners need to reconsider their current views of school leadership, and:

- interconnect school restructuring, mutual accountability for student achievement, and school site leadership around the idea of empowerment;

- reconceptualize school site leadership in a postmodern, constructivist approach as articulated in much of the educational reform literature;

- recognize the risks and challenges associated with shared leadership, and promote and support school site leadership that is grounded in a collective sense of responsibility; and

- build capacity through leadership development that includes all members of the educational community, and focuses on leadership as a change process and an influence relationship.

\section{Translating Policy Into Practice in a Reform Culture}

This study illustrates that it is a complex process to translate policy into practice and make reform a reality. The findings exemplify how an educational policy interacts uniquely with each context, particularly within a culture of restructuring, site-based accountability, and participatory 
governance and leadership. Policies thus evolve through their implementation. Each school in this study began with the same policy statement and the same training. However, the interpretation of that policy, the translation of the training into action, and thus the ultimate outcomes were unique to each setting.

The Leadership in Accountability Demonstration Schools were charged with developing a prototype accountability system model based on the district student achievement accountability policy. Several expected outcomes, primarily procedural, were identified prior to the initial training; to differing degrees, these expected outcomes were achieved by the three schools studied. It was not the expected outcomes, however, but the unexpected and undefined ones that made the project not just an exercise in policy implementation but a valuable experience with school reform.

First, there was an emergent sense of self-determination at each school: Teachers and administrators realized their fate was in their own hands, and they could make of the project and thus of school reform as much or as little as they wanted. In addition, there were significant changes in perceptions, in actions, and in cultures at each of these schools. And finally, teachers in particular gained an increased sense of professionalism and empowerment through their engagement with colleagues in substantive conversations about teaching and learning, and through their active involvement in school site decisionmaking, governance, and leadership. 
In education, policy has been primarily viewed as a static statement, with an accompanying expectation that its translation into practice will occur similarly across school sites. In addition, reform has generally been seen as a special event or as a series of sporadic efforts that have definable beginnings and endings. However, many of those within and outside of education are coming to recognize that policy implementation is indeed a complex process, and that reform involves ongoing evolutionary changes that take place within particular contexts and within particular cultures.

Thus, in translating policy into practice and making reform a reality, educational policymakers and practitioners must:

- clearly define the elements and issues involved in each policy, then recognize and support the unique interpretation and implementation of the policy in each context;

- acknowledge unknowns and expect unexpected outcomes in the process of policy implementation within reform cultures;

- reorient their thinking toward a view of school reform and policy implementation as ongoing, steady work that involves both reculturing (developing new values, beliefs and norms), as well as restructuring (creating new roles, relationships, structure, and mechanisms for enabling the new cultures to thrive); and

- provide continuing direction and support to schools and their stakeholders, and counsel patience as the reform process is multifaceted, complex, and unfolds only over time. 


\section{Recommendations}

This report has presented a study of school engagement in a process of reform. It has looked through the eyes of teachers and administrators to tell the stories of three elementary school sites that took a journey to restructure their schools and build cultures of shared accountability for the improvement of student achievement. It has developed, for each individual school and across the three sites, a description of the processes undertaken to create sitebased accountability systems; an investigation into changes in teaching and learning; an examination of governance structures and decisionmaking practices; a discussion of the challenges and successes of engagement in school reform efforts; and a look into the emergent school accountability cultures. The study has also presented a holistic look at leadership as conceptualized by teachers at these three schools. Finally, it has discussed implications for educators relative to restructuring, accountability, and school site leadership.

What then are some recommendations that can be made to schools, to educators, to researchers? This section first offers some suggestions, from teachers in the study, to both policymakers and practitioners. Next, it presents four recommendations from the researcher based on an integration of the findings, the identified implications, and the suggestions from the participants. Finally, it introduces ideas for further study in this area. Words of Wisdom From Participants

Educational policymakers and practitioners can learn a great deal from listening to the voices of those in the field. Teachers in this study were asked 
to consider their experiences with the LAD project, then dispense some advice to the district and to other schools and teachers that are trying to engage in school reform and improve student achievement.

Have a vision and keep it alive. To initiate and maintain any change effort requires vision as well as commitment. The vision sets the direction and inspires others to come along on the journey. As Andrea from Paloma indicated, it is essential to "have people with vision who will keep it going, and empower a lot of people on the staff-have lots of leaders and lots of people who are very enthused."

Carrying the vision and thus the reform work forward then requires commitment. Engaging teachers in the process as professionals, and empowering them to make decisions and implement changes, builds ownership, respect, professionalism, and collegiality. Kent, a member of Sierra's accountability leadership team, said that schools need to "make the teachers feel empowered, make them part of the process ... because they have to buy-in to it." Allison, another Paloma teacher, summarized these ideas:

You need buy-in from all the teachers, and they need to put into practice all the principles that the school is adopting, and you need follow-through. It's great to start something with a great vision of how it could be, but it takes so long for real change to happen.... You need to keep working on it, and make it happen, and keep the same vision. Start slow and keep focused. Starting slowly, and allowing the process to grow and evolve, was a key recommendation from many teachers. Kent, at 
Sierra, said "I think it's important to go slow, it's important to make it an evolution ... give it a chance to grow, a chance to change." Tina, a teacher at Mariposa, added "start it slow ... it's got to develop into more, continue to look at it, to revise it, to make changes." Marie, from Paloma, emphatically recommended that schools "do it slowly and consult the staff."

Focus was important to teachers as well-most of them have experienced, in the course of their careers, the crush of new ideas and programmatic changes that seem to flood the educational realm. Helen, a long-time teacher now at Paloma, suggested that educators "just focus on certain areas, start with one area that needs reform and work and stick with it." Marie added, "we don't need to do everything, just a few things and do them very well and thoroughly and with quality."

School site power, school site models. Teachers stressed that locating the power to change at the school site level is an essential element of school reform work. Nancy, a lead teacher at Mariposa, felt that schools sometimes have little power to make significant changes; she proposed that the district "give us the resources and the power to meet the needs of the students, and then give us a little time to make it work."

However, teachers also indicated that every school does not need to start over from scratch; schools can learn from the work of these sites and others that have taken the lead in school reform. Wendy, Sierra resource teacher, noted that the LAD schools "are really research bases." Nancy, from Mariposa, asked, "why aren't these three or four schools getting together and 
developing a model for the district?" She added that, while "some staffs may be pretty self motivated where they get a project and they go right to work on it, some schools need more modeling and guidance."

Learning from those out in front. These teachers acknowledged that school reform is not easy; they hope others can learn from their experiences and their struggles. Perhaps if they had known exactly what they were getting into, how much work it would be, they might have shied away. Then again, maybe they wouldn't-reformers usually have an entrepreneurial spirit.

However, the cautions and suggestions these teachers offer to practitioners in the field are well advised-start slow, keep focused, have a vision, empower others to keep the vision alive. As Andrea from Paloma said, "take baby steps because things just don't happen that fast," but keep moving forward with the vision always in mind. The suggestions the teachers make to districts and policymakers have merit as well-give schools the resources and the power to make changes, give them the time and latitude to try things out and to make things work, and use successful efforts as models and inspirations for other schools.

Recommendations From the Researcher

As a researcher, a significant part of my responsibility is to now put forward my own recommendations based on a thoughtful, integrated metaanalysis of the literature, the collected data, the voices of the participants, and the emergent conclusions and implications. I propose the following four 
recommendations to policymakers and to practitioners across school sites, districts, and educational systems.

\section{Recommendation 1: Encourage and sustain site autonomy and} accountability by building capacity for meaningful, participatory decisionmaking. Since the mid-1980s, a great deal of attention has been paid in education to the idea of shared decisionmaking at the school site level. It is central to the literature on restructuring and site-based management, and integrated into much of the discussion about educational accountability. However, the literature and the findings of this study indicate mixed results on the degree to which decisionmaking authority has truly devolved to school sites, the amount of actual implementation of participatory governance processes, the extent of stakeholder involvement in the processes that do exist, and the content and effectiveness of the decisions made by participatory governance councils.

Shared decisionmaking must go hand-in-hand with the ideas of restructuring and reculturing, and with the placement of accountability at the school site level. To improve shared decisionmaking processes and sustain site autonomy and accountability, I recommend the following:

A. District educators must critically review policies and practices related to site-based shared decisionmaking. This should include expanding to the fullest extent possible the degree of authority which devolves to the school site level, and clearly defining in which areas decisions are truly under the control of stakeholders at the school site. 
B. School systems must provide appropriate training for school site stakeholders to enable them to engage effectively and meaningfully in shared decisionmaking focused on the improvement of student achievement.

C. Districts should rethink and redesign current school and system structures, cultures, schedules, and communication processes in order to provide stakeholders at the school site level with the authority, flexibility, time, knowledge, and resources they need to engage in significant discussions about policy and practice, and thus make informed decisions.

Recommendation 2: Invest heavily in ongoing, systematic professional and organizational development. Capacity is a theme that winds through much of the literature on restructuring and accountability; it also wove through my conversations with teachers and administrators as they discussed their experiences with the accountability demonstration project. Investing time, energy, and resources in support of comprehensive, sustained, systematic, systemic professional and organizational development will help build capacity to enact changes in teaching and learning, governance and decisionmaking, roles and relationships, cultures and structures.

To support school reform around restructuring and accountability, I recommend that:

A. A fully-funded, well-trained department of professional and organizational development should be a part of every school system, with staff working at both district and school site levels. 
B. The professional development process should include needs assessment, systematic planning, and effective training experiences based on the best knowledge about adult learning. It must also incorporate mechanisms to monitor implementation, provide appropriate follow-up, and support maintenance and evolution.

C. School systems must extend multiple opportunities for participation in appropriate professional development to administrators, teachers, support staff, parents, and community members. The system must also enable, promote, and support such participation through the investigation of different processes for the dissemination of information, the use of time and personnel, and the allocation of resources.

D. Professional development activities must be integrated, broadbased, grounded in research, and conceptual as well as practical. They need to address key concepts prominent in the literature on school reform, restructuring, and accountability, including: teaching and learning processes, participatory decisionmaking, school structure and organization, collaboration, change, leadership.

E. School districts must better integrate resources and services across central office departments in order to provide direct support to schools. This requires focused attention to processes and structures for communication, collaboration, strategic planning, policymaking, and policy implementation.

F. Districts must work to build the capacity of school site stakeholders, to enable them to rethink and redesign school organizational structures; 
change teaching and learning; and implement more effective planning, communication, and decisionmaking processes.

Recommendation 3: Promote entrepreneurial mindsets that are grounded in sound educational practice, and consider reform efforts as a research and development process. Charter schools are the rage in the 1990s, touted as oases in a bureaucratic desert where innovation and creativity are encouraged rather than stifled. Yet as this study reports, innovation can be found within a large urban public school district, and can even be promoted by the system itself. The difficulty seems to lie not in encouraging innovation at the individual classroom or school level, but in grounding that innovation in sound educational research and practice, sustaining it, nourishing its growth, and seeding its expansion.

To promote not only innovative ideas, but the translation of those ideas into practice, I recommend the following:

A. Educational policymakers and practitioners across all levels of the system should foster entrepreneurial mindsets and promote risk-taking by administrators, teachers, staff, parents, and community. However, they must simultaneously take care to ensure that ideas and innovations are based on the needs of the individual school community and grounded in research about best educational practices.

B. System administrators should consider classrooms and schools as research and development sites. Collegial sharing, professional networking, and cross-fertilization should be encouraged and promoted among teachers 
within and across schools, among schools within and across communities, and among school districts within the country and around the world.

C. Policymakers and district administrators must look carefully at personnel policies and practices in order to ensure that schools have sufficient continuity in staff to sustain their reform work; and cadres of knowledgeable, experienced teachers across classrooms and programs.

D. Site-level educators must promote their own reform efforts throughout the educational community. While district support and recognition are valuable, site-based decisionmaking goes hand-in-hand with site ownership of the change process and its outcomes.

Recommendation 4: Reconceptualize and develop school site leadership as an empowering and relational process. It is time for educators to get serious about the essential interconnection of restructuring, accountability, and leadership. The educational reform literature clearly indicates that a revised and expanded conceptualization of leadership, in line with emerging postmodern values, is needed to both implement and sustain educational reform efforts. Those educators addressing the concept of accountability, while making connections to school reform and restructuring, do not seem to make the associated connections with reformed leadership.

I recommend that educators clearly and explicitly link school restructuring, site-based accountability for the improvement of student achievement, and new conceptualizations of leadership: 
A. Educational policymakers and practitioners, from the national level to the local school site, need to embed into their thinking and practice a postmodern construct of leadership. Leadership, in this sense, is empowering: it involves democratic relationships grounded in a sense of communal responsibility; civic discourse about critical issues, and sensitive critique of ideas and practices; individual and collective learning; the intent and pursuit of change; and praxis, where theory becomes located in activity and intent becomes translated into action.

B. Policies and practices must be critically analyzed to ensure they both promote and support the exercise of shared leadership, and the acceptance of responsibility and accountability among the leadership community.

C. Professional development practices should be designed and implemented at all stages and levels, from preservice to inservice and from the school site to the central office, to build the capacity of current and future participants in the educational enterprise to meaningfully and productively engage in collaborative leadership relationships.

\section{Suggestions for Further Study}

This research project dug into one tiny corner of the potential field of study relative to restructuring, accountability, and leadership. This is an explosive field, with a multitude of activity underway at local, state, national, and international levels. For this study, I chose to investigate three elementary schools, within one large urban school district, that engaged in a pilot project to design and implement site-based systems to demonstrate 
accountability for student achievement. Looking through the eyes of a selected group of involved teachers and administrators, I focused on the processes in which they engaged, the effects they identified on teaching and learning, the types of governance structures and decisionmaking processes they embraced, the challenges and successes they experienced, the cultures they developed, and their views on leadership. There are many things I did not touch; in fact, I had to constantly remind myself to stay focused on my path, and not branch off and begin traveling along other roads that looked equally as interesting.

What, then, are some other areas in which additional investigation might complement and supplement this study in its contribution to the body of educational research? I propose the following two fields of study to further expand the educational knowledge base relative to school restructuring, accountability for student achievement, and school site leadership.

The San Diego accountability demonstration school project. In-depth and longitudinal research are both sorely needed in education. There are few investigations that delve deep into schools and their cultures. There are few as well that cover a long enough time span to look into how reform efforts are sustained, how they evolve, or what long-term effects there may be for students, staff, and the educational community. Continuing study of these three schools and others from the San Diego accountability demonstration school project might include: 
- expanding participation in the study to other teachers (for example, the resisters rather than the supporters) and/or to other stakeholder groups (support staff, parents, students) in order to get a broader picture;

- extending the study over several years to investigate how their work evolves and whether changes are sustained;

- embedding the researcher into a school as a true ethnographer to further investigate school and/or classroom cultures;

- identifying and describing specific changes in teaching practices;

- determining the influence on student achievement through the analysis of site and district assessment data; and

- observing and documenting the process and content of shared decisionmaking activities and/or the practice of leadership.

The interconnection of school restructuring, site-based accountability, and school site leadership. The restructuring movement suggests that, in exchange for increased site autonomy, schools must also assume greater accountability for student outcomes. The educational reform literature also connects restructuring with new conceptualizations of leadership.

Qualitative approaches such as case study, ethnography, phenomenology, and grounded theory offer an opportunity to conduct further research across school levels, campus sizes, and geographic locations. This study of school reform might address:

- the degree of devolution of authority and associated accountability at restructuring schools and in restructuring districts; 
- school organizational structures, management practices, and teaching and learning processes;

- shared decisionmaking and participatory governance processes, including the types of decisions available to be made as well as those actually made at the school site level, the participants in shared decisionmaking groups, the impact of decisions on school practices;

- the reordering of rules, roles, and relationships at the school site and/or relationships between the school site and the district offices;

- the conceptualization and practice of leadership.

Thus, it is obvious that the interconnected areas of school restructuring, educational accountability, and school site leadership are open for many researchers. I strongly encourage educators to begin conducting action research within their own settings. I also recommend that other researchers, both within and outside the educational enterprise, consider investigating this exciting and critically important field of study.

\section{Concluding Remarks: Odysseys}

In the fall of 1993, I embarked on an odyssey by entering the doctoral program in leadership studies at the University of San Diego. The time was right, it seemed: I had just been promoted to an administrative position with the school district, requiring me to now complete professional credential coursework; I was involved in some of the current work in the educational field relative to school reform, standards, alternative assessment, and student 
achievement accountability; and I felt ready once again for the rigorous intellectual challenge of post-graduate study.

Nearly every course offered an opportunity to extend my knowledge base and pursue my area of emergent interest-school reform and accountability - from different angles. So I researched leadership and educational reform, investigated the issues of ethics and shared decisionmaking, wrote about mentoring, studied educational policymaking and implementation, facilitated a future search, and analyzed a restructuring organization. I designed an evaluation study for the district accountability demonstration project, and practiced qualitative methodology by interviewing teachers and observing an innovative school program.

Thus the doctoral program and this dissertation reflect an intricate interconnection of my professional interests with my intellectual ones, and the interweaving of my career with my graduate study. My work provided me with valuable insights into my studies and those studies, in turn, provided me with valuable insights into my work. I leave the program more prepared-personally, intellectually, professionally-to face the challenges of education and of society as the twentieth century draws to a close.

Over the past decade, the San Diego Unified School District has also embarked on an odyssey. In 1988, the school board adopted a formal policy statement on restructuring, focusing attention on shared governance at the school site level. In 1990, a Student Achievement Accountability Committee (SAAC) was formed to address the highly-charged issue of improving student 
learning outcomes and closing the achievement gap. In 1993, following the SAAC's report to the board, the Leadership in Accountability Demonstration (LAD) School project was launched. Also in 1993, the new district superintendent put forth sixteen expectations for the improvement of student achievement and organizational effectiveness. In 1994 and 1995, work proceeded with the accountability demonstration project, development of content standards, and initiation of a new site planning process.

A confluence of events occurred in 1996: a teachers' strike in which processes for shared decisionmaking and accountability joined salary issues at center stage; an operational audit which led to central office restructuring and a focus on school clusters as the unit of change; school board adoption of consultation drafts of content and performance standards; and the formation of an accountability implementation task force, representing all major stakeholder groups, which brought forward for a plan for districtwide implementation of a student achievement accountability system.

In 1997, the district continues to pursue reform on multiple fronts: the articulation of challenging, world-class standards for student performance; mutual accountability for the improvement of student achievement; significant and meaningful shared decisionmaking at school site and district levels; professional and organizational development; strategic planning. These elements are beginning to come together as the district and its staff, students, parents, and community approach the new century. 
As individuals, as educators, as a society, we are embarking on a collective odyssey. Glickman (1993a, p. 3) observes that "each generation justifies its uniqueness by claiming to live in either the best or, more usually, the worst of times. 'Never before in history' is a nice phrase for a speaker or writer to use in flattering an audience with the uniqueness of its generation." Streshly and Newcomer (1994, p. 62) indeed use that exact phrase: "Never before in history has there been such as demand for American educators to 'stand and deliver' regarding their performance." To read the newspaper, to listen to campaign rhetoric, to talk to the man or woman on the street, one could come to believe that American education and, indeed, American society are in critical condition.

Yet my travels across the country, my visits to schools and their communities, my conversations with teachers and administrators through this study, lead me to conclude differently. Yes, there are problems in our society. No, all schools are not demonstrating success with all students. But there are many dedicated teachers and administrators, and many concerned parents and community members, who are trying to make a difference, whether it's in the life of one child or a thousand children. There are many schools and districts seeking out new ideas and new approaches to schooling. There are many educators striving to engage in a new level of collegial discourse about teaching and learning, about professionalism and accountability, about the improvement of student achievement. 
We cannot say never before, but we do find ourselves in a rare place in history, perched on the brink of not only a new century but a new millennium. While we know, in our hearts, that no miraculous change will occur when the clock ticks past midnight and the calendar page flips over, just the idea fills many of us with a sense of optimism. I hope that all of usindividually and collectively-will use this time for reflection and then for action. We need to seize the sense of opportunity that hovers in the air and embrace change as a journey we are ready and willing to undertake.

This study told the stories of three schools that took their own journeys and found educational reform at the intersection of school restructuring, accountability for student achievement, and school site leadership. Teachers and administrators at these schools discussed what students should know and be able to do, created ways to assess those knowledge and skills, began changing the teaching and learning process, embraced participatory governance and collaborative decisionmaking, faced challenges, and celebrated successes. They found that leadership is essential for change in the educational context and they began to reconceptualize leadership, building opportunities for those within their professional communities to enter into leadership relationships.

Key to their journeys has been the theme of empowerment: as a collaborative process, as a sense of personal and professional identity, as an opportunity for entrepreneurial behavior. It is time now for us to embark on our collective odyssey and empower students, empower teachers, empower 
schools and their communities, and empower leadership itself. Empowering leadership has a dialogic dimension. It requires engagement with others to actualize the leadership relationship. It also requires engagement with others to bring the experience which those in the leadership relationship strive to enact-school reform and the improvement of student achievement-from capacity to realization. Through empowering leadership in education and in society, we may also empower the children of today to become our leaders of tomorrow-those who will lead our odyssey through the twenty-first century and the third millennium. 


\section{REFERENCES}

Accountability Implementation Task Force. (1996, November). District accountability system. San Diego: San Diego City Schools.

Accountability Implementation Task Force. (1997, March). A district accountability system for improoing student achievement. San Diego: San Diego City Schools.

Amundson, K. J., \& Richardson, C. (1991). Straight $A^{\prime}$ s: Accountability, assessment, achievement (NSBA Leadership Reports No. 1991-1). Alexandria, VA: National School Boards Association. (ERIC Document Reproduction Service No. ED 342 057).

Angus, L. B. (1986). Developments in ethnographic research in education: From interpretive to critical ethnography. Journal of Research and Development in Education, 20 (1), 59-67.

Angus, L. (1989). 'New' leadership and the possibility of educational reform. In J. Smyth (Ed.), Critical perspectives on educational leadership (pp. 63-92). London: Falmer.

Astin, H., \& Leland, C. (1991). Women of influence, women of vision. San Francisco: Jossey-Bass.

Bellah, R. N., Madsen, R., Sullivan, W. M., Swidler, A., \& Tipton, S. M. (1985). Habits of the heart: Individualism and commitment in American life. Berkeley: University of California Press.

Bellah, R. N., Madsen, R., Sullivan, W. M., Swidler, A., \& Tipton, S. M. (1991). The good society. New York: Vintage.

Bennett, S. J. (1995a, January). Interim report on the implementation of accountability at the Leadership in Accountability Demonstration (LAD) Schools. San Diego: San Diego City Schools, Planning, Assessment, and Accountability Division.

Bennett, S. J. (1995b, October). Evaluation of the implementation of accountability at the Leadership in Accountability Demonstration (LAD) Phase I Schools. San Diego: San Diego City Schools, Planning, Assessment, and Accountability Division.

Bergquist, W. (1993). The postmodern organization: Mastering the art of irreversible change. San Francisco: Jossey-Bass. 
Block, P. (1993). Stewardship: Choosing service over self-interest. San Francisco: Berrett-Koehler.

Bredeson, P. V. (1994). Empowered teachers-empowered principals: Principals' perceptions of leadership in schools. In N. A. Prestine \& P. W. Thurston (Eds.), Advances in educational administration: New directions in educational administration: Policy, preparation, and practice (pp. 195-220). Greenwich, CT: JAI Press.

Brenner, M., Brown, J., \& Canter, D. (1985). Introduction. In M. Brenner, J. Brown \& D. Canter (Eds.), The research interview: Uses and approaches (pp. 1-8). London: Academic Press.

Brown, P. R. (1990). Accountability in public education (Policy Briefs No. 14). San Francisco: Far West Laboratory for Educational Research and Development.

Burns, J. M. (1978). Leadership. New York: Harper \& Row.

Caldwell, B. J., \& Spinks, J. M. (1992). Leading the self-managing school. London: Falmer.

California Department of Education. (1996). Guide to challenge school district reform. Sacramento: Author.

Carlson, R. V. (1996). Reframing and reform: Perspectives on organization, leadership, and school change. White Plains, NY: Longman.

Carnegie Forum on Education and the Economy. (1986). A nation prepared: Teachers for the 21st century. Washington, DC: Author.

Carriedo, R., Callahan, F. P., Bennett, S. J., \& Morgan, F. (1995, November). Implementation timeline for district accountability plan. San Diego: San Diego City Schools, Planning, Assessment, and Accountability Division.

Chance, E. W. (1992). Visionary leadership in schools. Springfield, IL: Charles C. Thomas.

Charlotte-Mecklenburg Schools. (1995). Benchmark Goals 1995-96: Description and rules. Charlotte-Mecklenburg, NC: Research, Assessment and Planning Services.

Coffey, A., \& Atkinson, P. (1996). Making sense of qualitative data. Thousand Oaks, CA: Sage. 
Cohen, M. (1989). Restructuring the system. Society, 26 (4), 40-48.

Conley, D. T. (1996). Are you ready to restructure? Thousand Oaks, CA: Corwin.

Conley, D. T., \& Goldman, P. (1994). Facilitative leadership: How principals lead without dominating (OSSC Bulletin Vol. 37, No. 9). Eugene, OR: Oregon School Study Council. (ERIC Document Reproduction Service No. ED 379 728)

Council of Chief State School Officers. (1989). Success for all in a new century. Washington, DC: Author. (ERIC Document Reproduction Service No. ED 318 122)

Council of Chief State School Officers. (1992). Leadership versus control: A strategic approach to lasting school reform. Washington, DC: Author.

Cullen, C., \& Altschuld, J. W. (1994, July). Teachers' perspectives on accountability. Paper presented at the Third Annual National Evaluation Institute, Gatlinburg, TN. (ERIC Document Reproduction Service No. ED 376 165).

Darling-Hammond, L. (1988). Accountability and teacher professionalism. American Educator, 12 (4), 8-13, 38-43.

Darling-Hammond, L. (1993). Reframing the school reform agenda: Developing capacity for school transformation. Phi Delta Kappan, 74, 752-761.

Darling-Hammond, L., \& Ascher, C. (1991). Creating accountability in big city schools (Urban Diversity Series No. 102). New York: ERIC Clearinghouse on Urban Education.

Darling-Hammond, L., \& Snyder, J. (1992). Reframing accountability: Creating learner-centered schools. In A. Lieberman (Ed.), The changing contexts of teaching: Ninety-first yearbook of the National Society for the Study of Education (pp. 11-36). Chicago: University of Chicago Press.

Darling-Hammond, L., Snyder, J., Ancess, J., Einbender, L., Goodwin, A. L., \& Macdonald, M. B. (1993). Creating learner-centered accountability. New York: National Center for Restructuring Education, Schools, and Teaching. (ERIC Document Reproduction Service No. ED 364 592)

David, J. L. (1989). Synthesis of research on school-based management. Educational Leadership, 46 (8), 45-53. 
David, J. L. (1991). What it takes to restructure education. Educational Leadership, 48 (8), 11-15.

DeMoulin, D. F., \& Kendall, R. (1993). The administrative role in an accountability network: A developmental conceptualization. Journal of School Leadership, 3, 688-698.

Donahoe, T. (1993). Finding the way: Structure, time, and culture in school improvement. Phi Delta Kappan, 75, 298-305.

Duignan, P. A., \& Macpherson, R. J. S. (1992). A practical theory of educative leadership. In P. A. Duignan \& R. J. S. Macpherson (Eds.), Educative leadership: A practical theory for new administrators and managers (pp. 171-185). London: Falmer.

Education Commission of the States. (1995). Rising to the challenge: A new agenda for California schools and communities. Denver: Author.

Edwards, W. L. (1991). Accountability and autonomy: Dual strands for the administrator. In W. Walker, R. Farquhar., \& M. Hughes (Eds.), Advancing education: School leadership in action (pp. 29-50). London: Falmer.

Eisner, E. W. (1991). The enlightened eye: Qualitative inquiry and the enhancement of educational practice. New York: Macmillan.

Eisner, E. W., \& Peshkin, A. (1990). Closing comments on a continuing debate. In E. W. Eisner \& A. Peshkin (Eds.), Qualitative inquiry in education: The continuing debate (pp. 365-368). New York: Teachers College Press.

Fetler, M. (1990). California's role in school accountability (Policy Briefs No. 14). San Francisco: Far West Laboratory for Educational Research and Development.

Finn, C. E. Jr. (1992). Up from mediocrity: What next in school reform. Policy Review, 61, 80-83.

Finn, C. E., Jr., \& Rebarber, T. (1992). The changing politics of education reform. In C. E. Finn, Jr. \& T. Rebarber (Eds.), Education reform in the '90s (pp. 175-193). New York: Macmillan.

Firestone, W. A., \& Dawson, J. A. (1988). Approaches to qualitative data analysis: intuitive, procedural, and intersubjective. In D. M. Fetterman (Ed.), Qualitative approaches to evaluation in education: The silent scientific revolution (pp. 209-221). New York: Praeger. 
Forest, S. A. (1994, June). A progress report on the Leadership in Accountability Demonstration (LAD) Schools. San Diego: San Diego City Schools, Planning, Assessment, and Accountability Division.

Foster, W. (1986). The reconstruction of leadership. Victoria, Australia: Deakin University.

Foster, W. (1988). Education administration: A critical appraisal. In D. E. Griffiths, R. T. Stout, \& P. B. Forsyth (Eds.), Leaders for America's schools (pp. 68-81). Berkeley: McCutchan.

Foster, W. (1989). Toward a critical practice of leadership. In J. Smyth (Ed.), Critical perspectives on educational leadership (pp. 39-62). London: Falmer.

Fullan, M. G. (1994, July). Turning systemic thinking on its head. Paper prepared for the United States Department of Education, Toronto, Canada.

Fullan, M. G., \& Miles, M. B. (1992). Getting reform right: What works and what doesn't. Phi Delta Kappan, 73, 743-752.

Garmston, R., \& Wellman, B. (1995). Adaptive schools in a quantum universe. Educational Leadership, 52 (7), 6-12.

Glickman, C. D. (1993a). Renewing American's schools: A guide for school-based action. San Francisco: Jossey-Bass.

Glickman, C. D. (1993b). Restructuring policy for America's schools. NASSP Bulletin, 76 (549), 87-97.

Goens, G. A., \& Clover, S. I. R. (1991). Mastering school reform. Boston: Allyn and Bacon.

Goodlad, J. I. (1984). A place called school: Prospects for the future. New York: McGraw-Hill.

Griffiths, D. E., Stout, R. T., \& Forsyth, P. B. (1988). Preface. In D. E. Griffiths, R. T. Stout, \& P. B. Forsyth (Eds.), Leaders for America's schools (pp. xiii-xv). Berkeley: McCutchan.

Guba, E. G., \& Lincoln, Y. S. (1989). Fourth generation evaluation. Newbury Park, CA: Sage. 
Guskey, T. R. (Ed.). (1994). High stakes performance assessment: Perspectives on Kentucky's educational reform. Thousand Oaks, CA: Corwin.

Hansen, J. B. (1990, April). Accountability as a tool for education reform: Is it an oxymoron? In Accountability legislation and school reform: Issues and perspectives from districts and states. Symposium conducted at the annual meeting of the American Education Research Association, Chicago, IL. (ERIC Document Reproduction Service No. ED 330 010)

Hargreaves, A. (1995). Renewal in the age of paradox. Educational Leadership, 52 (7), 14-19.

Harrington-Lueker, D. (1990). The engine of reform gathers steam: Kentucky starts from scratch. American School Board Journal, 177 (9), 17-21.

Heck, R. H. (1992). Principals' instructional leadership and school performance: Implications for policy development. Educational Evaluation and Policy Analysis, 14, 21-34.

Heifetz, R. A. (1994). Leadership without easy answers. Cambridge, MA: Belknap.

Herman, J. J., \& Herman, J. L. (1993). School-based management: Current thinking and practice. Springfield, $\mathrm{IL}$ : Charles $\mathrm{C}$. Thomas.

Hess, G. A. Jr. (1992). Anthropology and school reform: To catalog or critique? Anthropology \& Education Quarterly, 23, 175-184.

Hill, P. T., \& Bonan, J. (1991). Decentralization and accountability in public education. Santa Monica, CA: RAND. (ERIC Document Reproduction Service No. ED 334 665)

Hill, P. T., Bonan, J. J., \& Warner, K. (1992). Uplifting education. American School Board Journal, 179 (3), 21-25.

Houston Independent School District. (1996). 1996 Texas Education Agency Accountability System (Research Brief). Houston, TX: Department of Research and Evaluation.

Kentucky Department of Education. (1995, June). Kentucky education reform: The first five years at a glance, 1990-1995. Frankfort, KY: Author.

Kentucky Department of Education. (1996, October). Nearly all Kentucky schools show improvement in latest KIRIS scores, but middle schools lag behind. Press release. 
Kifer, E. (1994). Development of the Kentucky instructional results information system (KIRIS). In T. R. Guskey (Ed.), High stakes performance assessment: Perspectives on Kentucky's educational reform (pp. 7-18). Thousand Oaks, CA: Corwin.

Kirst, M. W. (1990). Accountability: Implications for state and local policymakers. Washington, DC: Office of Educational Research and Improvement. (ERIC Document Reproduction Service No. ED 318 804).

Lane, J. J., \& Epps, E. G. (1992). Introduction and overview. In J. J. Lane \& E. G. Epps, (Eds.), Restructuring the schools: Problems and prospects (pp. ixxvi). Berkeley: McCutchan.

Law, N. (1994). Holding schools accountable. Thrust for Educational Leadership, 24 (2), 39-43.

Lemahieu, P. G., \& Foss, H. K. (1994). Standards at the base of school reform: What are the implications for policy and practice? The School Administrator, 51 (5), 16-22.

Lessinger, L. M. (1971a). Accountability for results: A basic challenge for America's schools. In L. M. Lessinger \& R. W. Tyler (Eds.), Accountability in education (pp. 7-14). Worthington, OH: Charles A. Jones.

Lessinger, L. (1971b). Engineering accountability for results in public education. In L. M. Lessinger \& R. W. Tyler (Eds.), Accountability in education (pp. 28-41). Worthington, $\mathrm{OH}$ : Charles A. Jones.

Lieberman, A. (1992). Introduction: The changing context of education. In A. Lieberman (Ed.), The changing contexts of teaching: Ninetyfirst yearbook of the National Society for the Study of Education (pp. 1-10). Chicago: University of Chicago Press.

Lieberman, A., \& Miller, L. (1990). Restructuring schools: What matters and what works. Phi Delta Kappan, 69, 759-764.

Louis, K. S., \& Murphy, J. (1994). The evolving role of the principal: Some concluding thoughts. In J. Murphy \& K. S. Louis (Eds.), Reshaping the principalship: Insights from transformational reform efforts. Thousand Oaks, CA: Corwin.

Malen, B., \& Ogawa, R. T. (1992). Site-based management: Disconcerting policy issues, critical policy choices. In J. J. Lane \& E. G. Epps, (Eds.), Restructuring the schools: Problems and prospects (pp. 185-206). Berkeley: McCutchan. 
Malen, B., Ogawa, R. T., \& Kranz, J. (1990). Site-based management: Unfulfilled promises. The School Administrator, 47 (2), 30, 32, 53-56, 59.

Martin, D. T., Overholt, G. E., \& Urban, W. J. (1976). Accountability in American education: A critique. Princeton: Princeton Book Company.

McDonnell, L. M. (1989). Restructuring American schools: The promise and the pitfalls (Report No. EDO-UD-89-7). New York: ERIC Clearinghouse on Urban Education, Institute for Urban and Minority Education. (ERIC Document Reproduction Service No. ED 314 546)

Merriam, S. B. (1988). Case study research in education: A qualitative approach. San Francisco: Jossey-Bass.

Midgley, C., \& Wood, S. (1993). Beyond site-based management: Empowering teachers to reform schools. Phi Delta Kappan, 75, 245-252.

Miles, M. B., \& Huberman, A. M. (1988). Drawing valid meaning from qualitative data: Toward a shared craft. In D. M. Fetterman (Ed.), Qualitative approaches to evaluation in education: The silent scientific revolution (pp. 222-244). New York: Praeger.

Mojkowski, C. (1991). Developing leaders for restructuring schools: New habits of mind and heart. Washington, DC: U. S. Department of Education, Office of Educational Research and Improvement. (ERIC Document Reproduction Service No. ED 330 078)

Moloney, W. J. (1989). Restructuring's fatal flaw. The Executive Educator, $11(10), 21-23$.

Moorman, H., \& Egermeier, J. (1992). Educational restructuring: Generative metaphor and new vision. In J. J. Lane \& E. G. Epps, (Eds.), Restructuring the schools: Problems and prospects (pp. 15-59). Berkeley: McCutchan.

Murphy, J. (1992). Restructuring America's schools: An overview. In C. E. Finn, Jr. \& T. Rebarber (Eds.), Education reform in the '90s (pp. 3-20). New York: Macmillan.

Murphy, J. (1994). Transformational change and the evolving role of the principal: Early empirical evidence. In J. Murphy \& K. Louis (Eds.), Reshaping the principalship: Insights from transformational reform efforts, pp. 20-53. Thousand Oaks, CA: Corwin.

Neufeldt, V., \& Guralnik, D. B. (Eds.). (1994.) Webster's new world dictionary of American English (3rd college ed.). New York: Prentice Hall. 
O'Neil, J. (1990). Piecing together the restructuring puzzle.

Educational Leadership, 47 (7), 4-10.

Patton, M. Q. (1987). How to use qualitative methods in evaluation. Newbury Park, CA: Sage.

Payzant, T. W. (1991). From the bottom up: San Diego restructures. Thrust for Educational Leadership, 21 (1), 18-23, 50-51.

Peterson, T. K. (1992). Designing accountability to help reform. In C. E. Finn, Jr. \& T. Rebarber (Eds.), Education reform in the '90s (pp. 109-132). New York: Macmillan.

Petrosko, J. M. (1993, April). The plan for assessing the impact of the Kentucky Education Reform Act (KERA). Paper presented at the annual meeting of the American Educational Research Association, Atlanta, GA. (ERIC Document Reproduction Service No. ED 358 171)

Porter, J. W. (1971). Accountability in education. In L. M. Lessinger \& R. W. Tyler (Eds.), Accountability in education (pp. 42-52). Worthington, OH: Charles A. Jones.

Ricoeur, P. (1992). Oneself as another. Chicago: University of Chicago.

Rivzi, R. (1992). Educative leadership in a multicultural society. In P. A. Duignan \& R. J. S. Macpherson (Eds.), Educative leadership: A practical theory for new administrators and managers (pp. 134-170). London: Falmer.

CT: Praeger.

Rost, J. C. (1993). Leadership for the twenty-first century. Westport,

San Diego City Schools. (1990). Shared decisionmaking information packet. San Diego: Author.

Schlechty, P. C. (1990). Schools for the twenty-first century: Leadership imperatives for educational reform. San Francisco: Jossey-Bass.

Schmoker, M. (1996). Results: The key to continuous school improvement. Alexandria, VA: Association for Supervision and Curriculum Development.

School District of Philadelphia. (1994a). Children achieving: Action design, 1995-1999. Philadelphia: Office of the Superintendent. 
School District of Philadelphia \& Philadelphia Public School/Business Partnership for Reform. (1994b). Meeting the Annenburg challenge: Philadelphia responds. Philadelphia: Author.

Schwandt, T. A. (1993). Theory for the moral sciences: Crisis of identity and purpose. In D. J. Flinders \& G. E. Mills (Eds.), Theory and concepts in qualitative research: Perspectives from the field (pp. 5-23). New York: Teachers College Press.

Schwartz, H. (1991). Putting the pieces together: A systemic approach to educational reform. Planning and Changing, 22, 231-239.

Seidman, I. E. (1991). Interviewing as qualitative research: A guide for researchers in education and the social sciences. New York: Teachers College Press.

Senge, P. M. (1990). The fifth discipline: The art and practice of the learning organization. New York: Doubleday Currency.

Sergiovanni, T. J. (1990). Adding value to leadership gets extraordinary results. Educational Leadership, 47 (8), 23-27.

Singleton, J. (1983). Teaching fieldwork to educational researchers: Furry and bald approaches. Anthropology \& Education Quarterly, 14, 209-212.

Smyth, J. (Ed.). (1989). Critical perspectives on educational leadership. London: Falmer.

Southeastern Regional Vision for Education. (1994). A new framework for state accountability systems. Washington DC: Office of Educational Research and Improvement. (ERIC Document Reproduction Service No. ED 377 572)

Starratt, R. J. (1993). The drama of leadership. London: Falmer.

Steffy, B. E. (1993). Top-down-bottom-up: Systemic change in Kentucky. Educational Leadership, 51 (1), 42-44.

Stinnette, L. J. (1993). Decentralization: Why, how, and toward what ends? (Special Policy Report No. 1, Policy Briefs Series). Oak Brook, IL: North Central Regional Educational Laboratory. (ERIC Document Reproduction Series No. ED 368 047)

Streshly, W. A., \& Newcomer, L. (1994). Managing change with accountability: A challenge for educators. NASSP Bulletin, 78 (560), 62-68. 
Student Achievement Accountability Committee. (1993, March). Report and recommendations of the Student Achievement Accountability Committee. San Diego: San Diego City Schools, School Services Division, Area VI.

Theobald, P., \& Mills, E. (1995). Accountability and the struggle over what counts. Phi Delta Kappan, 76, 462-466.

Thomson, S. D. (1992). Preface. In S. D. Thomson (Ed.), School leadership: A blueprint for change (pp. v-viii). Newbury Park, CA: Corwin.

Trinity University. (1993). Getting accountability and school improvement on track in Texas: A report by the school superintendents of Bexar County. San Antonio: Center for Educational Leadership. (ERIC Document Reproduction Service No. ED 368 037)

U. S. Department of Education. (1983). A nation at risk: The imperative for educational reform. Washington DC: National Commission on Excellence in Education.

U. S. Department of Education. (1988). Creating responsible and responsive accountability systems: Report of the OERI State Accountability Study Group. Washington, DC: Office of Educational Research and Improvement. (ERIC Document Reproduction Service No. ED 299 706)

U. S. Department of Education. (1996a, March). Guidance on standards, assessment, and accountability (Draft). Washington DC: Compensatory Education Programs.

U. S. Department of Education. (1996b). Mapping out the national assessment of Title I: The interim report. Washington DC: Office of the Under Secretary, Planning and Evaluation Service, Elementary and Secondary Education Division.

Wagner, R. B. (1989). Accountability in education: A philosophical inquiry. New York: Routledge. 56-59.

Wasley, P. A. (1995). Straight shooting. Educational Leadership, 52 (7),

Webster, W. J., \& Edwards, M. E. (1993, April). An accountability system for school improvement. Paper presented at the annual meeting of the American Educational Research Association, Atlanta, GA. (ERIC Document Reproduction Service No. ED 358 132) 

14-18.

Wiggins, G. (1994). None of the above. The Executive Educator, 16 (7),

Wolcott, H. F. (1987). On ethnographic intent. In G. Spindler \& L. Spindler (Eds.), Interpretive ethnography of education: At home and abroad (pp. 37-57). Hillsdale, NJ: Lawrence Erlbaum Associates.

Wynne, E. (1972). The politics of school accountability: Public information about public schools. Berkeley: McCutchan.

Yin, R. K. (1984). Case study research: Design and methods. Beverly Hills, CA: Sage. CA: Sage.

Yin, R. K. (1993). Applications of case study research. Newbury Park:

Zaharlick, A. (1992). Ethnography in anthropology and its value for education. Theory Into Practice, 31, 116-125.

Zurhellen, H. S. (1987, November). Educational accountability within a context of academic freedom. Paper presented at the annual meeting of the American Educational Studies Association, Chicago, IL. (ERIC Document Reproduction Service No. ED 293 223). 


\section{APPENDIX A}

\section{LEADERSHIP IN ACCOUNTABILITY DEMONSTRATION SCHOOL}

APPLICATION PROCEDURE 
ADMINISTRATIVE CIRCULAR NO. Superintendent's Office No.

\section{SAN DIEGO CITY SCHOOLS}

Date:

To:

Subject:

\section{Department and/or \\ Persons Concerned:}

\section{Reference:}

Action Requested:

\section{Brief Explanation:}

December 16, 1992

School Principals and Site Governance Team Chairpersons

APPLICATION PROCEDURE FOR LEADERSHIP IN ACCOUNTABILITY DEMONSTRATION SCHOOLS

\author{
School Principals and Site Governance Team Chairpersons
}

None

Interested schools apply for demonstration school status

You are invited to participate in the district's Leadership in Accountability Demonstration (LAD) project. This project will serve as a prototype system for understanding, developing, and reporting accountability in student achievement across the district.

For nearly two years, the Student Achievement Accountability Committee (SAAC) has met to develop a set of guiding principles in accountability. The committee's final report is attached for your information.

\section{Incentives for Participation}

LAD schools will develop accountability plans to demonstrate progress in student achievement. Many sites have initiated projects, strategies, and/or activities aimed at improving students' achievement. For example, some schools have developed learner outcomes for certain subject areas, while others have become involved in the development of performance assessments at the classroom level. Others have redesigned their instructional day to maximize learning, or have focused their staff development for 1992-93 in one particular instructional area. Such sites will find that $L A D$ participation will add congruence to their work, by tying their activities into one coherent educational program with high standards for all students. Other benefits of participation include:

- Sustained attention from an interdivisional District Assistance Team.

- Opportunity to provide leadership in accountability for the rest of the district.

- Intensity of support from the area assistant superintendent.

- Increased flexibility in the design of their restructuring plan.

- Priority for waivers from Restructuring Leadership Team.

- Opportunities for innovations in staff evaluations.

- Opportunities for involvement in national and state projects in performance assessment.

- Flexibility in the use of unrestricted resources (block grant).

- Increased professional inservices based on identified needs. 
Administrative Circular No.

Superintendent's Office No.

Page 2

\section{Responsibilities of Demonstration Schools}

In conjunction with existing planning processes demonstration schools will:

- Infuse accountability elements into existing planning processes.

- Receive training in the four facets of accountability (standards, assessments, recognition/intervention, and reporting).

- Work with a District Assistance Team to meet school site needs.

- Design or identify multiple criteria for assessing student progress.

- Establish baseline measures and improvement targets.

- Design simple reporting tools and process for revising plans.

- Describe and recommend appropriate district recognition/intervention measures within budget constraints.

- Serve as a mentor for other district schools.

\section{Application and Review Process}

Interested schools and their site governance teams should work together to complete the attached application. Please note the attached project timeline for an overview of all future deadlines. Applications should be submitted by the site governance team to Freda Callahan in Room 3126, Education Center, by February 18. A combined committee of SAAC members in consultation with School Service Division assistant superintendents will review the applications that are received.

\section{Application Assistance}

The Grant Development Office will conduct three workshops in January to assist schools in preparing applications. A Workshop Registration Form is attached for those schools interested in attending.

Questions related to the application narrative should be directed to Dr. Callahan (293-8412) or Linda Carstens (293-8464). Questions related to the attachments or application format should be directed to Roxie Knupp, Grant Development Office (293-8024 or -8025).

\section{$\underline{\text { Selection Criteria }}$}

Approximately ten schools will be selected for participation and will be representative of each School Services Division area, all school levels, and all types of integration programs. Extensive commitment by the site governance team will be a primary factor in the selection process. Applications will also be evaluated on the school's vision and efforts in restructuring and their reasons for seeking $L A D$ status.

Participation in the accountability development and assessment phase will commence as soon as the demonstration schools have been selected. All other district schools will follow the lead of the demonstration schools beginning in school year 1994-95.

I look forward to your participation in the development of an accountability process for San Diego City Schools. 


\section{Application Narrative}

Please answer all of the questions thoughtfully and candidly.

1. What are your site goals or vision of restructuring for 1992-93?

2. How would your involvement as a LAD school in accountability tie to your restructuring goals or vision?

3. What assessment practices do you have in place now? How would you choose to augment those practices for greater accountability?

4. How do you envision the role of your primary stakeholders (district staff, area assistant superintendent, school site staff, parents, students, community, business, colleges and universities) in designing your accountability plan?

5. How do you foresee public reporting to parents and community of your accountability findings?

6. What activities do you have in place now to recognize staff efforts in improving student achievement?

7. What activities or system do you have in place now to assist staff to improve, expand or change their efforts related to student achievement? 
APPENDIX B

APPROVAL TO CONDUCT RESEARCH IN SAN DIEGO CITY SCHOOLS 


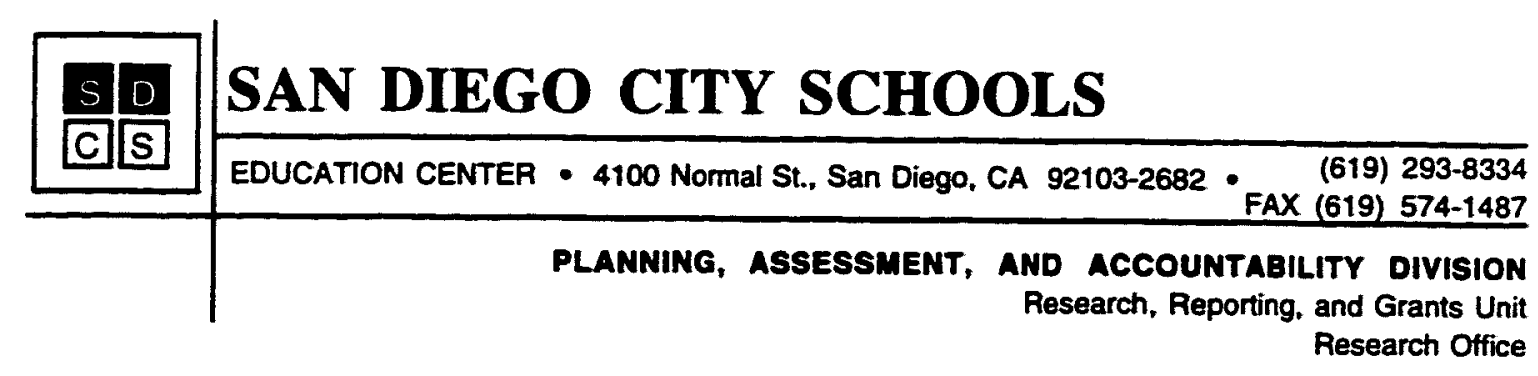

January 9, 1996

Ms. Sally Jean Bennett

San Diego City Schools

4100 Normal Street, Rm. 2008

San Diego, CA 92103

Dear Sally:

Our Research Proposal Review Panel was happy to review your application to conduct research in San Diego City Schools on "Student Achievement Accountability and School Leadership: Implications for Changing School Practices and Governance." Our committee has decided to approve your request.

I am sure that you will find the experience of conducting research in the district a valuable one. Freda Callahan, of course, stands ready to lend assistance for your study in working with district schools and central offices. Our office would greatly appreciate a copy of the final report on your findings.

If you have any questions or if I can be helpful to you, please contact me at (619) 293-8629.

Sincerely,

Peter D. Bell

Supervising Educational Researcher

c: Callahan 
APPENDDXC

SAMPLE INTERVIEW INVITATIONS AND FOLLOW-UP LETTERS 


\section{SAMPLE INVITATION TO GROUP INTERVIEW: LEADERSHIP TEAM}

October 1, 1996

Dear «FirstName»,

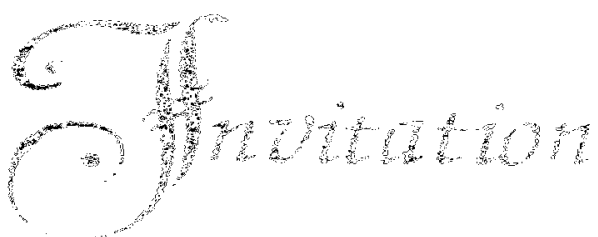

With permission from San Diego City Schools and the University of San Diego, I am conducting research for my doctoral dissertation at three of the district's original Leadership in Accountability Demonstration (LAD) schools. (School) is one of these schools. I am interested in learning about what your school has done as you have worked, over the past several years, on changes in teaching and learning, in decision-making, and in accountability for student achievement.

I believe that one of the best ways to find out about (school)'s work is to ask teachers who have been at the school since the initiation of the $\mathrm{LAD}$ project to share their perspectives, and as a member of (school)'s LAD Leadership Team, you have a unique perspective to offer. I would therefore like to invite you to participate in an interview with other LAD team teachers from your school, to "tell the story" of your school's experiences. This group interview will take place on:

Tuesday, October 15 at 2:30 p.m.

in the Teachers' Lounge

We will share some light refreshments, and will end the session with a drawing for some prizes for the classroom. In addition, recognizing that your participation in this interview takes some of your classroom preparation time which you may need to make-up on another day before or after regular working hours, you can be reimbursed for one hour at the curriculum development/materials preparation rate.

At the end of this group interview, I will be asking for volunteers who would be interested in participating in an additional interview to delve further into changes in the classroom, as well as in school site decision-making and governance processes. I will also ask you to discuss, from your perspective, the successes and challenges of your school's experiences; and share some personal and professional "words of wisdom" that might benefit other schools and teachers.

Please be assured that all your responses will remain confidential and your anonymity will be preserved. Attached is a copy of the consent form you will be asked to sign before the first interview, which further explains the expectations and your rights as a participant in the study. If you have any questions about the study or the interviews, please call me at my office (293-8505) or my home (222-0445).

I look forward to your participation in the study. Your perspective would be a valuable contribution to my research. I hope to see you on October 15.

Sincerely,

Sally Bennett

Program Manager for Program Accountability

San Diego City Schools

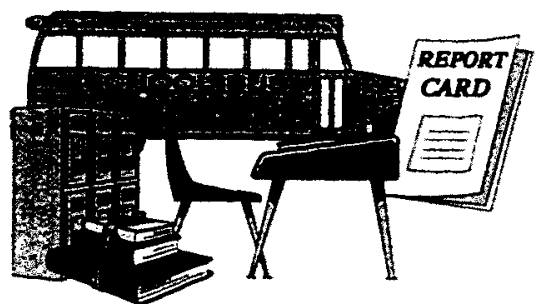




\section{SAMPLE INVITATION TO GROUP INTERVIEW: TEACHERS}

October 1,1996

Dear «FirstName»,

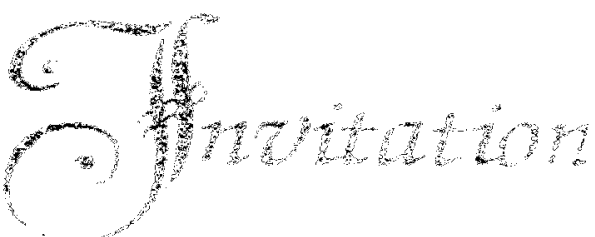

With permission from San Diego City Schools and the University of San Diego, I am conducting research for my doctoral dissertation at three of the district's original Leadership in Accountability Demonstration (LAD) schools. (School) is one of these schools. I am interested in learning about what your school has done as you have worked, over the past several years, on changes in teaching and learning, in decision-making, and in accountability for student achievement.

I believe that one of the best ways to find out about (school)'s work is to ask teachers who have been at the school since the initiation of the LAD project to share their perspectives. I would therefore like to invite you to participate in an interview with other teachers from your school, to "tell the story" of your school's experiences. This group interview will take place on:

\section{Wednesday, October 9 at 1:30 p:m.}

in the Teachers" Eounge

We will share some light refreshments, and will end the session with a drawing for some prizes for the classroom. In addition, recognizing that your participation in this interview takes some of your classroom preparation time which you may need to make-up on another day before or after regular working hours, you can be reimbursed for one hour at the curriculum development/materials preparation rate.

At the end of this group interview, I will be asking for volunteers who would be interested in participating in an additional interview to delve further into changes in the classroom, as well as in school site decision-making and governance processes. I will also ask you to discuss, from your perspective, the successes and challenges of your school's experiences; and share some personal and professional "words of wisdom" that might benefit other schools and teachers.

Please be assured that all your responses will remain confidential and your anonymity will be preserved. Attached is a copy of the consent form you will be asked to sign before the first interview, which further explains the expectations and your rights as a participant in the study. If you have any questions about the study or the interviews, please call me at my office (293-8505) or my home (222-0445).

I look forward to your participation in the study. Your perspective would be a valuable contribution to my research. I hope to see you on October 9.

Sincerely,

Sally Bennett

Program Manager for Program Accountability San Diego City Schools

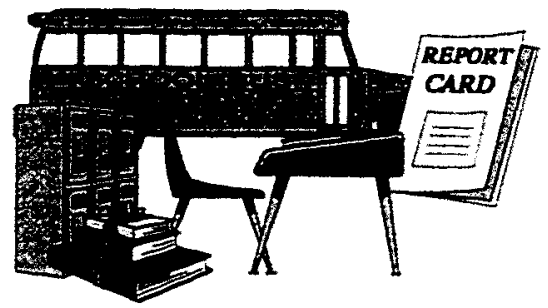




\section{SAMPLE FOLLOW-UP RESPONSE FORM}

\section{(SCHOOL NAME)}

YES, I am interested in participating in a follow-up interview with Sally Bennett, to further discuss (school)'s work with the LAD project.

Name

Grade Level(s)

Special Program(s): (check all that apply)

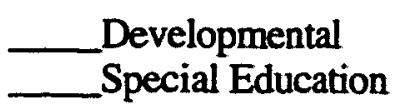

Number of Years at (School)

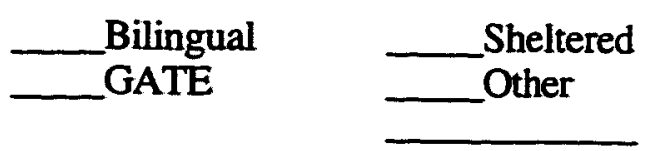

Total Years Teaching
Member of: (check all that apply)

Governance Team

School Site Council

Design Team

Other

Other
Current Member (96-97) Former Member
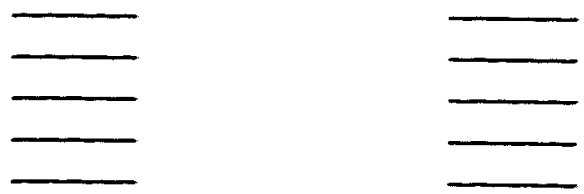

If I am selected for an interview:

The best day(s) and time(s) are:

First Preference: Day(s)

Second Preference:

Day(s)
Time(s)

Time(s)
I preferred to be interviewed at:
(School)

(Note: you may be compensated for interviews that take place outside regular working hours, and with mileage reimbursement for interviews that take place off the school site.)

I prefer to be contacted at:

\begin{tabular}{l} 
(School) (Phone \\
Home (Phone \\
\hline E-Mail (E-Mail Address___
\end{tabular}

Please be assured that your confidentiality will be protected and your anonymity preserved.

\section{THANK YOU in advance for your willingness to share your time and your perspective on (school)'s work.}

??? Questions ??? Call Sally Bennett at 293-8505 (office) or 222-0445 (home)

RETURN THIS PAGE TO:

SALLY BENNETT, EDUCATION CENTER, ROOM 2008 


\section{SAMPLE FOLLOW-UP LETTER FOR TEACHERS NOT ATTENDING GROUP INTERVIEW}

October 14, 1996

Dear «FirstName»,

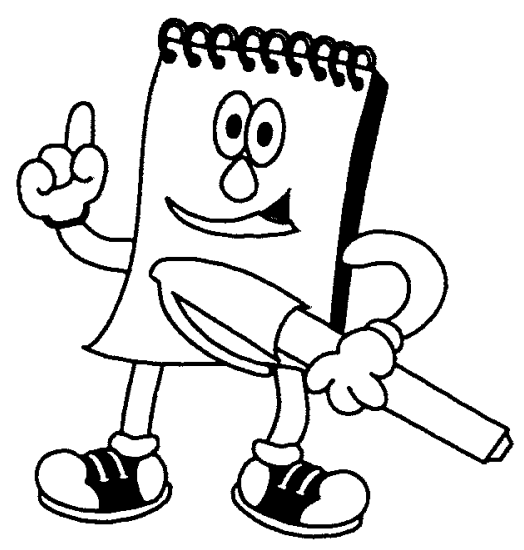

I'm sorry you were unable to join us last Wednesday afternoon to talk about (school)'s work over the past several years as you addressed standards, assessment, and accountability for student achievement through participation in the LAD project. However, I certainly recognize how busy you are and how much you value that preparation time!

As part of my dissertation research, I would still very much like to have an opportunity to talk with you for about 30 minutes about your experiences at (school)-the successes as well as the challenges! I am willing to arrange this interview at your convenience: before or after school, on a modified day, in the evening; at (school), at another location, or by telephone.

If you are able to spare a little time for either an in-person or a telephone interview, please return the attached response form, or give me a call at my office (293-8505) or my home (222-0445). Again, in recognition of the impact on your time, I can compensate you for one hour at the non-classroom materials preparation rate.

Thank you in advance!

Sincerely,

Sally Bennett

Program Manager, Program Accountability Unit

San Diego City Schools 


\section{APPENDIX D}

INFORMED CONSENT FORM 


\section{University of San Diego \\ CONSENT TO ACT AS A RESEARCH SUBJECT}

Sally Bennett, a doctoral student in the School of Education at the University of San Diego, is conducting a research study of restructuring and site-based accountability at three San Diego elementary schools that participated in the Leadership in Accountability Demonstration (LAD) school project. The study aims to describe the accountability implementation process, investigate changes in school practices and decisionmaking, and explore the role of school site leadership. The purpose is to learn what kinds of governance and leadership have been most embraced by schools accepting site accountability in exchange for increased flexibility, and to discuss implications for policymakers relative to school site and district-level restructuring.

As a participant in this study, I understand that I will respond to questions in one or two group and/or individual interview sessions. Each interview may last up to an hour and will take place between May and November, 1996. Participation in the study should not involve any added risks or discomforts to me other than the commitment of my time. I can benefit from the opportunity to intellectually discuss issues of professional interest.

My participation in this study is entirely voluntary, and I understand my choice to participate in the project is totally unrelated to my job status. I understand that I may refuse to participate and I may withdraw at any time without jeopardy. I understand that the interview sessions will be audiotaped, and I have a right to review and edit the interview transcripts. I understand that my research records, including audio-tapes and transcriptions, will be kept completely confidential and my identity will not be disclosed without consent required by law.

Sally Bennett has explained this study to me and answered my questions. If I have other research-related questions or problems, I can reach her at home at 222-0445 or at work at 293-8505. I understand that I may also contact her dissertation director, Dr. Mary Abascal-Hildebrand, Associate Professor at USD, at $260-4270$.

There are no other agreements, written or verbal, related to this study beyond that expressed on this consent form. I have received a copy of this consent document. I, the undersigned, understand the above explanations and, on that basis, I give consent to my voluntary participation in this research.

\begin{tabular}{lll}
\hline Signature of Subject & Date & Location
\end{tabular}

Signature of Researcher Date 


\section{APPENDIX E}

\section{INTERVIEW GUIDES}




\section{Interview Guides}

All interviews followed a semi-structured, open-ended format. While these questions served as guides, based on the study's themes and purpose, other issues emerged and were explored during the interviews themselves.

\section{Individual Interviews: Site Administrators, Other Key Staff}

A. Tell me the LAD story-walk me through some of the key events since your school began the LAD project in the spring of 1993.

B. Why did your school volunteer to become a Leadership in Accountability Demonstration (LAD) school?

C. Tell me about decisionmaking at your school-how are major teaching and learning decisions made? Walk me through a typical decisionmaking process.

D. From your perspective, what has changed in teaching and learning as a result of your school's involvement with the LAD project-what impact has this work had on the classroom?

E. What do you consider to be some of your greatest successes? To what do you attribute these successes?

F. What have been some of the challenges associated with the LAD project?

G. Where do you see your school now? What are the next steps?

H. What personal and professional words of wisdom do you have for your colleagues at other schools just entering this process of restructuring and site-based accountability?

\section{Group Interviews: LAD Leadership Teams, Classroom Teachers}

A. Looking at the past $3+$ years, tell me about some of the key events that you feel have had the biggest impact on your school in terms of teaching and learning, decisionmaking, student achievement, etc.

B. From your perspective, what has changed in teaching and learning as a result of your participation in the LAD project-what impact has this work had on the classroom? 
C. Tell me about decisionmaking at your school: how are major decisions made, such as those related to curriculum, school organization, instructional strategies, etc.? Describe for me a typical decisionmaking process.

D. What have been some of the biggest challenges associated with the LAD project?

E. What do you consider to be some of your greatest successes? To what do you attribute those successes?

F. Where do you see the school now, and what might be the next steps?

G. Anything else you'd like to share?

III. Follow-Up Individual Interviews: LAD Team Members, Other Teachers

A. Why do you think your school volunteered to become a LAD school?

B. From your perspective, what would you identify as some of the key events during your school's work over the past three years?

C. What has changed in your classroom as a result of your school's work with the LAD project? What kinds of things have changed in teaching and learning across the school?

D. What is the teacher's role in decisionmaking? Can you describe a decisionmaking situation in which you feel teachers had a major role in making a significant change?

E. Describe leadership at your school. What does leadership "look like"? Who are the leaders?

F. What have been some of the challenges associated with your school's work over the past three years?

G. What have been the greatest successes?

H. What "words of wisdom" do you have for other teachers and schools that may want to start working on school reform?

I. Is there anything else you'd like to share? 
APPENDIX F

SCHOOL PROFILES 
SCHOOL PROFILE

MARIPOSA ELEMENTARY

\begin{tabular}{|c|c|c|c|c|c|c|c|}
\hline \multirow[t]{2}{*}{$\begin{array}{l}\text { School } \\
\text { Year }\end{array}$} & \multirow{2}{*}{$\begin{array}{l}\text { Eniolle } \\
\text { ment: } \\
\text { Gr. } K=6\end{array}$} & \multicolumn{6}{|c|}{$\begin{array}{c}\text { Ethnich Distribution } \\
\text { (Percentages) }\end{array}$} \\
\hline & & $\begin{array}{l}\text { African- } \\
\text { American }\end{array}$ & $\begin{array}{l}\text { Asiany } \\
\text { Pac Island: }\end{array}$ & Filipino & Hispanic & $\begin{array}{l}\text { Indo- } \\
\text { chinese }\end{array}$ & White \\
\hline $1986-87$ & 946 & 3.2 & 2.7 & 28.3 & 7.6 & 6.6 & 51.1 \\
\hline $1987-88$ & 1029 & 3.0 & 2.4 & 26.3 & $\overline{7.6}$ & 7.7 & 52.5 \\
\hline $1988-89$ & 981 & 4.0 & 3.0 & 26.1 & 6.9 & 10.2 & 49.2 \\
\hline $1989-90$ & 1019 & 5.1 & 3.4 & 23.2 & 6.0 & 11.6 & 50.1 \\
\hline $1990-91$ & 1091 & 5.2 & 4.4 & 23.8 & 8.4 & 10.9 & 46.4 \\
\hline 1991-92 & 1142 & 4.5 & 4.7 & 27.1 & 8.9 & 10.1 & 44.2 \\
\hline 1992-93 & 1139 & 3.9 & 4.4 & 30.8 & 8.7 & 11.6 & 40.0 \\
\hline 1993-94 & 1066 & 5.1 & $\overline{4.7}$ & 32.0 & 8.1 & 13.0 & 36.5 \\
\hline 1994-95 & 1086 & 6.2 & 5.9 & 32.2 & 10.8 & 12.2 & 32.4 \\
\hline 1995-96 & 1080 & 5.9 & 6.3 & 31.9 & 10.0 & 14.5 & 31.1 \\
\hline
\end{tabular}

\begin{tabular}{|c|c|c|c|c|}
\hline School & $\begin{array}{c}\text { English Language } \\
\text { Learners } \\
\text { (Percent limited } \\
\text { English proficient } \\
\text { students) }\end{array}$ & $\begin{array}{c}\text { Poverty Rate } \\
\text { (Percent of students } \\
\text { eligible for } \\
\text { free/reduced lunch) }\end{array}$ & $\begin{array}{c}\text { Mobility Index } \\
\text { (Rate of new } \\
\text { enrollees + transfers } \\
\text { per 100 students) }\end{array}$ & $\begin{array}{c}\text { Stability Rate } \\
\text { (Percent enrolled } \\
\text { frombeginning to end } \\
\text { of school year) }\end{array}$ \\
\hline $1990-91$ & 14.8 & 23.7 & 49.8 & 83.9 \\
\hline $1991-92$ & 16.3 & 25.4 & 47.5 & 84.1 \\
\hline $1992-93$ & 18.3 & 27.3 & 42.4 & 85.4 \\
\hline $1993-94$ & 20.5 & 29.7 & 38.7 & 86.8 \\
\hline $1994-95$ & 18.0 & 31.4 & 36.9 & 87.4 \\
\hline $1995-96$ & 20.3 & 34.9 & 23.8 & 89.2 \\
\hline
\end{tabular}

\begin{tabular}{|c|c|c|c|c|c|c|c|c|c|c|c|c|}
\hline \multirow[t]{3}{*}{$\begin{array}{l}\text { School } \\
\text { Year }\end{array}$} & \multicolumn{12}{|c|}{$\begin{array}{l}\text { Abbreviated Stanford Achievement Test (ASAT) } \\
\text { lents scoring at or above the 50th percentile (publishe }\end{array}$} \\
\hline & \multirow{2}{*}{\multicolumn{2}{|c|}{$\frac{\text { Grade } 1}{\text { Read. }}$}} & \multirow{2}{*}{\multicolumn{2}{|c|}{$\frac{\text { Grade. }}{\text { Read! Math }}$}} & \multirow{2}{*}{\multicolumn{2}{|c|}{$\frac{\text { Grade } 3}{\text { Read Math }}$}} & \multirow{2}{*}{\multicolumn{2}{|c|}{$\begin{array}{l}\text { Grade 4 } \\
\text { Read I Math }\end{array}$}} & \multirow{2}{*}{\multicolumn{2}{|c|}{ Grade 5}} & \multicolumn{2}{|c|}{ Grade.6 } \\
\hline & & & & & & & & & & & Read. & Math \\
\hline 1990-91 & 35 & 59 & 49 & 59 & 61 & 75 & 56 & 63 & 51 & 59 & 60 & 68 \\
\hline 1991-92 & 46 & 52 & 54 & 59 & 56 & 71 & 59 & 70 & 52 & 56 & 61 & 69 \\
\hline 1992-93 & 48 & 54 & 54 & 64 & 59 & 72 & 58 & 67 & 63 & 62 & 56 & 71 \\
\hline 1993-94 & 44 & 59 & 65 & 64 & 63 & 70 & 57 & 72 & 56 & 58 & 62 & 81 \\
\hline 1994-95 & $\cdots$ & 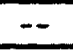 & 56 & 45 & 52 & 71 & 49 & 78 & 50 & 67 & 53 & 67 \\
\hline 1995-96 & $=$ & $\cdots$ & 59 & 61 & 67 & 65 & 55 & 77 & 50 & 65 & 57 & 65 \\
\hline
\end{tabular}


SCHOOL PROFILE

\section{SIERRA ELEMENTARY}

\begin{tabular}{|c|c|c|c|c|c|c|c|}
\hline $\begin{array}{c}\text { School } \\
\text { Year }\end{array}$ & $\begin{array}{l}\text { Enroll: } \\
\text { ment }\end{array}$ & \multicolumn{6}{|c|}{$\begin{array}{c}\text { Ethnic Bistribution } \\
\text { (Percentages) }\end{array}$} \\
\hline & Gr $K=6$ & $\begin{array}{l}\text { African- } \\
\text { American }\end{array}$ & $\begin{array}{l}\text { Asiant } \\
\text { Pac Íland. }\end{array}$ & Filipino & Hispanic: & $\begin{array}{l}\text { Indo- } \\
\text { chinese }\end{array}$ & White \\
\hline $1986-87$ & 936 & 9.9 & 0.7 & 45.6 & 6.0 & 0.6 & 37.0 \\
\hline $1987-88$ & 1109 & 11.0 & 0.6 & 44.9 & 8.7 & 0.5 & 34.1 \\
\hline $1988-89$ & 1194 & 11.2 & 1.7 & 42.7 & 9.0 & 0.7 & 34.6 \\
\hline $1989-90$ & 1269 & 13.5 & 1.5 & 40.7 & 9.7 & 0.5 & 34.0 \\
\hline $1990-91$ & 1262 & 12.1 & 2.9 & 40.5 & 11.6 & 0,5 & 32.3 \\
\hline 1991-92 & 1382 & 12.8 & 2.4 & 38.7 & 13.4 & 0.7 & 32.1 \\
\hline $1992-93$ & 1367 & 13.4 & 3.0 & 39.0 & 13.2 & 0.5 & 30.7 \\
\hline 1993-94 & 1420 & 16.8 & 3.7 & 38.0 & 13.6 & 0.6 & 27.3 \\
\hline 1994-95 & 1453 & 16.4 & 3.7 & 38.5 & 14.1 & 0.3 & 26.8 \\
\hline 1995-96 & 1419 & 17.8 & 2.8 & 37.5 & 17.2 & 0.4 & 24.2 \\
\hline
\end{tabular}

\begin{tabular}{|c|c|c|c|c|}
\hline$\frac{\text { School }}{\text { Year }}$ & $\begin{array}{c}\text { English Language } \\
\text { Leamers } \\
\text { (Percentlimited } \\
\text { English proficient } \\
\text { students) }\end{array}$ & $\begin{array}{c}\text { Poverty Rate } \\
\text { (Percent of students } \\
\text { eligible for } \\
\text { free/reducedlunch) }\end{array}$ & $\begin{array}{c}\text { Mobility Index } \\
\text { (Rate of new } \\
\text { enrollees + transfers } \\
\text { per-100. students) }\end{array}$ & $\begin{array}{c}\text { Stability Rate } \\
\text { (Percent enrolled } \\
\text { frombeginning to end } \\
\text { of school.year) }\end{array}$ \\
\hline $1990-91$ & 10.9 & 20.5 & 42.9 & 87.7 \\
\hline $1991-92$ & 24.5 & 25.7 & 41.4 & 86.4 \\
\hline $1992-93$ & 23.0 & 28.9 & 44.3 & 88.1 \\
\hline $1993-94$ & 24.9 & 28.0 & 40.1 & 85.8 \\
\hline $1994-95$ & 27.6 & 33.7 & 39.7 & 85.8 \\
\hline $1995-96$ & 23.8 & 38.3 & 32.8 & 86.0 \\
\hline
\end{tabular}

\begin{tabular}{|c|c|c|c|c|c|c|c|c|c|c|c|c|}
\hline \multirow[t]{3}{*}{$\frac{\text { School }}{\text { Year }}$} & \multicolumn{12}{|c|}{$\begin{array}{l}\text { Abbreviated Stanford Achievement Test (ASAT) } \\
\text { Idents scoring at or above the } 50 \text { th percentile (publisher's:median) }\end{array}$} \\
\hline & \multirow{2}{*}{\multicolumn{2}{|c|}{$\frac{\text { Grade } 1}{\text { Read Math }}$}} & \multirow{2}{*}{\multicolumn{2}{|c|}{$\frac{\text { Grade 2 }}{\text { Read : Math }}$}} & \multirow{2}{*}{\multicolumn{2}{|c|}{ Grade 3}} & \multirow{2}{*}{\multicolumn{2}{|c|}{ Grade 4 }} & \multicolumn{2}{|c|}{ Grade-5 } & \multirow{2}{*}{\multicolumn{2}{|c|}{ Grade 6}} \\
\hline & & & & & & & & & Read & Math & & \\
\hline $1990-91$ & 27 & 40 & 51 & 69 & 51 & 63 & 46 & 65 & 56 & 57 & 49 & 59 \\
\hline $1991-92$ & -- & -- & -- & -- & -- & -- & 51 & 63 & 43 & 53 & 59 & 69 \\
\hline $1992-93$ & -- & -- & -- & $\ldots$ & -- & -- & 51 & 56 & 52 & 52 & 48 & 64 \\
\hline 1993-94 & 29 & 24 & 39 & 44 & 43 & 49 & 32 & 44 & 55 & 55 & 52 & 61 \\
\hline $1994-95$ & 42 & 47 & 39 & 47 & 43 & 55 & 39 & 58 & 40 & 48 & 56 & 60 \\
\hline $1995-96$ & $\ldots$ & -- & 40 & 46 & 44 & 62 & 46 & 58 & 50 & 59 & 52 & 65 \\
\hline
\end{tabular}


SCHOOL PROFILE

PALOMA ELEMENTARY

\begin{tabular}{|c|c|c|c|c|c|c|c|}
\hline $\begin{array}{l}\text { School } \\
\text { Year }\end{array}$ & $\begin{array}{l}\text { Enroll: } \\
\text { ment }\end{array}$ & \multicolumn{6}{|c|}{$\begin{array}{c}\text { Ethnic Distribution } \\
\text { (Percentages) }\end{array}$} \\
\hline & Gr K 5 & $\begin{array}{l}\text { African- } \\
\text { American }\end{array}$ & $\begin{array}{c}\text { Asiant } \\
\text { Pac Island }\end{array}$ & Filipino & Hispanic & $\begin{array}{l}\text { Indo- } \\
\text { chinese }\end{array}$ & White \\
\hline $1986-87$ & 552 & 21.7 & 1.3 & 2.4 & 16.7 & 29.2 & 27.5 \\
\hline $1987-88$ & 558 & 25.6 & 1.8 & 2.0 & 18.5 & 31.9 & 19.2 \\
\hline $1988-89$ & 619 & 28.8 & $\overline{2.1}$ & 1.1 & 19.4 & 30.7 & 16.8 \\
\hline $1989-90$ & 705 & 25.0 & 2.2 & 1.1 & 26.5 & 30.1 & 13.9 \\
\hline $1990-91$ & 822 & 26.5 & 2.5 & 0.9 & 24.6 & 31.1 & 13.7 \\
\hline 1991-92 & 825 & 25.8 & 2.0 & 1.1 & 26.2 & 34.5 & 9.9 \\
\hline $1992-93$ & 903 & 26.1 & 2.7 & 1.4 & 26.7 & 34.7 & 7.8 \\
\hline 1993-94 & 835 & 24.9 & 2.8 & $\overline{0.6}$ & 30.7 & 31.6 & 8.7 \\
\hline 1994-95 & 915 & 31.9 & 3.2 & 0.4 & 31.8 & 25.0 & $\overline{7.4}$ \\
\hline $1995-96$ & 870 & 38.6 & 2.2 & 0.5 & 34.3 & 18.2 & 6.2 \\
\hline
\end{tabular}

\begin{tabular}{|c|c|c|c|c|}
\hline$\frac{\text { School }}{\text { Year }}$ & $\begin{array}{c}\text { English Language } \\
\text { Leamers } \\
\text { (Percent limited } \\
\text { English proficient } \\
\text { students) }\end{array}$ & $\begin{array}{c}\text { Poverty Rate } \\
\text { (Percent of students } \\
\text { eligible for } \\
\text { free/reduced lunch) }\end{array}$ & $\begin{array}{c}\text { Mobility Index } \\
\text { (Rate of new } \\
\text { enrollees + transfers } \\
\text { per 100 students) }\end{array}$ & $\begin{array}{c}\text { Stability Rate } \\
\text { (Percent enrolled } \\
\text { from beginning to end } \\
\text { of schoolyear) }\end{array}$ \\
\hline $1990-91$ & 43.7 & 91.3 & 85.2 & 72.5 \\
\hline $1991-92$ & 59.2 & 92.1 & 81.0 & 79.4 \\
\hline $1992-93$ & 64.2 & 93.1 & 100.0 & 71.9 \\
\hline $1993-94$ & 63.8 & 94.4 & 99.9 & 69.6 \\
\hline $1994-95$ & 70.3 & 95.2 & 72.6 & 74.6 \\
\hline $1995-96$ & 71.3 & 97.5 & 86.1 & 73.7 \\
\hline
\end{tabular}

\begin{tabular}{|c|c|c|c|c|c|c|c|c|c|c|c|c|}
\hline \multirow[t]{3}{*}{$\frac{\text { School }}{\text { Year }}$} & \multicolumn{12}{|c|}{$\begin{array}{l}\text { Abbreviated Stanford Achievement Test (ASAT) } \\
\text { dents scoring at or above the } 50 \text { th percentile (publisher's median) }\end{array}$} \\
\hline & \multirow{2}{*}{\multicolumn{2}{|c|}{$\frac{\text { Grade 1 }}{\text { Read I Math }}$}} & \multirow{2}{*}{\multicolumn{2}{|c|}{$\frac{\text { Grade2 }}{\text { Read. Math }}$}} & \multirow{2}{*}{\multicolumn{2}{|c|}{$\frac{\text { Grade } 3}{\text { Read }}$}} & \multirow{2}{*}{\multicolumn{2}{|c|}{$\frac{\text { Grade } 4}{\text { Read }}$}} & \multirow{2}{*}{\multicolumn{2}{|c|}{$\frac{\text { Grade } 5}{\text { Read }}$}} & \multirow{2}{*}{\multicolumn{2}{|c|}{$\frac{\text { Grade } 6}{\text { Read }}$}} \\
\hline & & & & & & & & & & & & \\
\hline $1990-91$ & 8 & 19 & 25 & 40 & 19 & 33 & 22 & 35 & 27 & 34 & & \\
\hline 1991-92 & 20 & 23 & 14 & 40 & 28 & 41 & 32 & 46 & $\overline{23}$ & 22 & & \\
\hline $1992-93$ & 66 & 79 & 15 & 49 & 21 & 53 & 29 & 53 & 26 & 39 & & \\
\hline 1993-94 & 25 & 20 & 4 & 27 & 43 & 43 & 27 & 41 & 23 & 20 & & \\
\hline 1994-95 & 29 & 32 & 14 & 40 & 10 & 10 & 21 & 26 & 31 & 46 & & \\
\hline $1995-96$ & -- & -- & 21 & 17 & 11 & 21 & 4 & 19 & 17 & 8 & & \\
\hline
\end{tabular}

